\title{
Resilience and vulnerability factors in risk for posttraumatic stress disorder
}

Citation for published version (APA):

Engelhard, I. M. (2002). Resilience and vulnerability factors in risk for posttraumatic stress disorder. [Doctoral Thesis, Maastricht University]. Datawyse / Universitaire Pers Maastricht. https://doi.org/10.26481/dis.20020704ie

Document status and date:

Published: 01/01/2002

DOI:

10.26481/dis.20020704ie

Document Version:

Publisher's PDF, also known as Version of record

\section{Please check the document version of this publication:}

- A submitted manuscript is the version of the article upon submission and before peer-review. There can be important differences between the submitted version and the official published version of record.

People interested in the research are advised to contact the author for the final version of the publication, or visit the DOI to the publisher's website.

- The final author version and the galley proof are versions of the publication after peer review.

- The final published version features the final layout of the paper including the volume, issue and page numbers.

Link to publication

\footnotetext{
General rights rights.

- You may freely distribute the URL identifying the publication in the public portal. please follow below link for the End User Agreement:

www.umlib.nl/taverne-license

Take down policy

If you believe that this document breaches copyright please contact us at:

repository@maastrichtuniversity.nl

providing details and we will investigate your claim.
}

Copyright and moral rights for the publications made accessible in the public portal are retained by the authors and/or other copyright owners and it is a condition of accessing publications that users recognise and abide by the legal requirements associated with these

- Users may download and print one copy of any publication from the public portal for the purpose of private study or research.

- You may not further distribute the material or use it for any profit-making activity or commercial gain

If the publication is distributed under the terms of Article $25 \mathrm{fa}$ of the Dutch Copyright Act, indicated by the "Taverne" license above, 
RESILIENCE AND VULNERABILITY FACTORS IN RISK FOR POSTTRAUMATIC STRESS DisORDER 
Cover photograph: Frans Nikkels, De Twentse Courant Tubantia, Vuurwerkramp Enschede 13 mei 2000

Coverdesign: Datawyse

Publisher: Datawyse / Universitaire Pers Maastricht

O Iris Maria Engelhard, Maastricht 2002

ISBN 905278-350-0 


\title{
RESILIENCE AND VULNERABILITY FACTORS IN RISK FOR POSTTRAUMATIC STRESS DISORDER
}

\author{
PROEFSCHRIFT \\ ter verkrijging van de graad van doctor \\ aan de Universiteit Maastricht, \\ op gezag van de Rector Magnificus, \\ Prof. dr. A.C. Nieuwenhuijzen Kruseman, \\ volgens het besluit van het College van Decanen, \\ in het openbaar te verdedigen op \\ donderdag 4 juli 2002 om 16 uur \\ door \\ Iris Maria Engelhard
}

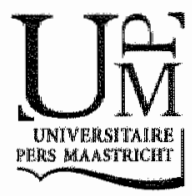


Promolores:

Prof. Dr. M.A. van den Hout

Prof Dr. R.J. McNally (Harvard University, Cambridge, MA, USA)

Beoordelingscommissie:

Prof. Dr. A. Arntz (voorzitter)

Prof. Dr. P.M.G. Emmelkamp (Universiteit van Amsterdam)

Dr. M. Kindt

Dr. A. van Minnen (Katholieke Universiteit Nijmegen)

Prof. Dr. M.W. de Vries 


\section{Afscheid}

Zul je voorzichtig zijn?

Ik weet wel dat je maar een boodschap doet hier om de hoek en dat je niet gekleed bent voor een lange reis

je kus is licht je blik gerust en vredig zijn je hand en woet

Maar achter deze hoek een werelddeel achter dit ogenblik een zee van rijd Zul je voorzichtig zijn?

\section{Adriaan Morriën}





\section{Contents}

I Background 9

$\begin{array}{ll}\text { II Empirical studies } & 29\end{array}$

1. Posttraumatic stress disorder after preeclampsia: An exploratory study. 29

2. Posttraumatic stress disorder after pregnancy loss. 39

3. The relationship between neuroticism, pretraumatic stress, and posttraumatic stress: A prospective study.

4. Peritraumatic dissociation and posttraumatic stress after pregnancy loss: A prospective study.

5. The sense of coherence in early pregnancy and crisis support and posttraumatic stress after pregnancy loss.

6. "Emotion and intrusion-based reasoning" in Vietnam veterans with and without chronic posttraumatic stress disorder.

7. "Intrusion-based reasoning" and posttraumatic stress disorder after exposure to a train disaster: A longitudinal study.

III General dïscussion

Samenvatting / Dutch summary

Dankwoord / Acknowledgments 



\section{PART I BACKGROUND}

\section{Introduction}

Grom ancient times, observations have been made that threatening experiences may F affect mental and physical health. For example, in the $19^{\text {th }}$ Century BC in Egypt ("Kunyus Papyrus"; Wilson \& Raphael, 1993) and $8^{\text {th }}$ century BC in Greece ("The Iliad" by Homer; Martin, 1996), psychological symptoms were reported after threatening events. In "The history of Henry the Fourth", William Shakespeare (1598) describes Lady Percy's concerns about Prince Harry after his battlefield experiences: "Tell me, sweet Lord, what is"t that takes from thee; thy stomach, pleasure, and thy golden sleep? Why dost thou bend thine eyes upon the earth, and start so often when thou sitt'st alone? . . . Thy spirit within thee hath been so at war, and thus hath so bestirred thee in thy sleep, that beads of sweat thave stood upon thy brow; like bubbles in a late-disturbed stream; and in thy face strange motions have appeared, such as we see when men restrain their breath" (Act 2, Scene 1).

Nevertheless, systematic interest in the psychologicall aftermath of traumatic events was not shown until the late 19 th century AD. Around this time, Charcot, Janet, Freud, and others recognized that such events could evoke psychopathological states. However, this notion shifted and the prevalent view in most of the $20^{\text {th }}$ century was that premorbid vulnerability rather than traumatic events were the origin of psychopathology (van der Kolk, Weisaeth, \& van der Hart, 1996). Accordingly, the first and second editions of the Diagnostic and Statistical Mamual of Mental Disorders (DSM) only included a pathological response to trauma as "gross stress reaction" and "transient emotional disturbance", respectively (APA, 1952, 1968), which meant that chronic disorders after trauma were conceptualized as anxiety or depressive neuroses (McFarlane, \& Girolamo, 1996). The 1970s set the stage for changes. Political and social developments initiated concerns about the psychological effects of trauma. Studies focused on the effects of concentration camp experiences, rape, battering, childhood trauma, life threatening experiences, and Vietnam War trauma. Initially, this work suggested that specific types of traumatic events caused specific syndromes, such 
as "concentration camp syndrome", "rape trauma syndrome", "battered wife syndrome", and "shell shock" (Herman, 1992). Later, it became clear that the psychological effects of different extreme events manifested in similar ways, and that the similarities far outweigh the differences (Blank, 1993). The focus of psychiatric nosology shifted to the psychiatric syndrome resulting from trauma-exposure (March, 1990), which was called Posttraumatic Stress Disorder (PTSD).

\section{THE PTSD CONCEPT}

In 1980, PTSD was formally established as a psychiatric diagnosis in DSM-III and, placed within the anxiety disorders, it was defined as characteristic symptoms following exposure to a traumatic event (A.PA, 1980). This implied that PTSD was a typical stress response caused primarily by tramatic events (Yehuda \& McFarlane, 1995), which was a crucial step in acknowledging the psychological effects of overwhelming experiences and resulted in extensive research. The PTSD diagnosis was based on a set of symptoms reported by treatment seekers (van der Kolk et al., 1996), and it was revised in DSM-III-R and DSM-IV (APA, 1987, 1994). The DSM-IV continued to conceptualize PTSD as a stressor-driven anxiety disorder, while also acknowledging the role of subjective factors. To meet the current criteria for PTSD, as defined by DSM-IV, an individual must have experienced or witnessed an event that has been threatening to the safety or integrity of themselves or others, to which the person responded with intense fear, horror, or helplessness. The characteristic symptoms are persistent reexperiencing of the event, persistent avoidance of stimuli associated with the event or numbing of general responsiveness, and persistent symptoms of increased arousal. Table 1 depicts the DSM-IV criteria. The PTSDdiagnosis is made if at least 1 reexperiencing symptom, 3 avoidance/numbing symptoms, and 2 symptoms of increased arousal are present for more than 1 month and cause significant impairment in functioning. Individuals with symptoms insufficient for the PTSD diagnosis may be classified with "partial" or "sub-threshold" PTSD (i.e. meeting 2 out of 3 symptom-clusters). If the duration of symptoms is less than 1 month, acute stress disorder may be diagmosed. The DSM-IV states that PTSD symptoms typically begin immediately or shorty after the traumatic event. If symptoms develop more than 6 months after the event, a delayed onset is specified. If the duration is more than 3 months, the course is considered chronic. 
Table 1. DSM-IV diagnostic criteria for PTSD

A. The person has been exposed to a trammatic event in which both of the following were present:

(1) the person experienced, witnessed, or was confronted with an event or events that involved actual or threatened death or serious injury, or a threat to the physical integrity of self or others

(2) the person's response involved intense fear, helplessness, or horror.

$B$. The traumatic event is persistently reexperienced in one (or more) of the following ways:

(1) recurrent and intrusive distressing recollections of the event, including images, thoughts, of perceptions.

(2) recurrent distressing dreams of the event.

(3) acting or feeling as if the traumatic event were recurring.

(4) intense psychological distress at exposure to intemal or external cues that symbolize or resemble an aspect of the traumatic event.

(5) physiological reactivity on exposure to intemal or external cues that symbolize or resemble an aspect of the traumatic event.

C. Persistent avoidance of stimuli associated with the trauma and numbing of general responsiveness (not present before the trauma), as indicated by three (or more) of the following.

(1) efforts to avoid thoughts, feelings, or conversations associated with the trauma.

(2) efforts to awoid activities, places, or people that arouse recollections of the trauma.

(3) inability to recall an important aspect of the trauma.

(4) markedly diminished interest on participation in significant activities.

(5) feeling of detachment or estrangment from others.

(6) restricted range of affect.

(7) sense of a foreshortened future.

D. Persistent symptoms of increased arousal (not present before the trauma), as indicated by two (or more) of the following:

(1) difficulty falling or staying asleep

(2) irritability or outbursts of anger

(3) difficulty concentrating

(4) hypervigilance

(5) exaggerated startle response

E. Duration of the disturbance (symptoms in Criteria B, C, and D) is more than I month.

F. The disturbance causes clinically significant distress or impaiment in social, occupational, or other important areas of functioning.

PTSD is consistently associated with psychiatric comorbidity in general (e.g., Kessler, Sonnega, Bromet, Hughes \& Nelson, 1995) and patient populations (e.g., Kulka et al., 1990), and particularly with depression. Only part of this is due to symptom-overlap (e.g., Shalev et al., 1998). Other common comorbid disorders are specific phobia, social phobia, agoraphobia, and substance abuse (Kessler et al., 1995). Thus, ironically, comorbidity is particularly high in affective and anxiety disorders: the diagnoses used to describe these patients before PTSD was recognized (Yehuda \& McFarlane, 1995). PTSD is also related to physical morbidity, mortality, and physical and psychiatric problems (Davidson \& Foa, 1991). The DSM-IV criteria are briefly discussed in the following. 


\section{The Stressor}

The DSM-IV indicates that traumatic events are severe enough to evoke PTSD independently of the individual's preexisting vulnerabilities. However, both the traumatic event and the individual"s initial appraisals/responses are necessary for the diagnosis (The terms fraumatic event and trauma are used in this dissertation to describe events that qualify for the DSM stressor criterion). It is currently not possible to discriminate a set of stressors that reliably result in PTSD. In fact, this issue has been the subject of considerable debate (e.g, Breslau and Davis, 1987; Horowitz, Weiss, and Marmar, 1987). DSM-1V qualifying events include a broad range of events. Events typically associated with PTSD are external to the individual and involve interpersonal wolence (e.g., rape, assault, and torture), exposure to threatening accidents (e.g., motor vehicle accidents), or disasters (e.g., fires and earthquakes; Yehuda, 2002). In addition, life-threatening illness may give rise to PTSD (A.PA, 1994). Events may be discrete, with a clear beginning and end, or enduring, involving chronic or repeated exposure to threat. The focus of this dissertation is mainly on discrete trauma in adulthood.

PTSD may not only develop in individuals who were the target of threat, but also in those who observed the event or were told about it, provided there is sufficient associated shock or terror (North et al., 1999). For example, the disorder was documented in disaster workers (Schooler, Dougall, \& Baum, 1999), and in local community members who witnessed the Oklahoma City bombing (North et al., 1999) and the terrorist attacks on the World Trade Center and Pentagon (Schlenger et al., 2001). PTSD has also been reported in offenders, for example, after committing homicide (Rogers, Gray, Williams, \& Kitchener, 2000) and participation in waratrocities (Breslau \& Davis, 1987).

There are boundaries to the two-part DSM-IV stressor-criterion. First, PTSD has been documented after stressors not meeting the objective criterion, such as divorce, death of a loved one; or a spouse's affair (Mol et al, 2002; Solomon \& Canino, 1990). March (1993) notes that such studies might have failed to adequately capture the fear conditioning inherent in PTSD. Alternatively, low stressor magnitude may evoke PTSD given the individual has sufficient valnerability. Second, individuals whose emotional responses to trauma do not meet the subjective criterion (e.g, shame, anger), may also develop PTSD (Brewin, Andrews, \& Rose, 2000a).

\section{PTSD symptoms}

Empirical studies provide strong support for the three PTSD-symptom clusters (Davidson \& Foa, 1991 ) and convergent validation for certain PTSD criteria (McNally, 1992). Although the DSM-IV does not state whether particular classes of events produce different types or magnitudes of responses, there may be qualitative differences in the nature of symptoms. For example, as noted by O'Donohue and Eliott (1990), post-rape fear seems primarily rape-related, whereas fear after war or childhood sexual abuse tends to generalize. 
Recurrent and intrusive recollections of the traumatic event have often been recognized as the hallmark symptoms of PTSD (e.g., Jones \& Barlow, 1990). These may manifest. in perceptual forms or thoughts. For example, regarding the nature of intrusive recollections after a road accident, Steil and Ehlers (2000) found that $69 \%$ of subjects reported visual images, $54 \%$ reported sounds or smells, $48 \%$ somatosensory sensations, and $45 \%$ thoughts (reported by Ehlers \& Steil, 1995). Intrusive recollections can be triggered by stimuli associated with the traumatic event (e.g., a similar emotional state, perceptual cues, anniversary dates; Macleod, 1994), but often there is no apparent trigger (Ehlers \& Clark, 2000). Avoidance symptoms include behavioral and cognitive efforts to avoid reminders of the trauma. Symptoms of reduced emotional responding (restricted affect, feelings of estrangement from others, and foreshortened future) are also included in this cluster, but are distinct from avoidance symptoms in that they best differentiate victims with and without PTSD (Foa, Riggs, \& Gershuny, 1995). Increased arousal symptoms include hypervigilance, exaggerated startle, concentration problems, difficulty sleeping, and irritability. Psychophysiological research showed that individuals with PTSD suffer from conditioned autonomic arousal to trauma-related cues and are extremely aroused in response to various stimuli (Pitman, 2000).

Several PTSD symptoms overlap with depression and other anxiety disorders (see McNally, 1992). Overlap with major depression includes social withdrawal, concentration problems, difficulty sleeping, irritability, dysphoria, and guilt. Specific for PTSD are exaggerated startle and reexperiencing symptoms, including physiological reactivity to trauma-related cues. Similarities between PTSD and panic disorder include sudden episodes of arousal and fear of arousal symptoms themselves. Distinctive PTSD-features are reexperiencing and numbing symptoms, and a severe stressor that is related to flashbacks. Finally, resemblances between PTSD and specific phobia include fear and avoidance of specific stimuli. Emotional numbing is unique for PTSD.

PTSD remains a controversial diagnosistic category. It is one of the few psychiatric disorders that implicate an etiological factor in its criteria, which suggests at least partial knowledge about its etiology. However, cumulated data since 1980 are inconsistent with the original conceptualization of PTSD as a typicall stress response caused primarily by a traumatic event (Yehuda \& McFarlane, 1995). A striking finding is that other psychiatric disorders are strongly linked to PTSD and that other psychiatric syndromes may also occur after a traumatic event (Shalev \& Yehuda, 1998). Moreover, studies of the prevalence and course of PTSD show heterogeneous responses to traumatic events, with only a minority of individuals developing the disorder (e.g., Kessler et al., 1995). This gave rise to the search for other factors involved in the etiology of the disorder, of which several have been identified. Thus, considerable uncertainty remains with respect to resilience and vulnerability in the etiology of PTSD. In the next sections, the prevalence and course of the disorder are discussed. 


\section{EPIOEMIOLOGY}

To begin with, it should be noted that prevalence-estimates warrant careful interpretation because they strongly depend on sampling procedures (e.g., inclusion criteria) and response-rates (victims may decline participation to avoid their memories). Epidemiological studies of the general population show that PTSD occurs only in a minority of individuals exposed to PTSD qualifying stressors. According to a recent estimate, about $90 \%$ of citizens in the USA are exposed to at least one DSM-IV traumatic event in their lifetime, whereas lifetime PTSD prevalence is about $18 \%$ for women and 10\% for men (Breslau, 1998; Breslau et al., 1998). Based on DSM-III-(R), using a stricter stressor criterion, lifetime trauma-exposure was estimated from 40 to $69 \%$ and lifetime PTSD prevalence ranged from 5 to $6 \%$ in males and 10 to $14 \%$ in females. In a review, Breslau (1998) concluded that the overall risk of PTSD given exposure to any traumatic event is 10 to $15 \%$.

However, there is variability by the type of event. In a retrospective study of young adults, Breslau and colleagues (1991) found that the highest risk for PTSD (based on DSM-M-R) was rape ( $80 \%$ ). Sudden injury or serious accident had a lower rate (12\%) than physical assault $(23 \%)$, seeing someone killed or seriously hurt $(24 \%)$, news of sudden death or accident to a close relative or friend (21\%), or threat to life $(24 \%)$. Estimates also depend on the methodology used. For example, studies that assessed

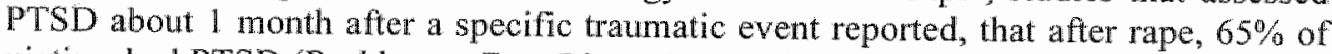
victims had PTSD (Rothbaum, Foa, Riggs, Murdock, \& Walsh, 1992), after non-sexual assault (e.g., robbery), 37\% showed PTSD (Riggs, Rothbaum, \& Foa, 1995), and after a motor vehicle accident, 34\% suffered from PTSD (Ursano et al., 1999).

\section{COURse}

The course of PTSD may be acute, delayed, chronic, intermittent, residual, or reactivated (Blank, 1993). The disorder typically starts in the immediate aftermath of the event (APA, 1994) and it fails to remit in about one-third (Kessler et al., 1995). The prognosis varies by the type and intensity of trauma, with physical attack and wimessing someone hurt or killed at the highest risk for chronicity (Breslau, 1998). Nonetheless, there are similarities in its course for different trauma populations. Longitudinal studies show that PTSD symptoms decrease substantially within three months. Symptoms that persist beyond three to six months tend to remain chronic (Foa \& Rothbaum, 1998). For example, two weeks after rape, $94 \%$ of victims had PTSD (excluding the duration criterion), which decreased to $65 \%$ at one month, $53 \%$ at wo months, and $47 \%$ at three months. The rates were $42 \%$ at six months and $47 \%$ at nine months (Rothbaum et al., 1992). About one week after non-sexual assault (e.g.s robbery), 65\% showed PTSD, which decreased to $37 \%$ after one month, $25 \%$ at two months, $15 \%$ at three months, $12 \%$ at six months, and none at nine months (Riggs et al., 1995). After a motor vehicle accident, $74 \%$ of individuals who had PTSD at three 
months still did at one year (Ehlers et al., 1998). In fact, symptoms may be present after many years. For example, about 17 years after rape, $17 \%$ of victims had PTSD (Kilpatrick, Saunders, Veronen, Best, \& Von, 1987), and 19 years after Vietnam War combat, $15 \%$ of male veterans had the disorder (Kulka et al., 1990).

Symptom-profiles differ between the acute and chronic post-trauma phase. In the initial weeks, reexperiencing and arousal symptoms are very common, whereas avoidance symptoms are uncommon (e.g., Bryant \& Harvey, 1997; McMillen et al., 2001; Shalev et al., 1996). Accordingly, initial reexperiencing symptoms are highly sensitive to the PTSD diagnosis, but are less specific. Early PTSD symptoms have little predictive power for chronic PTSD (Shalev, Freedman, Brandes, \& Peri, 1997). Longitudinal studies suggest that initial reexperiencing and anxiety decrease in most individuals. For individuals with later PTSD, these symptoms remain elevated whereas avoidance symptoms increase substantially (Shalev et all., 1996).

PTSD appears to follow an atypical transition in the immediate post-trauma period. McFarlane, Atchison, and Yehuda (1997) found that PTSD symptoms one day after a motor vehicle accident did not differentiate individuals with and without PTSD at six months. A second assessment on the tenth day showed that symptoms started to intensify in individuals with later PTSD and decline in individuals without PTSD. Shalev and colleagues (1996) reported differences one week after medical trauma: individuals who had PTSD six months later reported more initial reexperiencing and anxiety relative to non-PTSD traumatized individuals. Initial avoidance/numbing symptoms were similar between the groups. This suggests that the stressor initiates traumatic memories, and what may be critical in determining long-term outcome is the individual's ability to tolerate associated symptoms.

The transition from acute to chronic symptoms is currently under investigation. The data suggest there may be two critical periods: day 1 to 10 and day 10 to succeeding months. Important challenges are to clarify when acute stress becomes chronic (changes over time reflect the general etiological process; McFarlane, 2000), and how this transition occurs, taking account of different factors at different time points.

In sum, studies show that (1) PTSD prevalence increases with stressor-severity, (2) given a particular traumatic event, people differ in the risk of developing PTSD symptoms, (3) not everyone who develops PTSD maintains the disorder, and (4) the longer PTSD lasts, the less trauma-exposure explains symptoms. What mechanisms underly the occurrence of PTSD symptoms? What mechanisms cause initial PTSD symptoms to wane spontaneously or to remain?

\section{COGNITIVE THEORY}

Although a number of psychological theories of PTSD have been proposed, the cognitive framework appears the most fully developed, and offers the greatest explanatory and predictive power (Brewin, Dalgleish, \& Joseph, 1996). Cognitive theorists have proposed that knowledge acquired during life is represented in memory 
in the form of abstract knowledge structures, called "schemas" or "memory networks" (e.g., Bower, 1981). There is general agreement that a tramatic event provides significant information (e.g." life-threat) that is incompatible with prior "safety" schemas that a person may hold, such as the world is a meaningful place, others can be trusted, and the self is invulnerable (Janoff-Bulman, 1992), which produces a sense of threat. Due to need of coherence in assigning meaning to experiences, significant information requires integration into prior models. These attempts are thought to manifest in the characteristic initial PTSD symptoms (i.e., intrusions), which are considered to indicate normal adaptation (e.g., Rachman, 1990). Resolution of symptoms is thought to occur when trauma-related information becomes coherently integrated in prior models. Cognitive and behavioral avoidance is thought to impede this process (e.g., Brewin et al, 1996; Foa \& Riggs, 1993; Foa, Steketee, \& Rothbaum, 1989; Horowitz, Wilner, Kaltreider, Alvarez, 1980). In addition, a traumatic event may activate existing 'danger' schemas about the world being dangerous and the self as vulnerable, which also produces a sense of threat. Individuals with extremely rigid schemas, involving "safety" or "danger", may be less able to adaptively process a traunatic event. In contrast, individuals with mone balanced views may be better able to process the trauma as anique and unusual event (Foa \& Riggs, 1993 ).

Interest has also focused on traumatic memories. Many theorists believe traumatic memonies to be qualitatively distinct from other memories. Foa and colleagues (e.g., Foa \& Riggs, 1993; Foa et al., 1989) proposed that the traumatic event is stored in a memory network, which includes representations of trauma-related stimuli (e.g., sensory impressions), reactions (bodily sensations and intense emotions), and interpretative information. Due to activation of this network (e.g., by traumareminders), associated stimuli enter consciousness (e.g., a state of fear). The trauma network is thought to be large, disorganized, and fragmented, and to involve intense responses. Integration into prior schemas requires that the structure is activated so that the cognitive schema can be modified, and that new information is introduced that challenges the fear-related schema. The larger and more fragmented the memory, the more difficult it is to activate the entire structure, because many loose representations require priming. In addition, the more intense fear is representated, the more activation of the memory may be avoided. According to the theory, cognitive processing is impared if strategies are used that prevent the individual from activating the fear network. In PTSD, trama memories appear to be characterized by poor elaboration and contextualization, strong associative memory, and strong perceptual priming
(Enless $\&$ Clark, 2000). The role of appraisals of the immediate trauma aftermath has also been highlighted. Ehlers and Clark (2000) proposed that PTSD symptoms become persistent when tratma sequelae (e.g., initial symptoms and other people"s responses) are interpreted in a way that incites a sense of curent threat. This may arise from negative appraisals of initial PTSD symptoms (e.g., these symptoms mean I've lost control) and the perception that others have failed to be supportive after the event. Such a threat may 
amplify distress, foster avoidance strategies (which prevents disconfirmation of negative beliefs), and lead to selective attention to further threat, which maintains PTSD symptoms.

In sum, Ehlers and Clark (2000) proposed that recovery from the traumatic event requires: (1) elaboration and integration of the traumatic memory into the context of other experiences, (2) modification of negative appraisals of the trauma and/or its sequelae, and (3) decline of avoidance strategies. How might resilience and vulnerability for PTSD symptoms fit into these frameworks?

\section{RESILIENCE AND VULNERABIITY}

Cognitive theory suggests which conditions lead to acute and chronic PTSD symptoms and to recovery. Empirical research with respect to this issue is important for two reasons. First, it may serve to critically test and develop cognitive theory. Second, it may be clinically relevant in predicting, after a given trauma, which individuals are at risk of PTSD, and in preventing this to occur. Obviously, the best available psychological treatments have a sound foundation in empirical research.

However, it is difficult to examine vulnerability and resilience in PTSD due to several practical and methodological problems that are inherent to trauma-studies (e.g., see Shalev \& Yehuda, 1998). To study the effects of a traumatic event and systematically control for confounding variables, requires manipulation of real-life threat. Needless to say, experimental trauma studies cannot be conducted for ethical reasons. Moreover, prospective studies, in which pretraumatic variables are assessed prior to the traumatic event, are difficult to do due to the randomness with which traumatic events occur. Finally, longitudinal studies of acutely traumatized individuals are uncommon because people rarely present for treatment in the acute trauma phase. Therefore, the data-base for the traumatic stress field is derived from retrospective studies that are generally cross-sectional and often based on clinical samples. These are limited by reporting bias, memory bias, and there are problems with controlling for confounding factors and selection bias. By their very nature, cross-sectional studies are silent about cause and effect relations. In a recent meta-analysis, Brewin, Andrews, and Valentine (2000b) reported only one prospective study since 1980 in which pretraumatic variables were assessed prior to trauma-exposure in individuals who were exposed to similar adulthood trauma (i.e., the Vietnam War veterans study of Macklin et al., 1998). Nevertheless, various studies investigated risk factors for PTSD, resulting in extended knowledge of its correlates.

This dissertation includes several empirical studies of resilience and vulnerability for PTSD symptoms that were guided by cognitive theory. They involve various samples and address several issues. First, a retrospective, exploratory study was conducted in women with former preeclampsia. Preeclampsia is a disease that complicates 6 to $8 \%$ of all pregnancies. Clinical signs typically develop in the second half of pregnancy and may be severe. The unborn baby is often in jeopardy because of concomitant placental 
insufficiency (van Beek \& Peeters, 1998). This study explored whether this stressor not typically regarded as psychologically traumatic may also result in PTSD symptoms, and possibly, full-blown PTSD. Second, a prospective study was carried out of PTSD symptoms in women who experienced pregnancy loss. This provided a way to assess pretraumatic factors prior to the stressor and test the effects of a discrete, relatively homogeneous, stressor longitudinally. Third, a cross-sectional study was carried out in Vietriam combat veterans with and without PTSD. This study tested whether individuals with chronic PTSD, relative to traumatized controls without the disorder, exhibit a reasoning bias that could render PTSD self-perpetuating. Finally, a longitudinal study was done of acutely traumatized individuals who witnessed a tragic train crash. This allowed us to study whether this reasoning bias is involved in the transition from acute to chronic PTSD symptoms. Accordingly, these studies focused on the stressor, pretraumatic factors, peritraumatic (i.e., during or immediately after the event) factors, and posttraumatic factors. A short and general introduction to these four domains is given below.

\section{The stressor}

Typical threatening events associated with psychological trauma are external to the individual, such as war, interpersonal violence, accidents, or disasters. According to cognitive theory, the development of PTSD critically depends on negative attributions of the event or its sequelea and the integration of memories about the incident in prior schemas. This implies that PTSD may also present after other serious incidents. The occurrence of PTSD symptoms was explored retrospectively in response to preeclampsia, and was tested longitudinally in response to pregnancy loss, at one and four months.

Appraisals of the traumatic event and the nature of the memory network may be partly influenced by stressor severity. The more severe the stressor, the more it violates or existing schemas, which produces a sense of threat. In addition, the greater, more intense and fragmented the memory network, the more difficult assimilation will be. Indeed, the risk of PTSD is directly proportional to stressor severity, and particularly to life-threat, injury, loss, exposure to grotesque death, participation in atrocities, and duration (March, 1993). In the preeclampsia and pregnancy loss study, we explored the predictive power of objective indicators of stressor-severity in predicting PTSD
symptoms.

\section{Pretraumatic factors}

Cognitive theory predicts that negative attributions of the effects of trauma-exposure are crucial to the development of PTSD symptoms. For example, individuals may overgeneralize from the traumatic event and perceive other events to be more intrusions mean they will never be normal again. They may misinterpret other people's 
reactions, and so forth (Ehlers \& Clark, 2000). Neuroticism is a stable personality trait that involves the matural inclination to interpret events in a negative way (e.g. see Watson \& Pennebaker, 1989). Therefore, one would expect that, given a negative event, neuroticism predisposes to PTSD symptoms. Indeed, neuroticism has been associated with PTSD symptoms in several cross-sectional studies (see Bowman, 1999). However, the nature of these associations is equivocal: there is evidence that anxiety states may affect neuroticism ratings (Reich, Noyes, Coryell, \& O'Gorman, 1986). Therefore, in the pregnancy loss study, we measured neuroticism prior to pregnancy loss. Still, there might be an alternative explanation for this association. Although PTSD is conceptualized as a stressor-driven disorder (i.e., its phenomenology is linked to the stressor; APA, 1994), PTSD measures that are typically used in traumatic stress research (e.g., the Posttraumatic Stress Diagnostic Scale; Foa, 1995; PTSD Symptom Scale; Foa, Riggs, Dancu, \& Rothbaum, 1993; the Mississippi Scale for Combat-related PTSD; Keane, Caddell, \& Taylor, 1988), do not specify this linkage for items of increased arousal. In fact, arousal symptoms as such resemble aspects of neuroticism (Clark, Watson, \& Mineka, 1994), which raises the possibility that correlations between neuroticism and PTSD symptoms reflect symptom-overlap. Hence, in the pregnancy loss study, we controlled the predictive value of neuroticism for this potential symptom-overlap.

Negative beliefs after a traumatic event may arise because the event violated existing rigid safety schemas or primed existing rigid danger schemas. Prior danger schemas may partly be the result of prior negative events, which suggests a curvilinear relationship between prior negative life events and PTSD symptoms. Such a relationship was reported between general life stress and posttrauma adjustment (Ruch, Chandler, \& Harter, 1980). That is, moderate levels of prior life stress were related to better post-trauma adjustment than were low or high levels. However, studies of prior negatiwe life events generally report linear relations between (retrospectively assessed) prior negative events and PTSD symptoms (Shalev, 1996). Again, the causal sequence is unclear, particularly because the recall of prior life events may be affected by stress and neuroticism (Brett, Brief, Burke, George, \& Webster, 1990). Consequently, in the pregnancy loss study, we assessed negative life events prior to pregnancy loss and controlled its predictive power for the role of neuroticism.

The development of anxiety over initial PTSD symptoms may be determined by the degree of control over emorions prior to trauma (Jones \& Barlow, 1990). Individuals who perceive little control over their emotions may interpret characteristic post-trauma symptoms as a sign that they are falling apart or going crazy. They may be more likely to avoid cues that may evoke anxiety or intrusive recollections, which maintains symptomatology. However, trauma-exposure may also foster perceived loss of control (Foa, Zinbarg, \& Rothbaum, 1992). In the pregnancy loss study, we evaluated the relation between prior control over emotions and PTSD symptoms prospectively.

Elaboration and integration of the traumatic memory into the context of other experiences is also considered crucial. Individuals with a natural tendency to 
experience separated mental processes and alterations in consciousness, such as general dissociative rendencies and absorption (i.e., openness to self-altering experiences; see Kihlstrom, Glisky, \& Angiulo, 1994), may be more prone to experiencing disintegration of traumatic memories. The role of dissociation and imagery in PTSD has been acknowledged (Brett \& Ostroff, 1985; Spiegel, Hunt, \& Dondershine, 1988), but there is a lack of prospective data. In the pregnancy loss study, we measured general dissociative tendencies and absorption prior to pregnancy loss.

If integration of the traumatic memory with earlier memories is crucial in PTSD, one would expect that, given a certain traumatic event, cognitive flexibility reduces risk of PTSD symptoms. Higher cognitive ability may increase the ability to process the meaning of the event into an organized, coherent, rather than dissociative, way. Indeed, the prospective study of Macklin and colleagues (1998) showed that lower pretrauma intelligence is an important risk factor for PTSD. In the pregnancy loss study, we tested whether education predicts peritraumatic dissociation and PTSD symptoms.

Finally, the factors leading to recovery, as proposed by Ehlers and Clark (2000), ressemble the sense of coherence (SOC) concept. Antonovsky (1987) defined the SOC as the ability to perceive a stressor as comprehensible, manageable, and meaningful. Individuals with a higher SOC are thought to be better able to select and mobilize appropriate resources, such as social support, to cope with a given stressor. It follows that individuals with this natural inclination are at an advantage in coming to terms with a stressful event. Retrospective studies lend support for this hypothesis (e.g., Frommberger et al., 1998). However, there is serious doubt over the extent to which retrospective reports of the SOC predict PTSD Symptoms: the SOC may be affected by a stressful event, particularly when mastery fails (Geyer, 1997). Thus, prospective data are needed. In the pregnancy loss study, we assessed the SOC prior to pregnancy loss, and also investigated whether it predicts the mobilization of crisis support after pregnancy loss.

\section{Peritraumatic factors}

Cognitive theory predicts that integration of traumatic memory partly depends on its nature, which depends on what actually happened and on the quality of processing at encoding (see Ehlers \& Clark, 2000). Peritraumatic dissociative reactions, that is, alterations in the normally integrated functions of memory, identity, and consciousness (Marmar, Weiss, \& Metzler, 1997), are thought to result in fragmented memories (e.g., Foa \& Riggs, 1993). The degree of peritraumatic dissociation is, in fact, considered one of the strongest predictors of PTSD symptoms (Marmar et al., 1997), and memory fragmentation has also been found to predict PTSD (reported by Elhlers \& Clark, 2000). However, empirical data linking peritraumatic dissocation to memory fragmentation is deficient. Peritraumatic dissociation may also be an early marker for later whether the link between peritraumatic dise pregnancy loss study, we investigated 
mediated by memory characteristics (e.g., fragmentation) or cognitive avoidance of traumatic memories. With respect to the time of assessment, retrospective reporting of peritraumatic factors may inflate the effects of these variables, whereas assessments too soon after the event may underestimate trauma intensity (Brewin et al., 2000b). We chose to measure peritraumatic factors about one month after pregnancy loss in relation to PTSD symptoms measured at one and four months. Finally, if peritraumatic dissociation is one of the strongest predictors of PTSD symptoms, what are its predictors? Again, there is a lack of prospective data. In the pregnancy loss study, we investigated the relative role of stressor severity, neuroticism, prior negative events, control over emotions, dissociative tendencies, absorption, and education in predicting later peritraumatic dissociation.

Memory encoding may also be affected by the intensity of peritrawmatic distress. Extreme distress increases attention to threat-relevant stimuli, which may result in more threat representations in memory. This may result in a more disorganized network that includes extreme anxiety, which may promote avoidance strategies (Foa et al., 1989). Peritraumatic distress has repeatedly been related to PTSD (e.g., Brewin et al., 2000a). Cognitive theorists proposed that the individual's peritraumatic reactions are only partly influenced by objective stressor severity. Indeed, several studies found that the intensity of peritraumatic distress and dissociation predict PTSD over and above objective indicators of stressor severity (e.g., Shalev et al., 1996; Marmar et all, 1997). In the preeclampsia study, we explored the relative contribution of objective stressor-severity and peritraumatic distress and dissociation.

\section{Posttraumatic factors}

Cognitive theory predicts that the ways in which individuals interpret the trauma and its sequelae and cope with it determine the course of symptoms. According to Ehlers and Clark (2000), negative appraisals produce a sense of current threat, which amplifies distress and fosters the use of avoidance strategies, thus rendering PTSD symptoms self-perpetuating. Ehlers's group showed that negative interpretations of initial symptoms predict the persistence of symptoms, over and above the severity of initial symptoms, and that these interpretations also predict distress and avoidance strategies (e.g., Ehlers et al., 1998; Ehlers \& Steil, 1995; Steil \& Ehlers, 2000). Negative interpretations of other people's posttrauma reactions also predict the persistence of symptoms (Dunmore et al., 1999). In the preeclampsia study, we explored the role of negative interpretations of PTSD symptoms. Ehlers and Clark"s cognitive model of PTSD parallels cognitive models of other anxiety disorders in that these disorders persist because individuals catastrophize the meaning of particular symptoms (Clark, 1999). There is evidence that other anxiety patients not only catastrophize the meaning of anxiety symptoms, but also draw invalid conclusions about situations based on anxiety response information. That is, they use anxietyrelated information to make erroneous inferences about impending danger (Arntz, 
Rauner, \& van den Hout, 1995). This 'emotion-based reasoning' (ER) bias may also contribute to symptom-persistence: it may amplify distress, foster avoidance of anxiety-evoking cues, and motivate people to search selectively for danger-confirming information. It is presently unknown whether PTSD patients also engage in ER. Moreover, analogous to ER, danger may also be inferred from the presence of PTSDrelated intrusions: "intrusion-based reasoning' (IR). If this reasoning bias is indeed related to PTSD, the question becomes whether it predicts the persistence of symptoms. In the Vietnam combat study, we tested whether chronic PTSD is related to the ER tendency found in other anxiety patients, and whether it is related to IR. To control for the effects of trauma-exposure, Vietnam War combat veterans with and without PTSD were compared. In the train crash study, we studied whether acutely traumatized individuals showing a greater degree of IR are at higher risk of chronic PTSD symptoms.

Disconfirmation of maladaptive beliefs and changes in traumatic memory are prevented by avoidance of trauma-related information. Avoidant coping is related to acute PTSD symptoms (e.g., Bryant \& Harvey, 1995; Roemer, Litz, Orsillo, \& Wagner, 2001) and predicts the persistence of symptoms, even after controlling for initial symptoms (e.g., Ehlers et al, 1998). In the preeclampsia and pregnancy loss study, we studied the role of suppression of traumatic mernories.

Appraisals of the traumatic event and its sequelae and memory elaboration could be influenced by social support. This may aid in normalizing PTSD symptoms and reestablishing a positive schema of others. Talking about the event may activate the trauma network, provide corrective information, and organize memories. Indeed, crisis support appears to be an important resilience factor (Joseph, 1999). In the pregnancy loss study, crisis support was measured one month post-loss.

\section{AIMS OR DUSSERTATION}

The empirical studies are presented next, in the following seven chapters:

Chapter 1 describes the preeclampsia study. The aims were to explore (1) whether preeclampsia predisposes to PTSD (symptoms) and (2) the relative importance of objective indicators of stressor-severity versus individual risk factors in the onset of PTSD symptoms. Four groups participated: women with a past $(<2$ years) hospitalization for preterm preeclampsia, term preeclampsia, preterm delivery, or nomal term delivery. Most of their partners were also tested.

Chapters 2 through 5 report the pregnancy loss study. In early pregnancy, a large sample of women volunteers enrolled in the study and was assessed for several pretraumatic factors. They were followed for every two months thereafter, until one month after the due-date of birth. Women with a pregnancy loss were assessed one and four months later for PTSD and other factors. Chapter 2 addresses the prevalence of PTSD (symptoms) one month and four months after pregnancy loss. Chapter 3 reports the nature of the relationship between pretraumatic neuroticism, pretraumatic arousa! 
symptoms, and PTSD symptoms. The aim was to test whether neuroticism predicts PTSD symptoms after pregnancy loss, and whether the relationship is based on content overlap in arousal symptoms. Chapter 4 examined pretraumatic predictors for peritraumatic dissociation and PTSD symptoms, relations between peritraumatic dissociation and PTSD symptoms, and pathways regarding these relations. It was tested whether traumatic memory features (fragmentation, sensory impressions and emotional intensity) and thought suppression mediate the relation between peritraumatic dissociation and acute PTSD symptoms. Chapter 5 focuses on the relationship between the sense of coherence and later PTSD symptoms. It was also tested if this relation was mediated by crisis support.

Chapter 6 depicts the Vietnam combat study. The aim was to investigate whether chronic PTSD is related to 'emotion- and intrusion-based reasoning'. The participants were Vietnam veterans with and without PTSD.

Chapter 7 describes the rrain crash study. The aim was to test whether 'intrusion-based reasoning' is involved in the transition from acute to chronic PTSD symptoms. The participants were residents of a Belgian town exposed to the crash. They were tested for IR and PTSD symptoms 3 weeks after the crash and were re-assessed for PTSD symptoms at 3.5 months. Control residents who did not witness the crash were also tested at 3 weeks.

\section{REFERENCES}

American Psychiatric Association (1952, 1968, 1980, 1987, 1994). Diagnostic and statistical manual of mental disorders. Washington, DC: Author.

Antonovsky, A. (1987). Unraveling the mystery of health. How people manage stress and stay well. San Francisco: Jossey-Bass.

Arntz, A., Rauner, M., \& van den Hout, M. (1995). "If I feel anxious, there must be danger": Ex-consequentia reasoning in inferring danger in anxiety disorders. Behaviour Research and Therapy, 33, 917-925.

Blank, A.S. (1993). The longitudinal course of posttraumatic stress disorder. In: J.R.T. Davidson \& E.B. Foa (Eds.), Posttraunatic stress disorder: DSM-IV and beyond (pp. 3-22). Washington, DC: American Psychiatric Press.

Bower, G.H. (1981). Mood and memory, American Psychologist, 36, 129-148.

Bowman, M.L. (1999). Individual differences in posttraumatic stress: Problems with the DSM-IV model. Canadian Joumal of Psychiatry, 44, 21-33.

Breslau, N. (1998). Epidemiology of trauma and posttraumatic stress disorder. In : R. Yehuda (Ed.), Psychological trauma (pp. 1-29). Washington, DC: American Psychiatric Press.

Breslau, N., \& Davis, G.C. (1987). Posttraumatic stress disorder: The stressor criterion. Joumal of Nervous and Mental Disease, 175, 255-264. 
Breslau, N., Davis, G.C., Andresk, P., \& Peterson. E. (1991). Trammatic events and postraumatic stress disorder in an urban population of young adults. Archives of General Psychiatry, 48, 216-222.

Breslau, N. Kessler, R.C., Chillcoat, H.D., et al (1998). Trauma and postraumatic stress disorder in the community. Archives of General Psychiatry, 55, 626-632.

Bret, J.F, Brief, A.P, Burke, MJ., George, J.M., \& Webster, J. (1990). Negative affectivity and the reporting of stressfull life events. Health Psychology, 9, 57-68.

Brett, E.A. \& Ostroff, R. (1985). Imagery and postraumatic stress disorder: An overview. American. Jourhal of Psychiaty, 142, 417-24.

Brewin, C.R. Andrews, B., \& Rose, S. (2000a). Fear, helplessness, and horror in posttraumatic stress disorder: investigating DSM-IV criterion A2 in victims of violent crime. Jownal of Tramatic Stress, $13,499-509$.

Brewin, C.R., Andrews, B., \& Valentine, J.D. (2000b). Meta-analysis of risk factors for postraumatic stress disorder in tratma-exposed adults. Nowmal of Consulting and Clinical Psychology, 68, 748-766.

Brewin, C.R., Dalgleish, T., J Joseph, S. (1996). A dual representation theory of postraumatic stress disorder. Psychological Review, 103, 670-686.

Bryant, R.A., \& Harvey, A.G. (1995). Avoidant coping style and postraumatic stress following motor vehicle accidents. Behaviou Research and Therapy, 13,631-635.

Bryant, R.A., \& Harvey, A.G. (1997). Acute stress disorder: A critical review of diagnostic issues. Chinical Psychology Review, 17, 757-773.

Clark, D.M. (1999). Anxiety disorders: Why they persist and how to treat them. Behaviow Research and Therapy, 37, \$5-527.

Clark, L.A., Watson, D., \& Mineka, S. (1994). Temperament, personality, and the mood and anxiety disorders. Jownal of Abnomal Psychology, 103, 103-116.

Davidson, I.R.T., \& Foa, E.B. (1991). Diagnostic issues in postraumatic stress disorder: Considerations for the DSM-IV. Jommal of Abmomal Psychology. 100 ,
$346-355$.

Dunnore, E., Clark, D.M., \& Ehlers, A. (1999). Cognitive factors involved in the onset and maintenance of postraumatic stress disorder (PTSD) after physical or sexual Assault. Behawion Research and Therapy, 37, 809-829.

Ehlers, A., \& Clark, D.M. (2000). A cognitive model of postramatic stress disorder. Behaviou Research and Therapy. 38, 319-345.

Ehlers, A., Mayou, R.A., \& Bryant, B. (1998). Psychological predictors of chronic postrammatic stress disordar after motor vehicle accidents. Jownal of Abnomal
Psychology, 107, 508-519.

Bhlers, A. \& Steil, R. (1995). Maintenance of intrusive memories in postraumatic stress disorder: A cognitive approach. Behoviownal and Cognitive Psychomerapy,
23,217-249.

Foa, E.B. (1995). Postraumatic National Computer Systems.

Stress Diagnostic Scale: Manual. Minneapolis: 
Foa, E.B., \& Riggs, D.S. (1993). Postraumatic stress disorder and rape. In J. Oldham, M.B. Riba, \& A. Tasman (Eds.), Anmual review of psychiary, Vol. 12 (pp. 273303). Washington DC: American Psychiatric Association.

Foa, E.B., Riggs, D.S., Dancu, C.V., \& Rothbaum, B.O. (1993). Reliability and validity of a brief instrument for assessing post-traumatic stress disorder. Joumal of Traumatic Stress, 6, 459-473.

Foa, E.B., Riggs, D.S., \& Gershuny, B. (1995). Arousal, numbing, and intrusion: Symptom structure of postraumatic stress disorder following assault. American Jounal of Psychiatry, 152, 116-120.

Foa, E.B., Rothbaum, B.O. (1998). Treating the trawma of rape. New York: Guilford Press.

Foa, E.B., Steketee, G., \& Rothbaum, B.O. (1989). Behavioral/ cognitive conceptualization of posttraumatic stress disorder. Behavior Therapy, 20, 155-176.

Foa, E.B., Zinbarg, R., \& Rothbaum, B.O. (1992). Uncontrollability and unpredictability in post-traumatic stress disorder: An animal model. Psychological Bulletin, 112,218-238.

Frommberger, U., Stieglitz, R-D., Straub, S., et al. (1999). The concept of "sense of coherence" and the development of posttraumatic stress disorder in traffic accident victims. Joumal of Psychosomatic Research, 46, 343-348.

Geyer, S. (1997). Some conceptual considerations on the sense of coherence. Social Science and Medicine, 44, 1771-1779.

Herman, J.L. (1992). Trauma and recovery. New York: Basic Books.

Horowitz, M.J., Weiss, D.S., \& Marmar, C. (1987). Diagnosis of posttraumatic stress disorder. The Journal of Nervous and Mental Disease, 175, 267-268.

Horowitz, M.J., Willner, N., Kaltreider, N., \& Alvarez, W. (1980). Signs and symptoms of posttraumatic stress disorder. Archives of General Pychiatry, 37, 85-92.

Janoff-Bulman, R. (1992). Shattered assumptions: Towards a new psychology of trauma. New York: Free Press.

Jones, J.C., \& Barlow, D.H. (1990). The etiology of posttraumatic stress disorder. Clinical Psychology Review, 10,299-328.

Joseph, S. (1999). Social support and mental health following trauma. In W. Yule (Ed.), Post-traumatic stress disorders (pp. 71-91). New York: Wiley \& Sons.

Keane, T.M., Caddell, J.M., \& Taylor, K.L. (1988). Mississippi scale for combatrelated posttraumatic stress disorder: Three studies in reliability and validity. Journal of Consulting and Clinical Pychology, 56, 85-90.

Kessler, R.C., Sonnega, A., Bromet, E., Hughes, M., \& Nelson, C.B. (1995). Posttraumatic stress disorder in the National Comorbidity Survey. Archives of General Psychiatry, 52, 1048-1060.

Kihlstrom, J.F., Glisky, M.L., \& Angiulo, M.J. (1994). Dissociative tendencies and dissociative disorders. Journal of Abnormal Psychology, 103, 117-124. 
Kilpatrick, D.G., Saunders, B.E., Veronen, L.J, Best, C.L., \&on, J.M. (1987). Criminal victimization: Lifetime prevalence, reporting to police, and psychological impact. Crime and Delinguency, 33,479-489.

Kline; N.A. \& Rausch, J.L. (1985). Olfactory precipitants of hashbacks in posttraumatic strews disorder. Case reports Jounal of Clincal Psychiany, 46, 383-384.

Kulka, R.A., Schlenger, W.E., Fairbank, J.A., et al. (1990). Tramma and the Viemam War generation. Repont of findings from the National Vietnam Veterans Readjustment Study. New York: Brunner/Mazel.

Macklin, M.L., Metzger, L.J., Litz, B.T., et al. (1998). Lower precombat intelligence is a risk factor for postraumatic stress disorder. Jowmal of Consulting and Clinical Psychology, 66, 323-326.

Macleod, A.D. (1994). The reactivation of post-traumatic stress disorder in later life. Australian and New Zealand Jownal of Psychiary, 28, 625-634.

March, J.S. (1990). The nosology of postratumatic stress disorder. Jowmal of Anriety Disorders, 4,61-82.

March J.S. (1993). What constitutes a stressor? The "criterion A" issue. In: J.R.T. Davidson \& E.B. Foa (Eds.), Postraumatic stress disondex: DSM-IV and beyond (pp. 37-54). Washington, DC: American Psychiatric Press.

Mamar, C.R., Weiss, D.S., \& Metzler, T.J. (1997). The Peritraumatic Dissociative Experiences Questionnaire. In J.P. Wilson, \& T.M. Keane (Eds.), Assessing psychological tranma and PTSD: A practitioner's handbook (pp. 412-428). New York: Guilford Press.

Martin, T.R. (1996). Anciemt Greece: From prehistoric to hellenistic wmes. Ann Arbor: Yale University.

McFarlane, A.C. (2000). Posttraumatic stress disorder: A model of the longitudinal course and the role of risk factors. Jownal of Climical PSychiomy, 61, 15-20.

McFurlane, A.C., Atchison, M., \& Yehuda, R. (1997). The acute stress response following motor vehicle accidents and its relation to PTSD. Anmals of New York Academy of Sciences, $821,437-441$.

Mofarlane, A.C. \& de Girolamo, G. 1996). The nature of tramatic stressor and the epidemiology of postraumatio reactions. In B.A. van der Kolk, A.C. McFarlane, \& L. Weisaeth (Eds.), Tramatic stmess (pp. 129-154). New York: Guildford Press. McMillen, J.C. North, C.S., \& Smith, E.M. (2000). What parts of PTSD are normal: Intrusion, avoidance, or arousal? Data from the Northridge, California, earthquake. Jownal of Twamatic Siress. 13,57-75.

MoNally, RJ. (1992). Psychopathology of postraumatic stress disorder (PTSD): Boundaries of the syndrome. In M. Basoglu (Ed.), Torture and its consequences: Current treatment approaches (pp. 229-252). Cambridge: CUP.

Mol, S.S.L., Antz, A., Metsemakers, J.F.M., et al. (2002). PTSD symproms are not specific to mamatic events: evidence from the open population. Manuscript
submited for publication. 
North, C.S., Noxon, S.J., Shariat, S., et al. (1999). Psychiatric disorders among survivors of the Oklahoma City bombing. Joumal American Medical Associarion. $282,755-762$.

O'Donohue, W., \& Eliott, A. (1990). The current status of post-traumatic stress disorder as a diagnostic category: Problems and proposals. Joumal of Trammatic Stress, 5, 421-439.

Pitman, R. (2000). Stress hormones and the amygdala in PTSD: Possible implications for secondary prevention. Paper presented at the annual meeting of the International Society for Traumatic Stress Studies, San Antonio.

Rachman, S. (1980). Emotional processing. Behoviour Research \& Therapy, 18, 51-60.

Reich, J., Noyes, R., Coryell, W., \& O'Gorman, T.W. (1986). The effect of state anxiety on personality measurement. American Joumal of Psychiatry, 143, 760-763.

Riggs, D.S., Rothbaum, B.O., \& Foa, E.B. (1995). A prospective examination of symptoms of post-traumatic stress disorder in victims of non-sexual assault. Jownnal of Interpersonal Violence, 2, 201-214.

Roemer, L., Litz, B.T., Orsillo, S.M., \& Wagner, A.W. (2001). A preliminary investigation of the role of strategic withholding of of emotions in PTSD. Journal of Traumatic Stress, 14, 149-156.

Rogers, P., Gray, N.S., Williams, T., \& Kitchener, N. (2000). Behavioral treatment of PTSD in a perpetrator of manslaughter: A single case study. Journal of Traumatic Stress, 13, 511-519.

Rothbaum, B.O., Foa, E.B., Riggs, D.S., Murdock, T., \& Walsh, W. (1992). A prospective examination of post-traumatic stress disorder in rape victims. Journal of Traumatic Stress, 5, 455-475.

Ruch, L.O., Chandler, S.M., \& Harter, R.A. (1980). Life change and rape impact. Journal of Health and Social Behavior, 21, 248-260.

Schlenger, W.E. Caddell, J.M., Ebert, L., et al. (2001). National shudy of Americans reactions to September $1 /$ (N-SARS): Preliminary findings. Paper presented at the annual meeting of the International. Society for Traumatic Stress Studies, New Orleans.

Schooler, T.Y., Dougall, A.L., \& Baum, A. (1999). Cues, frequency, and the disturbing nature of intrusive thoughts: Patterns seen in rescue workers after the crash of flight 427. Journal of Tramatic Stress, 12,571-585.

Shalev, A.Y. (1996). Stress versus traumatic stress: From acute homeostatic reactions to chronic psychopathology. In B.A. van der Kolk, A.C. McFarlane, \& L. Weisaeth (Eds.), Traumatic stress: The effects of overwhelming experience on mind, body, and society (pp. 77-101). New York: Guildford Press.

Shalev, A.Y., Freedman, S., Peri, T., et al. (1998). Prospective study of posttraumatic stress disorder and depression following trauma. American Journal of Psychiary, $155,630-637$. 
Shalev, A.Y., Freedman, S., Brandes, D., \& Peri, T. (1997). Predicting PTSD in civilian trauma survivors: Prospective evaluation of self report and clinician administered instruments. British Journal of Psychiatry, 170, 558-564.

Shalev, A.Y., Peri, T., Canetti, L., \& Schreiber, S. (1996). Predictors of PTSD in injured trama survivors: A prospective study. American Journal of Psychatry, 153, 219-225.

Shalev, A.Y., \& Yehuda, R. (1998). Longitudinal development of traumatic stress disorders. In : R. Yehuda (Ed), Psychological trauma (pp. 31-66). Washington, DC: American Psychiatric Press.

Salomon, S.D., \& Canino, G.J. (1990). Appropriateness of DSM-III-R criteria for postraumatic stress disorder. Comprehensive Psychiatry, 31, 227-237.

Spiegel, D., Hunt, T., \& Dondershine, H.E. (1988). Dissociation and hypnotizability in postraumatic stress disorder. American Joumal of Psychiatry, 145, 301-305.

Steil, R. \& Ehlers, A. (2000). Dysfunctional meaning of posttraumatic intrusions in chronic PTSD. Behaviour Research and Therapy, 38, 537-558.

Ursano, R.J., Fullerton, C.S., Epstein, R.S., et al. (1999). Acute and chronic posttraumatic stress disorder in motor vehicle accident victims. American Journal of Psychialry, 156, 589-595.

van Beek, E., Peeters, L.L.H. (1998). Pathogenesis of preeclampsia: a comprehensive model. Obstetrical and Gynecological Survey, 53, 233-239.

van der Kolk, B.A., Weisaeth, L., \& van der Hart, O. (1996). History of trauma in psychiatry. In B.A. van der Kolk, A.C. McFarlane, \& L. Weisaeth (Eds.), Traumatic stress: The effects of overwhelming experience on mind, body, and society (pp. 4774). New York: Guildford Press.

Watson, D., \& Pennebaker, J.W. (1989). Health complaints, stress, and distress: Exploring the central role of negative affectivity. Psychological Review, 96,234-254.

Wilson, J.P. \& Raphael, B. (1993). Intemational handbook of traumatic stress syndromes. New York: Plenum Press.

Yehuda, R. (2002). Postatraumatic stress disorder. The New England Joumal of Medicine, $346,108-114$.

Yehuda, R., \& McFarlane, A.C. (1995). Conflict between current knowledge about posttraumatic stress disorder and its original conceptual basis. American. Joumal of Psychiary, 152, 1705-1713. 


\title{
PART II EMPIRICAL STUDIES
}

\author{
CHAPTER 1
}

\section{Posttraumatic Stress Disorder after Preeclampsia: An Exploratory Study *}

\begin{abstract}
Information about the psychological sequelae of preeclampsia (PE) is scarcePosttraumatic stress disorder (PTSD) may develop after exposure to a stress condition. This study explored whether PE predisposes to PTSD in patients and their partners. Primiparas with a recent history of preterm $\mathrm{PE}(n=18)$, preterm birth $(\mathrm{PT}, n=29)$, term $P E(n-23)$, or uneventful term bith $(C, n=43$ ), and most of their partners completed questionnaires measuring PTSD, depression, and related psychological factors. About one-fourth of patients developed PTSD after preterm PE as well as after PT. It occurred in $17 \%$ after term PE and in none of the control subjects. A substantial minority of partners was also affected. PTSD symptoms were strongly telated to individual psychological characteristics (peritraumatic dissociation, negative interpretations of symptoms, and thought suppression) rather than to objeetive indicators of condition-severity. The data suggest that PE predisposes to PTSD, primarily but not exclusively resulting from concomitant preterm birth.
\end{abstract}

\footnotetext{
"Engethard, I.M., van Rij, M. Boullart, 1., Ekhart, T.H.A., Spaanderman, M.E.A., van den Hout, M.A., \& Peeters, L......H. (in press). General Hospital Psychiaty
} 


\section{INTROOUCTION}

Preeclampsia (PE) is a disease that complicates 6 to $8 \%$ of all pregnancies. Although the pathogenesis dates back to the period of implantation, clinical signs rarely develop before the second half of pregnancy. Symptoms may vary widely. Particularly patients with early-onset $\mathrm{PE}$ ( $<32$ weeks) may develop severe symptoms, such as upper abdominal pain, headache, vision disturbances, weakness and discomfort [1]. These are often accompanied by anxiety about the condition of the unborn baby, which is often in jeopardy because of concomitant placental insufficiency. As the exact cause of PE is still obscure, management of $P E$ is limited to blood pressure control and symptom relief in combination with close maternal/fetal surveillance $[1,2,3]$. In most cases of early-onset $\mathrm{PE}$, a deteriorating fetal condition necessitates preterm pregnancy termination by cesarean section, often resulting in birth of an infant at risk for mortality or morbidity. These infants usually require prolonged management in a neonatal intensive care unit, which is a typically stressful period for the parents. It is unclear to what extent the psychological sequelae of PE might be attributed to the syndrome itself or to stress associated with the birth of the jeopardized infant.

Posttraumatic Stress Disorder (PTSD) may result from exposure to extreme psychological stress. More specifically, PTSD may develop following objective threat ("actual or threatened death or serious injury, or a threat to the physical integrity of self or others"), that elicits a typical subjective response ("intense fear, helplessness or horror") [4]. The disorder consists of persistent re-experiencing the causal stress condition (e.g. intrusive memories, flashbacks, and nightmares), avoiding reminders/ numbing (e.g. thoughts, activities, places), and hyperarousal (e.g. sleeping problems, irritability, difficulty concentrating). To diagnose PTSD, the occurrence of at least one re-experiencing symptom, three avoidance symptoms, and two symptoms of hyperarousal is required for a period of at least one month [4]. While the incidence of PTSD is only $1.7 \%$ after uneventful pregnancy [5], it is increased after pregnancy complicated by emergency cesarean birth, preterm birth, or term delivery of an infant with subsequent serious complications $[6,7,8]$. Stress-conditions predisposing to PTSD are typically unpredictable and uncontrollable [9]. Particularly early-onset PE develops unexpectedly and almost always ends in the cesarean birth of an infant at risk for morbidity. Moreover, this infant has a high chance to require prolonged treatment in a neonatal intensive care unit. It follows that PE is to be considered a condition with potentally strong psychological impact, not only for the mother, but also for her
partner.

This study was intended to explore the hypothesis that PE predisposes to PTSD and related morbidity in both the patient and her partner, with the associated preterm birth tather than the syndrome itself being the triggering factor. To this end, we compared the incidence of PTSD in formerly preterm and term preeclamptics with two "control" groups of women, matched for gestational age. That is to say, one control group
consisted of women who had a preterm birth, but no other complications. The other 
control group consisted of women who had an uneventful pregnancy and (term) delivery. Most of the partners were also tested. It is well established that not everyone exposed to a PTSD qualifying stressor develops the disorder. We also determined whether PTSD was associated with depressive symptoms and with risk factors known from the general PTSD literature. These are objective indicators of condition severity [10] (gestational age of hospital admittance and length of hospital stay), immediate psychological reactions (peritraumatic distress and dissociation) [11], negative interpretations of initial psychological symptoms (taking them as signs of going crazy or losing control) [12], and avoidant coping (suppression of condition-related thoughts) [13].

\section{METHOD}

Participants. Primiparas with a recent $(<2$ years) hospitalization for preterm PE $(n=$ $20)$, preterm birth (PT, $n=40)$, term PE $(n=25)$, or uneventful pregnancy $(\mathrm{C}, n=83)$ and their partners were invited (by telephone) to participate in this study. The former preeclamptics fulfilled the criteria of $\mathrm{PE}$ [1] and required clinical management for $\mathrm{PE}$ for at least one week. Subjects in both preterm groups delivered before 36 completed weeks and had been hospitalized for at least one week. Normal controls had an uneventful pregnancy and term ( $\geq 37$ weeks) delivery. Not invited were women younger than 18 years at delivery, illiterate in Dutch, or with pregnancy complicated by intrauterine fetal death. A total of 113 patients and 102 partners agreed to participate. That is to say, 18 preterm $\mathrm{PE}$ patients (response rate $=90 \%$ ) and 16 of their partners, $29 \mathrm{PT}$ patients $(73 \%)$ along with 27 of their partners, 23 term PE patients $(92 \%)$ with 20 partners, and $43 \mathrm{C}$ patients (52\%) with 39 partners. The length of time since birth was 14.1 months for preterm PE patients $(S D=3.5), 12.1$ montlis for PT patients ( $S D=$ 4.5), 15.3 months for term PE patients $(S D=4.1)$, and 13 months for controls $(S D=$ 4.2). This was significantly different between the groups, $F(3,109)=2.92, p=.037$. Respondents did not differ significantly from non-respondents in terms of sociodemographic and obstetric factors. Reasons given for refusal were unwillingness to be confronted with the experience (4 PE and $2 \mathrm{PT}$ patients), lack of time (5 PT patients), and lack of interest (most of the C-group).

Procedure. Participants gave written informed consent and were sent two sets of questionnaires, for the patient and her partner, to be returned within a week by prepaid envelope. With great emphasis, they were instructed to complete the two sets independently. The sets were identical except for pronoun-differences. The following relevant clinical data were retrieved from hospital records: gestational age at admission, features related to the delivery, birth weight, and length of maternal hospitalization. Approval was obtained from the medical ethics committee of Maastricht University Hospital. 
Measures. The following questionnaires were completed: a brief survey developed for this study (see below), the Peritraumatic Dissociative Experiences Questionnaire [14], the negative interpretations seale of the Response to Intrusions Questionnaire (RIQ) [15], the White Bear Suppression Inventory (WBSI) [16], the PTSD Symptom Scale (PSS) [17], and the Beck Depression Imventory (BDI) [18]. The brief survey assessed the intensity of perceived threat and distress at the time of each condition. It addressed to what extent the patient (and partner) felt at the time that her life and physical integrity were in danger and experienced fear, helplessness, or horror ( 1 = not at all, 5 = extreme). These emotional reactions were summed to a composite peritraumatic distress score (Cronbach's alpha $=.70$ ). The PDEQ includes 10 acute dissociative reactions to a stressful event (e.g., time distortion, derealization, and confusion) that are rated on a 5 -point scale $(1=$ not at all, $5=$ extremely). A sum score indicates the severity of peritramatic dissociation. The RIQ-scale measures negative interpretations of initial symptoms. Participants rated what their initial emotional reactions meant to them (e.g., 'My reactions mean that something is wrong with me', "My reactions mean that some day I will go out of my mind') on a 7 -point severity scale $(1=$ totally disagree; $7=$ totally agree). One itern of the original scale was omitted ("My reactions mean I wil] not be able to do my job well'), because it addressed work-related PTSD. Ten WBSI items measuring thought suppression as such [19] were rated for the way participants dealt with thoughts and memories of their condition. The PSS corresponds to the 17 DSM-IV symptoms of PTSD. Respondents rated the severity of these symptoms in response to their condition since giving birth, using a 4 -point severity scale $(0=$ not at all, 3 = almost always), and also rated the onset and duration of symptoms. The PSS has been shown to have good internal and test-retest reliability, good concurrent validity, and PTSD diagnosis based on this scale is in good agreement with a clinical interview [17]. Participants were classified with clinical levels of PTSD if they endorsed the DSM-IV subjective stresson criterion [i.e. peritraumatic fear, horror, or helplessness rated $\geq 4$ ("intense")], and at least $\mathbb{1}$ re-experiencing, 3 avoudance, and 2 hyperarousal symptoms for at least 1 month, which was similar as did others [11]. A symptom was considered present if it was rated at least 2 (half the time") [20]. The BDI was completed for the time PTSD symptoms were at their worst. Participants were classified with clinical depressive symptons if they had a BDI score of 15 or higher [21]. One item addressing weight loss was excluded for patients, given this would be
affected by the delivery.

Shatistical malyses. Group differences were tested with Pearson Chi-square or Fisher's exact test, as appropriate, or with analysis of variance. Associated factors of PTSD symptom severity were tested with Pearson correlation and multiple regression. These included 3 sets of variables: indicators of condition severity (gestational age, cesarean section, and length of hospital stay, peritraumatic reactions (distress and dissociation), and postraumatic factors (negative interpretations of symptoms and thought suppression). An
alpha level of 05 was used. 


\section{RESULTS}

Table 1 shows characteristics of patient samples and the significant outcome of paired comparisons only. The preterm PE-group differed from the PT-group by a higher rate of cesarean section and more perceived threat to life and to their physical integrity at the time. Relative to the C-group, the term PE-group delivered more often by cesarean section, perceived more threat, was admitted to the hospital at an earlier gestational age, and gave birth to infants with a lower birth weight. Since the latter two measures were strongly related $[r(110)=.88]$, only gestational age is used in further analyses.

Table 1. Characteristics (SD) of patients with former preterm preeclampsia ( $\mathrm{PE}$ ), preterm birth (PT), term $\mathrm{PE}$, and uncomplicated term birth (C)

\begin{tabular}{|c|c|c|c|c|}
\hline \multirow[b]{2}{*}{ Characteristic } & \multicolumn{4}{|c|}{ Patient groups } \\
\hline & $\begin{array}{l}\text { Preterm PE } \\
(n=18)\end{array}$ & $\begin{array}{l}\mathrm{PT} \\
(n=29)\end{array}$ & $\begin{array}{l}\text { Term PE } \\
(n=23)\end{array}$ & $\begin{array}{l}\mathrm{C} \\
(n=43)\end{array}$ \\
\hline Age, yr & $32(3.9)$ & $3 \|(4.0)$ & $32(2.2)$ & $32(4.9)$ \\
\hline Married or cohabited & 94 & 100 & 96 & 93 \\
\hline High school graduate & 67 & 66 & 61 & 62 \\
\hline College graduate or plus & 23 & 20 & 30 & 35 \\
\hline Gestational age, wh & $32(2.0)$ & $31(2.5)$ & $37(1.6)^{b}$ & $40(1.3)$ \\
\hline Birth weight, gr & $1541(507)$ & $1579(638)$ & $2717(649)^{18}$ & $3342(414)$ \\
\hline Hospitall stay, days & 12 & 9 & 15 & 10 \\
\hline Cesarean section & $77^{\text {is }}$ & 38 & $39^{b}$ & 0 \\
\hline Thareat to life & $50^{\text {ig }}$ & 3 & $39^{b}$ & 7 \\
\hline Threat to physical integrity & $56^{\circ}$ & 21 & $44^{b}$ & 7 \\
\hline
\end{tabular}

Note. Percentages reported unless otherwise specified. Group differences in (gestational) age, birth weight, and length of hospital stay were tested with one-way analysis of variance. Other group differences were tested with Pearson Chi-square or Fisher's exact test, as appropriate.

${ }^{*} p<.05$ for the difference between the pretem PE and PT-group

" $p<.05$ for the difference between the term PE and C-group

PTSD criteria and depression. The four patient groups differed significantly in meeting the DSM-IV subjective stressor criterion $\left[\chi^{2}(3)=27.10, p<.001\right]$, which was attributable to the $\mathrm{PE}$ and $\mathrm{PT}$-groups reporting more intense peritraumatic helplessness relative to the C-group. A similar pattern was found for partners $\left[\chi^{2}(3)=16.96, p=\right.$ $.001]$. For patients, the PTSD criteria were met by $28 \%$ after preterm PE, $28 \%$ after PT, $17 \%$ after term $\mathrm{PE}$, and none after $\mathrm{C}$. These figures were significantly different between the four groups $\left[\chi^{2}(3)=13.57, p=.004\right]$, which was attributable to the $C$ - 
group. The length of time between birth and participation in the study was not significantly different between PTSD cases $(M=12.7$ months, $S D=4.9)$ and non-cases $(M=13.5$ months, $S D=4.2), F(1,111)=.51, p=.48$. Nearly all PTSD cases reported the onset of symptoms within one month after delivery. The most common PTSD symptoms after $\mathrm{PE}$ were less interest $(56 \%)$, intrusive recollections $(42 \%)$, psychogenic amnesia (39\%), difficulty sleeping, (37\%), problems concentrating (37\%), feeling cut off from others $(32 \%)$, being upset at reminders $(27 \%)$, and nightmares $(22 \%)$. While more patients suffered from clinical levels of depression after preterm PE $(33 \%)$, PT $(24 \%)$, and term PE $(26 \%)$ than after C $(7 \%)$, this between-group difference was not significant $\left[\chi^{2}(3)=7.53, p=.06\right]$. However, comorbidity between PTSD and depression was significantly different between preterm PE (17\%), PT (21\%), term PE $(9 \%)$, and $C(0 \%),\left[\chi^{2}(3)=9.61, p=022\right]$. For partners, the PTSD criteria were met by $6 \%$ after preterm $\mathrm{PE}, 15 \%$ after $\mathrm{PT}, 10 \%$ after term $\mathrm{PE}$, and $3 \%$ after $\mathrm{C}$. These rates were non-significantly different between the groups $\left[\chi^{2}(3)=3.50, p=.32\right]$. Rates of clinical depressive symptoms were also non-significantly different between preterm PE $(0 \%)$, PT $(11 \%)$, term PE $(0 \%)$, and C $(3 \%)\left[\chi^{2}(3)=5.07, p=.17\right]$.

Correlates of PTSD symptoms. The PE and PT-groups were pooled for further analyses, because they showed similar relations between PTSD symptoms and risk factors. For patients, PTSD symptom severity was non-significantly related to cesarean section $[r(70)=.22, p=.07]$ and length of hospital stay $(r=.19, p=.12)$. It was significantly related to gestational age $(r=-27, p=.025)$, peritraumatic distress $(r=$ $59, p<.001)$, peritraumatic dissociation $(r=58)$, negative interpretations of symptoms $(r=.66)$, and suppression of condition-related thoughts $(r=.60)$. To test the relative contribution of these factors, a hierarchical multiple regression was conducted in 3 steps. On the first step, gestational age $(\beta=-.27, t=2.30, p=.025)$ alone accounted for $7 \%$ of the variance of PTSD symptoms. On the second step, peritratumatic distress $(\beta=.38, t=3.17, p=.002)$ and peritraumatic dissociation $(\beta=$ $.32, t=2.70, p=.009)$ together accounted for $43 \%$ of the variance. Gestational age $(\beta$
$=-10, t=.99, p=.33)$ was no longer significant. On the final step, peritraumatic
dissociation $(\beta=.27, t=2.73, p=008)$, negative int dissociation $(\beta=.27, \gamma=2.73, p=.008)$, negative interpretations of symptoms $\langle\beta=.40$, $t=4.25, p<.001)$, and thought suppression $(\beta=.25, t=2.57, p=.012)$ accounted for
$61 \%$ of PTSD symptoms in patients $[F(3,66)=34.84, p<.001]$. These explained $67 \%$
of symptoms in partners $[F(3,55)=36.38, p<.001]$, of symptoms in partners $[F(3,55)=36.38, p<.001]$.

\section{Discussion}

To our knowledge, this is the first study of PTSD in response to PE. About one-fourth of patients met diagnostic criteria for PTSD in response to both preterm PE and PT, muggesting that the physical strain of PE does not contribute to the psychological morbidity triggered by premature delivery. The prevalence of PTSD in the term PE group $(17 \%)$ was not significantly lower than that of the preterm groups, but was 
substantially higher relative to the $\mathrm{C}$ group (0\%), suggesting that $\mathrm{PE}$ as such may be psychologically stressful. In line with other studies [22], PTSD symptoms were more strongly associated with psychological factors than with objective indicalors of condition-severity. Of the objective condition-severity factors, only gestational age at admission was significantly (negatively) linked to PTSD symptoms. A stronger stressor-dose response relationship might have been found with additional severity factors, such as postmatal complications, clinical course of the hospitalized newborn [7], or persistent physical complaints [12]. However, other PTSD research [11, 12, 23] showed that the degree of peritraumatic distress and dissociation strongly relates to PTSD severity, independently of objective stressor severity, which points out the importance of distinguishing between subjective and objective indicators of stressor: severity. The major correlates of PTSD symptoms were peritraumatic dissociation, negative appraisals of symptoms, and thought suppression. Longitudinal studies among other psychologically traumatized individuals showed that immediate distress and dissociation [24], negative interpretations of initial psychological symptoms, and thought suppression as a coping strategy [12] predict later PTSD. The exact mechanism by which peritraumatic dissociation leads to PTSD is presently unclear. Negative attributions of symptoms might be critical in the persistence of symptoms, because they result in a sense of current threat [25], and the tendency to suppress upsetting thoughts may, paradoxically, increase the fiequency of such thoughts [26] and impede emotional processing [9].

To what extent are birth practices in the Netherlands different from other developed countries? Only the practice of home deliveries (30\% of all deliveries) in the Netherlands is different from that in most other countries in the developed world. "The management of the $70 \%$ clinical deliveries in our obstetrical population does not differ much from that in other countries. All patients in the study gave birth in the clinic, and both control groups and the preeclamptic groups were offered similar obstetrical care, the only difference being the pregnancy complication requiring specific clinical management. The latter is based on international management standards adopted by many clinics in the Western world, which does not differ much from the management in most other countries, including the USA.

Several limitations of this study should be taken into account. First, results are based on small sample sizes and self-1eports. The diagnoses of PTSD and depression require a full interview and our rates should be viewed as estimates. Second, all ratings were based on the subjects" recall of how they felt up to two years previously. Notwithstanding these limitations, our data suggest that the psychological scquelae of preeclampsia require more research and clinical attention. Future studies ought to include longitudinal study designs and structured interviews to refine the prevalence, course, and risk factors for PTSD.

What are the implications of these findings for clinical care? First, they suggest the need for physicians to be aware of possible PTSD symptoms in response to preeclampsia or preterm birth. This may be of special importance since one way of 
avoiding reminders of the condition might be to avoid a future pregnancy. Moreover, a subsequent pregnancy or delivery might reactivate unresolved PTSD, when cues reminiscent of preeclampsia or preterm birth arise [9]. Finally, unresolved PTSD might even contribute to subsequent undesirable pregnancy outcomes, since symptoms of anxiety or depression are predictive of adverse obstetric and neonatal outcomes [27, 281 .

It is premature to conclude that patients need psychological interventions after preeclampsia or preterm birth. Our data suggest that only a minority develops PTSD, and acute trauma interventions do not have established efficacy, and sometimes even have adverse effects [29]. Clinicians may be most helpful if they empathize with patients, support resources (e.g., social support) that they naturally rely on in difficult times, and target individuals at risk for PTSD [30]. If longitudinal studies confirm our results, short-term psychological support and follow-up should focus on individuals with intense acute distress and dissociative reactions. Patients may also benefit from educative interventions, such as written information about common responses and adaptive reactions, and these might help them assess their own risk of later problems. It is unclear how to prevent PTSD, but the disorder can be treated, if recognized.

\section{ACKNOWLEDGMENTS}

The authors thank Erik Schouten for statistical assistance. This paper was presented at the Annual meeting of the Society for Gynecologic Investigation (March 2001), Toronto, Canada.

\section{RERERENCES}

1. National High Pressure Education Program Working Group on High Blood Pressure in Pregnancy. Report of the National High Blood Pressure Education Program Working Group on high blood pressure in pregnancy: Am J Obstet Gynecol 183:S1-S22, 2000

2. van Beek E, Peeters LLH: Pathogenesis of preeclampsia: a comprehensive model. Obstet Gynecol Surv 53:233-239, 1998 3. Norwitz ER, Repke JT: Preeclampsia prevention and management. J Soc Gynecol
Investig 7:2] -36,2000

4. American Psychiatric Association: Diagnostic and statistical manual of mental disorders (4th ed). Washington DC, Author, 1994, pp 424-429

5. Wijma K, Soderquist J, Wijma B: Posttraumatic stress disorder after childbirth: a cross sectional study. J Anxiety Disord 11:587-597, 1997

6. Ryding EL, Wijma $\mathrm{B}$, Wijma $\mathrm{K}$ : Posttraumatic stress reactions after emergency cesarean section. Acta Obstet Gynecol Scand 76:856-861, 1997

7. DeMier RL, Hynan MT, Harris HB, Manniello RL: Perinatal stressors as predictors of symptoms of posttraumatic stress in mothers of infants at high risk. J Perinatol
$16: 276-280,1996$ 
8. Quinnell FA, Hynan MT: Convergent and discriminant validity of the Perinatal PTSD Questionnaire (PPQ): a preliminary study. I Trauma Stress 12:193-199* 1999

9. Foa EB, Steketee G, Rothbaum BO: Behavioral/ cognitive conceptualization of posttraumatic stress disorder. Behav Ther 20:155-176, 1989

10. March JS: What constitutes a stressor? The "criterion A" issue. In Davidson JRT, Foa EB (eds), Posttraumatic stress disorder: DSM-IV and beyond. Washington, DC, American Psychiatric Press, 1993, pp 37-54

11. Bernat JA, Ronfeldt HM, Calhoun KS, Arias I: Prevalence of traumatic events and peritraumatic predictors of posttraumatic stress symptoms in a nonclinical sample of college students. J Trauma Stress 1 1:645-664, 1998

12. Ehlers A, Mayou RA, Bryant B: Psychological predictors of chronic posttraumatic stress disorder after motor vehicle accidents. J Abnorm Psychol 107:508-519, 1998

13. Bryant RA, Harvey, AG: Avoidant coping style and posttraumatic stress following motor vehicle accidents. Behav Res Ther 13:631-635, 1995

14. Marmar CR, Weiss DS, Metzler TJ: The Peritraumatic Dissociative Experiences Questionnaire. In Wilson JP, Keane TM (eds), Assessing psychological trauma and PTSD. New York, Guilford Press, 1997, pp. 412-428

15. Clohessy S, Ehlers A: PTSD symptoms, response to intrusive memories and coping in ambulance service workers. Br J Clin Psychol 38:25 $1-265,1999$

16. Wegner DM, Zanakos S: Chronic thought suppression. J Pers 62:615-640, 1994

17. Foa EB, Riggs DS, Dancu CV, Rothbaum BO: Reliability and validity of a brief instrument for assessing posttraumatic stress disorder. I Trauma Stress 6:459-473, 1993

18. Beck AT, Rush AJ, Shaw BF, Emery G: Cognitive therapy of depression. New York, Guilford Press, 1979

19. Muris P, Merckelbach H, Horselenberg R: Individual differences in thought suppression. The White Bear Suppression Inventory: factor structure, reliability, validity, and correlates. Behav Res Ther 34:501-513, 1996

20. Brewin CR, Andrews B, Rose S: Fear, helplessness, and horror in posttraumatic stress disorder: investigating DSM-[V criterion A2 in victims of violent crime. $J$ Trauma Stress 13:499-509, 2000

21. Burns DD, Beck AT: Cognitive modification of mood disorders. In Foreyt JP, Rashjen DP (eds), Cognitive Behaviour Therapy. New York, Plenum Press, 1978, pp 109-134

22. Bowman ML: Individual differences in posttraumatic distress: problems with the DSM-IV model. Can J Psychuatry 44:21-33, 1999

23. Blanchard EB, Hickling EJ, Mitnick $N$, et al: The impact of severity of physical injury and perception of life threat in the development of posttraumatic stress disorder in motor vehicle accident victims. Behav Res Ther 33:529-534, 1995

24. Shalev AY, Peri T, Canetti L, Schreiber S: Predictors of PTSD in injured trauma survivors: a prospective study. Am J Psychiatry 153,219-225, 1996 
25. Ehlers $A_{n}$ Clark DM: A cognitive model of posttraumatic stress disorder. Behav Res Ther $38: 319-345,2000$

26. Harvey AG, Bryant, RA: The effect of attempted thought suppression in acute stress disorder. Behav Res Ther 36:583-590, 1998

27. Levin JS, DeFrank RS: Maternal stress and pregnancy outcomes: a review of the psychosocial literature. J Psychoson Obstet Gynaecol 9:3-16, 1988

28. Chung TKH, Lau TK, Yip ASK, Chiu HFK, Lee DTS: Antepartum depressive symptomatology is associated with adverse obstetric and neonatal ourcomes. Psychosom Med 63:830-834, 2001

29. Rose S, Bisson J: Brief early psychological interventions following trauma: a systematic review of the literature. J Trauma Stress 11:697-710, 1998

30. Raphael B, Dobson M: Acute posttraumatic interventions. In Wilson JP, Friedman MJ, Lindy JD (eds), Treating psychological trauma \& PTSD. New York, Guildford Press, 2001, pp 139-158 


\title{
CHAPTER 2
}

\section{Posttraumatic Stress Disorder after Pregnancy Loss}

\begin{abstract}
This prospective longitudinal study inyestigated the prevalence of posttraumatic stress disorder (PTSD) in response to pregnancy loss About 1,370 women were recruited in the early stages of pregnancy and 113 of them had a subsequent pregnancy loss. One and four nonths after pregnancy loss, they were assessed for PTSD with the Posttraumatic Symptom Scale. Depression was also assessed. The majority had an early loss, i.e, within 20 weeks. At one month, the prevalence of PTSD was $25 \%$, and the symptom-severity was similar to other traumatized populations. Women will PTSD had increased risk of depression. $36 \%$ of PTSD cases and $6 \%$ of non-cases reported depression. At four months, $7 \%$ met the criteria for PTSD, of which half were chronic. In contrast, rates for depression had not declined. The results indicate that pregnancy loss is potentially traumatic, putting women at risk of developing PTSD. In most cases, the disorder is immediate and persists for several months.
\end{abstract}

\section{INTRODUCTION}

At least 15 percent of known pregnancies end in a loss, with the majority occurring in the first three months [1]. Although pregnancy loss is common, it is often perceived as a stressful life event. In most cases the loss is sudden and unexpected [2], it seems unreal since there is no viable fetus to moum [3], and social support is deficient since others may not even have known about the pregnancy [4]. Subsequent reactions may vary, but sadness, anger [5], guilt, distress [6], preoccupation with the loss, and loss of interest [7] are frequent, normal bereavement, reactions. Over time these reactions decrease in frequency and intensity, and most women come to term with their losses [5]. However, some women develop psychiatric morbidity, indicating complicated

\footnotetext{
Engelhard, I.M., van den Hout, M.A., \& Arntz, A. (2001). General Hospital Psychatry, 23, $62-66$.
} 
grief $[8,9]$. Since miscarriage has primarily been viewed as a loss event, studies have mostly focused on depression, showing that about 30 to $50 \%$ develop severe depression symptoms within 6 months after miscarriage [8]. Yet pregnancy loss may also involve traumatic elements, resulting in anxiety. For example, six weeks after a miscarriage, women have higher anxiety scores than pregnant controls [10], and after three months, $32 \%$ has clinical anxiety levels [11]. Research regarding the nature of anxiety symptoms and disorders is scant. Recently, Geller, Klier, and Neugebauer [12] examined rates of obsessive compulsive disorder (OCD), panic disorder, and phobia within six months after miscarriage. They found that miscarriage increased risk for an initial or recurrent episode of $O C D$, but it did not increase risk for panic disorder or specific phobia. They suggested that especially the risk for posttraumatic stress disorder (PTSD) merits further investigation, which has also been noted by others [7, 13, 14], and may be particularly important because traumatically bereaved individuals require intervention that is more than mere grief facilitation [15].

The fourth edition of the Diagnostic and Statistical Manual of Mental Disorders (DSMIV) [16] describes PTSD as an anxiety disorder that is precipitated by a traumatic event and characterized by symptoms of re-experiencing (e.g., recollections, nightmares, flashbacks), avoidance of reminders of the event and numbing (e.g., restricted affect, estrangement from others), and increased arousal (e.g., sleeping problems, irritability, hypervigilance). To meet the DSM-IV diagnosis of PTSD, a person must endorse at least one re-experiencing symptom, three avoidance or numbing symptoms, and two symptoms of increased arousal. These must be present for more than one month and cause significant impairment. If symptoms persist after three months, they are regarded as chronic.

An important issue in the diagnosis of PTSD is the traumatic event criterion. Strictly speaking, the DSM-IV allows for diagnosis of PTSD after pregnancy loss, since it defines a traumatic event as one that inchudes "actual or threatened death or serious injury, or a threat to the physical integrity of self or others" (p. 427, Criterion A1). In addition, the person's response at the time of the event must involve intense horror, fear, or helplessness (Criterion A2). These can be assumed to be common reactions to pregnancy loss, especially if the death event is perceived and parental attachment has taken place [14]. Although the traumatic nature of pregnancy loss is increasingly recognized, the proportion of women traumatized is unknown [14]. Some studies documented subsequent symptoms of re-experiencing and avoidance $[3,17,18]$, with symptom-severity similar to that found in traumatized people seeking therapy [18], but did not assess arousal symptoms. One unpublished study [19] found that 2.5 months after pregnancy loss, 10\% of women met symptoms required for PTSD diagnosis. This dropped to $5 \%$ at 6 months and $4 \%$ at 12 months. However, the PTSD measure was not validated and symptoms were measured at a time when many may have dissipated. In addition, the severity of PTSD symptoms was not assessed. Yet even if symptoms are insufficient or not in the right combination to merit a diagnosis of PTSD, they may impair quality of life. Finally, previous studies did not incorporate the subjective 
trauma Criterion A2, since they were necessarily based on DSM-III-R criteria, which only defined a traumatic event with objective characteristics. Thus, as yet, it is unclear whether pregnancy loss may be considered a traumatic event as specified by the subjective DSM-IV criterion.

The purpose of this study was to assess acute and chronic PTSD after pregnancy loss, taking previous limitations into account. Specifically, we assessed PTSD diagnosis, including Criterion $\mathrm{A} 2$, and symptom severity at one month and four months. We also measured depression since this often co-occurs with PTSD [16]. Extrapolating from previous studies, we expected that post-event morbidity would be positively linked with gestational length $[17,19,20]$. Finally, we explored whether it was related to prior pregnancy loss, since conflicting findings have been reported [13].

\section{METHOD}

Participants and procedure. In order to limit a potential selection bias, women were recruited in the early stages of pregnancy, following the study of Janssen [19]. An editorial and two advertisements were placed in Dutch family magazines recruiting participants for a study 'about pregnancy-experiences'. About 1370 women within the first 12 weeks of pregnancy volunteered to participate. Immediately after enrollment, women were sent baseline questionnaires, assessing demographics, personality, social support, prior life events, and psychological symptoms. Every other month of pregnancy and one month after the due-date, they were sent short surveys about pregnancy (e.g., about health, contact with other pregnant women, reactions to ultrasound) and the (upcoming) delivery (e.g., about preparations for it, reactions during and after delivery). Participants were asked to return questionnaires with a postage-paid return envelope within one week, and to inform the researchers if they had experienced pregnancy loss. Women who had a pregnancy loss were sent questionnaires about one month and four months after the event, regarding peritraumatic reactions, coping, memory, social support, other life events, PTSD, and depression.

This paper reports on the PTSD and depression prevalence one month and four months after the loss. Of the original sample, 33 women withdrew from the study before completing the baseline questionnaire, mainly because it was too long. Of the remaining sample, 121 women $(9 \%)$ experienced a loss, and 113 completed the first post-loss questionnaire (drop out $=7 \%$ ). Background characteristics of these 113 respondents are shown in Table 1 . A total of 101 of them completed the second postloss questionnaire $(\mathrm{drop}$ out $=11 \%$ ). The twelve women who dropped out reported significantly more PTSD symptoms at one month relative to the others, $F(1,111)=$ $10.64, p<.01$. They did not differ in age, pregnancy length, and depression. 
Table 1. Background characteristics of respondents with pregnancy loss

\begin{tabular}{|c|c|}
\hline Age, yr $(S D)$ & $30.7(4.0)$ \\
\hline Gestationall age, wh ( $S D$; range) & $11.4(4.9 ; 5-39)$ \\
\hline Employed & 71 \\
\hline \multicolumn{2}{|l|}{ Marital status } \\
\hline Single & 3 \\
\hline Cohabited & 15 \\
\hline Married & 82 \\
\hline \multicolumn{2}{|l|}{ Education } \\
\hline Less than high school & 1 \\
\hline High school gradunte & 58 \\
\hline College graduate & 30 \\
\hline Graduate degrees & 11 \\
\hline \multicolumn{2}{|l|}{ Children } \\
\hline No children & 29 \\
\hline One child & 47 \\
\hline Two or more children & 24 \\
\hline \multicolumn{2}{|l|}{ Prior pregnancy loss } \\
\hline No prior loss & 63 \\
\hline One prior miscarriage & 28 \\
\hline Two of more prior miscarriages & 6 \\
\hline Prior stillbirth & 1 \\
\hline Prior abortion & 2 \\
\hline
\end{tabular}

Note. Data reported as percentages unless otherwise specified.

Measures. Emotional reactions of horror, fear; or helplessness during pregnancy loss were rated on a 5 - point scale $(1=$ not at all, $2=$ a litte bit, $3=$ moderate, $4=$ intense. $5=$ extreme) to assess PTSD Criterion A2. PTSD symptonns were measured with the Postramatic Symptom Scale-Self-Report version (PSS-SR) [21, 22], which corresponds to the 17 DSM-IV symptoms. Respondents rated how much they were bothered by each symptom in the prior month, using a 4 - point severity scale $(0=$ not at all, $1=$ once in a while, 2 = half the time, 3 =almost always). Foa et al. [21] reported good reliability and concurrent validity with other PTSD measures, and found good agrement with the Structured Clinical Interview for DSM-III-R (SCID) [23] in diagnosing PTSD. Internal consistency for our sample was .87. The Beck Depression Inventory (BDI) $[24,25]$ was also completed, but one item related to weight loss was omitted, given that this may be a likely result of pregnancy loss. 


\section{RESULTS}

First, we estimated PTSD diagnosis. Participants were classified as cases if they met the DSM-IV Criterion A2 and the diagnostic criteria. We considered Criterion A2 met if any of the emotional reactions were rated at least 4 ("intense"). Of all participants, $26 \%$ met the criterion for horror, $31 \%$ for fear, and $68 \%$ for helplessness during pregnancy loss. We considered responses of at least 2 ("half the time") indicative of presence of a PTSD symptoml. A close inspection of the PTSD-clusters showed that one month after pregnancy loss, $77 \%$ of women met the required criteria for reexperiencing, $40 \%$ for avoidance, and $42 \%$ for hyperarousal. Twenty-eight participants (25\%) met criteria for a PTSD diagnosis. After four months, these numbers dropped to $33 \%$ for re-experiencing, $14 \%$ for avoidance, and $21 \%$ for hyperarousal. Only seven participants ( $7 \%$ ) met criteria required for PTSD diagnosis. Four of them had chronic PTSD and the others had a late onset of the disorder during a subsequent pregnancy. Second, we assessed the prevalence of PTSD symptoms. At one month, in the group as a whole, the most common symptoms were: intrusive recollections $(65 \%)$, a sense of foreshortened future $(61 \%)$, diminished interest in activities $(57 \%)$, and psychological distress at exposure $(50 \%)$. At four months, these were intrusive recollections $(30 \%)$, foreshortened future $(28 \%)$, irritability (25\%), and sleeping problems $(23 \%)$. Third, we calculated PTSD severity scores. At one month, the severity-score for the PTSD group $(M=28.61, S D=7.23)$ was twice as high as that for the non-PTSD group $(M=14.60$, $S D=6.82$ ). The mean for the PTSD group was comparable to that found by Tiesema and Amtz [26] in Dutch PTSD outpatients who experienced various traumatic events $(M=25.75, S D=10.54)$, and may be considered moderate to severe compared to other traumatized women [27]. At four months, these scores dropped to $15.20(S D=10.53)$, and $7.62(S D=6.96)$, respectively. Fourth, we examined rates of depression. One month after the loss, $13 \%$ could be regarded as having mild to severe depression, using a cut-off score of 15 , as suggested by Burns and Beck [28]. Rates were significantly higher for PTSD cases (36\%) relative to non-cases $(6 \%), \chi^{2}(1)=16.28, p<.001$. At four months, rates for depression remained stable at $13 \%$ for the whole group, $35 \%$ of the initial PTSD group, and $8 \%$ of non-PTSD cases. Finally, gestational length was significantly linked to PTSD-severity at one month, $r(113)=.31, p<.01$, and four months, $r(101)=.45, p<.001$, and particularly to the reexperiencing cluster $, r=.38, r$ $=.46, p s<.001$, respectively. It was also strongly linked to depression-severity at one month, $r(113)=.47, p<.001$, and four months, $r(101)=.33, p<.01$. Prior pregnancy loss was not related to PTSD diagnosis, $\chi^{2}(1)=1.55$, ns. In contrast, it was related to depression: two-thirds of women with clinical depression had a prior pregnancy loss; $\chi^{2}(1)=6.74, p<.01$.

I Foa et al. [21] considered a symptom as present if it was rated at least $1\left({ }^{* 6} \mathrm{once}\right.$ in a while $\left.{ }^{4 t}\right)$ and found this to be more conservative in diagnosing PTSD than the SCID. However, since the findings were based on an chronic sample, we decided to use a more conservative cut-off rating. 


\section{DHSCUSBION}

To our knowledge, this is the first study to use a standardized instrument of DSM-IV criteria for PTSD among women who experienced a pregnancy loss. The main findings were that PTSD symptoms were commonly reported, and that $25 \%$ of our participants met criteria for PTSD diagnosis one month after the event, with a symptom-severity that was similar to other traumatized populations. The prevalence of chronic PTSD at 4 months was 4\% (4/101). However, this rate might be confounded by selective drop out: those who did not complete the 4-month questionnaires reported higher PTSD symptoms at one month compared to the others. In fact, 8 out of 12 them met criteria for PTSD diagnosis at 1 month, and including them in the rate for chronic PTSD increases it to $10 \%(12 / 113)$. Thus, the true estimate for chronic (4-month) PTSD is probably between 4 and $10 \%$.

It is unlikely that the one-month prevalence rates were inflated by a selection bias, since participants were recruited in early pregnancy. In fact, these rates might also be on the conservative side, since eight participants found the first post-loss questionnaire too upsetting to complete. An important issue is whether the substantial rate for PTSD is not accounted for by depression, e.g. due to symptom-overlap [29]. There are several indications that PTSD and depression represent two constructs in our participants. First, the time course differed between the two disorders. After one month, one-third of PTSD cases could be regarded as having depression, and while PTSD subsided in many within four months, the rates for depression remained high. This corresponds with studies showing that half of people recover from PTSD within three months [16] and that depression may be elevated up to one year after pregnancy loss [30]. Second, re-experiencing symptoms (e.g., intrusive recollections, psychological distress at exposure, and flashbacks) were prominent in the PTSD group, and are distinctive symptoms for PTSD [31]. Finally, we explored the clinical pattern of PTSD further, and randomly interviewed ten women of the PTSD-group. We asked them to describe their loss-event, as well as the symptoms they endorsed on the PSS-SR. The PTSDsymptoms they described were clearly shaped by horror and feat experienced during pregnancy loss. For example, a woman with a miscarriage said: ". . We had some people over and someone was snoking a cigarette. Suddenly something felt wrong. I lost a lot of blood with lange pieces of tissue. I could feet my body emptying itself and I was scared to death. I was terrified that all of my intestines would go. I got unconscious because of the blood loss... In the beginning, especially when I smelled cigaretre smoke, it all came back to me like a movie: the blood and tissue, that feeting of emptying, and even the crying of my foldery daughter. Now it mostly comes back when it's quiet and I'm alone or when I' $m$ in bed at night. . . I feel a lot of panic then and am afraid that it will happen again, that my body will empty itself' . . I try to distract myself a lot. I try to fool myself by trying not to think about it. . . Another women with a miscarriage said: ". . It happened in the toilet. My husband cut my pants, and we caught it in a bucker in the toilet. It was clearly a baby. . When I use 
the toilet, I see it all again: that bucket with my baby and the look on my husband s face. And when I'm lying in bed, these thoughrs come back and I see it happening again. It makes me feel terrible. I feel so revolted. And sad and helpless that I couldn't stop it . . I try not to think about the bucket. I stay busy with my family, I wy to block my thoughts, and look for distraction with my best friend. Life must go on. But Ifeel so disappointed in my body".

Another important issue is the distinction between PTSD and grief, which was beyond the scope of this study. Janssen [19] found that PTSD correlated .50 with grief intensity, suggesting these are different but related constructs. Although some authors consider post-loss psychiatric morbidity such as PTSD manifestations of complicated grief [8], similarities in symptoms between PTSD and grief are striking and their differences deserve more research attention [32].

Pregnancy length was linked to PTSD severity and especially to re-experiencing symptoms. As time progresses in pregnancy, a loss becomes more tangible, resulting in more fear-relevant cues that may provide the basis for intrusive recollections [33]. This can be illustrated by the experience of a woman with a stillbirth in the 32 nd week: "At the moment of birth, I saw Sara's head come out of me. I held her, and she was red. Her skin was torn. One of her eyes was open. I looked to see if it was a girl. Her belly was dark-red. She had beautiful ears. A very white nose. Blood was running from her nose. Her legs looked broken. My boyfriend was very supportive and often said that I was doing a good job. Other than that I can't remember anything. I missed Sara"s noises".

Several conclusions may be drawn from this study. First., pregnancy loss, regardless of gestational length, may not only be a loss event, producing depression, but also a threatening event, putting women at risk of developing PTSD. While the full clinical diagnosis of PTSD requires a more extensive interview, this study suggests that onefourth of women may meet criteria for PTSD at one month. Second, PTSD subsides in many within four months, and those who meet the criteria then are chronic and new cases. A late onset occurred in women during a subsequent pregnancy, which thas also been clinically observed [7]. Only $4 \%$ of women with a loss developed chronic PTSD, which, as mentioned, might be an underestimation. Nevertheless, although $4 \%$ may seem negligible, it involves large absolute numbers due to the common nature of pregnancy loss. For example, between 600,000 and 800,000 women miscarry annually in the United States [17]. Our study suggests that 150,000 to 200,000 of them may develop acute PTSD, and that this may take a chronic course in about 24,000 to 32,000 women. Especially these women may need help in the early phases, and it is important to predict individuals at high risk for such outcome. Third, gestational length was moderately related to PTSD, which implies that other factors are important in its onset, and awaits future research.

These findings should have great consequence for health care professionals, who regularly deal with miscarriage and stil» tend to regard it as an insignificant event [7]. Frequently, the loss is neither validated nor recognized [34] and follow-up 
apouments wot provided [13]. Since responses to pregnancy loss are diverse, it is

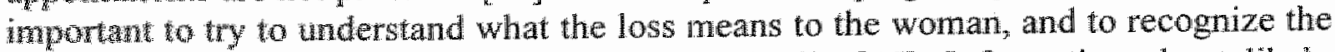
potental shess of the event for her and her family [35]. Information about likely

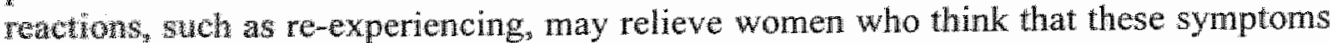
ard puthowical or signs that they are 'going mad' [36]. Furthermore, allowing women to discuss the feelings about the event may enhance adjustment [37].

\section{AUTHOR NOTP AND ACKNOWLEDGMENTS}

A preliminary version of this paper was presented at the 3 rd World Conference of the Intemational Society for Traumatic Stress Studies, Melboume, Australia, March 18, 2000. The authors would like to thank the participants for their time and enotional involvement. Special thanks are also due to Renate Kuiper for assistance in datacollection, Marjanne Cuisinier for helpful discussions, and Bert Hoekzema for developing a planner program.

\section{REFERENCES}

1. Alberman $E$ : The epidemiology of repeated abortion. In Beard $R W$, Sharp $F$ (eds), Pregnancy loss: Mechanisms and treatment. London, Springer-Verlag, 1988, pp $9-$ 17

2. LaFerla $\Pi$, Good RS: Helping patients cope with pregnancy loss. Contemp Obstet Gynaecol 25:107-115, 1985

3. Defrain $J$, Millspaugh $E$, Xie $X$ : The psychosocial effects of miscarriage: Implications for health professionals. Fam Syst \& Health $14: 331-347,1996$

4. Day RD, Hooks D: Miscarriage: A special type of family crisis. Fam Rel 36:305310,1987

5. Madden ME: The variety of emotional reactions to miscarriage. Women Health $21: 85-104,1994$

6. Seibel M, Graves WL: The psychological implications of spontaneous abortions. I Reprod Med 25:161-165, 1980

7. Frost M, Condon JT: The psychological sequelae of miscarriage: A critical review of the literature. Aust NZ J Psychiat 30:54-62, 1996

8. Janssen HJEM, Cuisinier MCJ, Hoogduin KAL: A critical review of the concept of pathological grief following pregnancy loss. Omega 33:21-42, 1996

9. Worden JW: Grief counseling and grief therapy: A handbook for the mental health practitioner (2nd ed). New York, Springer, 1991

10. Thapar AK, Thapar A: Psychological sequelae of miscarriage: A controlled study using the general health questionnaire and the hospital anxiety and depression
scale. Br J Gen Pract $42.94,96,1992$

11. Prettyman $\mathrm{RJ}$, Cordle $\mathrm{CI}$, Cook GD: A three-month follow-up of psychological morbidity atter early miscarriage. Br I Med Psychol 66:363-372, 1993 
12. Geller PA, Klier CM, Neugebauer R: Anxiety disorders following miscarriage. Presented at Annual Convention of the AABT. Toronto, Ontario, 1999

13. Lee C, Slade P: Miscarriage as a traumatic event: A review of the literature and new implications for intervention. J Psychosomatic Res 3:235-244, 1996

14.Speckhard A: Traumatic death in pregnancy: The significance of meaning and attachment. In Figley $\mathrm{CR}$, Bride $\mathrm{BE}, \mathrm{Mazza} N$ (eds), Death and trauma: The traumatology of grieving. Washington, DC, Taylor \& Francis, 1997, pp 67-100

15. Figley $\mathrm{CR}$, Bride $\mathrm{BE}$, Mazza $\mathrm{N}$ (eds): Death and trauma: The traumatology of grieving. Washington, DC, Taylor \& Francis, 1997

16. American Psychiatric Association: Diagnostic and statistical manual of mental disorders (4th ed). Washington, DC, Author, 1.994

17. Beil ER: Miscarriage: The influence of selected variables on impact. Women Ther $12: 161-173,1992$

18. Lee C, Slade P, Lygo $V$ : The influence of psychological debriefing on emotional adaptation in women following early miscarriage: A preliminary study. Br J Med Psychol 69:47-58, 1996

19. Janssen HJEM: A longitudinal prospective study of the psychological impact of pregnancy loss on women. Nijmegen, The Netherlands, Katholieke Universiteit Nijmegen, 1995, pp 65-92. Dissertation

20. Janssen HJEM, Cuisinier MCJ, Graauw KPHM de, Hoogduin KAL: A prospective study of risk factors predicting grief intensity following pregnancy loss. Arch Gen Psychiatry 54:56-61, 1997

21. Foa EB, Riggs DS, Dancu CV, Rothbaum BO: Reliability and validity of a brief instrument for assessing post-traumatic stress disorder. J Trauma Stress 6:459-473, 1993

22. Arntz A: Nederlandse vertaling van de PSS-SR. Maastricht, The Netherlands, Author, $\| 993$

23. Spitzer RL, Williams JBW, Gibbon M, First MB: Structured Clinical Interview for DSM-III-R. Washington, DC, American Psychiatric Press, 1990

24. Beck AT, Rush AJ, Shaw BF, Emery G: Cognitive therapy of depression. New York, Wiley \& Sons, 1979, pp 389-399

25. Bouman TK, Luteijn F, Albersnagel FA, Ploeg FAE vd: Enige ervaringen met de Beck Depression Inventory, BDI. Gedrag, 13:13-24, 1985.

26. Tiesema $M$, Antz A: Imaginal exposure with and without imagery rescriping as treatment of PTSD. In preparation.

27. Foa EB: Manual of the Posttraumatic Stress Diagnostic Scale. Minneapolis, National Computer Systems, Inc, 1995

28. Burns DD, Beck AT: Cognitive modification of mood disorders. In Foreyt JP, Rashjen DP (eds), Cognitive Behawiour Therapy. New York, Plenum Press, 1978, pp 109-134 
29. Keane TM, Taylor KL, Penk WE: Differentiating post-traumatic stress disorder (PTSD) from major depression (MDD) and generalized anxiety disorder (GAD). J Anxiety Disord 11:317-328, 1997

30. Janssen HJEM, Cuisinier MCJ, Hoogduin KAL, Graaw KPHM de: Controlled prospective study on the mental health of women following pregnancy loss. Am I Psychiatry 153:226-230, 1996

31. McNally RJ: Psychopathology of posttraumatic stress disorder (PTSD): Boundaries of the syndrome. In Başoglu $M$ (ed), Torture and its consequences: Current treatment approaches. New York, Cambridge University Press, 1992, pp 229-252

32. Simpson MA: Traumatic bereavements and death-related PTSD. In Figley CR, Bride $B E$, Mazza $N$ (eds), Death and trauma: The traumatology of grieving. Washington, DC, Taylor \& Francis, 1997, pp 3-16

33. Foa EB, Steketee G, Rothbaum BO: Behavioral/cognitive conceptualization of posttratumatic stress disorder. Behav Ther 20:155-176, 1989

34. Cuisinier MCJ, Kuijpers JC, Hoogduin CAL, Graauw CPHM de, Janssen HJEM: Miscarriage and stillbirth: Time since the loss, grief intensity and satisfaction with care. Eur J Obstet Gynecol Reprod Biol 52:163-168, 1993

35. Bakx H: De invloed van perinatale sterfte of gezinnen met jonge kinderen. Systeemther 8:17-24, 1996

36. Hamilton SM: Should follow-up be provided after miscarriage? B J Obstet Gynaecol 96:743-745, 1989

37. Jackman C, McGee HM, Turner M: The experience and psychological impact of early miscarriage. Ir J Psychol 12:108-120, 1991 


\title{
CHAPTER 3
}

\section{The Relationship between Neuroticism, Pretraumatic Stress, and Posttraumatic Stress: A Prospective Study"}

\begin{abstract}
The personality trait of Neuroticism hias been repeatedly associated with symptoms of postraumatic stress disorder (PTSD). However, the nature of this relationship is unclear. There are at least two possible interpretations neuroticism might be a risk factor for PTSD symptoms, or, alternatively, the relationship might be based on content overlap in arousal symptoms. With a prospective design, this study tested both possibilities. About 1370 women volunteers completed questionnaires early in pregnancy, measuring neuroticism and 'baseline' arousal symptoms, and for every fwo months thereafter unill one month after the due date of birth. Of these, 126 had a pregnaney loss, and most of them were assessed for PTSD symptomis one month later. The results showed that pre-trauma neuroticism strongly predicted PTSD symptoms; and particularly PTSD arousal symptoms, after pregnancy loss. However, neuroticism was also strongly related to pie-trauma arousal. After statistically controlling for pretrauma arousal symptoms, the relationship between neuroticism and PTSD symptoms after pregnaney loss was no longer significant. In other words, neuroticism did not predict rises in these symptoms from pre to post-trauma. This suggests that PTSD arousal symptoms tap a specific aspect of neuroticism, and that content-overlap largely accounts for the relationship between neuroticism and PTSD symptoms.
\end{abstract}

\section{INTRODUCTION}

Posttraumatic Stress Disorder (PTSD) may result from exposure to a traumatic event. It comprises three symptom-clusters: 'reexperiencing', "avoidance and numbing", and

\footnotetext{
"Engellhard, I.M., van den Hout, M.A. \& Kind, M (accepted pending rewision). Personality and Individual Differences
} 
"arousal" (APA, 1994). "Reexperiencing' and 'avoidance and numbing" symptoms explicitly refer to this event. That is, reexperiencing necessarily involves reliving a specific event (e.g., intrusive recollections, flashbacks, and nightmares), and avoidance and numbing reflect avoidance of reminders of a specific event (e.g., thoughts, activities, places, and memory). However, the arousal-cluster includes symptoms that not necessarily reflect an external cause (e.g., sleeping problems, irritability, difficulty concentrating).

Not everyone exposed to a traumatic event develops PTSD. Therefore, other risk factors must play a role in the development of the disorder. In recent years, numerous studies examined such factors. One factor that has repeatedly been assaciated with PTSD symptoms is the personality trait of neuroticism. This was found in two ways. First, studies comparing PTSD patients to non-PTSD traumatized controls found significantly higher neuroticism scores for the former group. This holds for exposure to combat (Casella \& Motta, 1990), bushfire (McFarlane, 1992), receiving HIV-diagnosis (Kelly, Raphael, Judd, Kernutt, Burnett, \& Burrows, 1998), and other traumatic events in a community sample (Breslau, Davis, Andreski, \& Peterson, 1991). Second, studies examining the degree of PTSD symptoms found higher neuroticism for individuals with more symptoms. This holds for exposure to combat (Hyer, Braswell, Albrecht, Boyd, Boudewyns, \& Talbert, 1994), earthquake (Lewin, Carr, \& Webster, 1998), plane crash (Chung, Easthope, Chung, \& Clark-Carter, 1999), bushfire (McFarlane, 1989), burn injury (Roca, Spence, \& Munster, 1992), and traumatic war events experienced by parents (Mook, Schreuder, van der Ploeg, Bramsen, van Tiel-Kadiks, \& Feenstra, 1997). More specifically, neuroticism has been related to arousal symptoms (Ormel \& Wohlfarth, 1991; Charlton \& Thompson, 1996), and less to reexperiencing (McFarlane, 1992), or avoidance (Roca et al., 1992) symptoms.

However, the interpretation of this association is unclear. Previous research was restricted by chronic patient populations, retrospective data, and long time intervals between the traumatic event and the study. There are at least two possible interpretations of this relation. First, neuroticism might be a risk factor in the development of PTSD symptoms (Breslau \& Davis, 1991; Kelly et al., 1998; McFarlane, 1989). In other words, individuals higher in neuroticism might be more reactive to a traumatic event (Bowman, 1999; Janssen et al., 1997). Clearly, in order to determine causality, neuroticism ought to be measured prior to trauma, and PTSD symptoms should be assessed within months after the event. Although prospective trauma studies are difficult to do because of the randomness with which traumatic evenis occur, recently, Janssen, Cuisinier, de Graauw, and Hoogduin (1997) used such a design, though not predicting PTSD, but grief intensity. In a large sample of pregnant women, they assessed several potential risk factors early in pregnancy to predict grief intensity in women who later experienced pregnancy loss. Grief intensity correlated .50 with PTSD symptoms (Janssen, 1995), and its strongest predictor was, indeed,
premorbid neuroticism. 
Nevertheless, in studying risk factors, researchers need to ensure that putative vulnerability factors do not have content overlap with the related outcome measure. This might be a problem for neuroticism and PTSD, and especially PTSD arousal symptoms (see also Costa \& McCrae, 1987; Watson \& Pennebaker, 1989). Symptoms of general distress are not unique to PTSD, but occur in other anxiety (Jones \& Barlow, 1990) and affective disorders (McNally, 1992), and are also prominently present in the trait of neuroticism that "predisposes" to such disorders (Clark, Watson, \& Mineka, 1994). Individuals high in neuroticism tend to experience more distress across time and regardless of the situation (Ormel \& Wohlfarth, 1990). This raises the possibility that symptoms similar to the PTSD arousal-cluster are already present in individualls high in neuroticism before a traumatic event. Accordingly, endorsement of PTSD symptoms by individuals with high neuroticism may merely reflect pre-existing symptoms. In other words, neuroticism may manifest in PTSD arousal symptoms.

This prospective study intended to further clarify the relationship between neuroticism and PTSD symptoms. The specific aims were to test a) whether pre-trauma neuroticism predicts PTSD symptoms, b) whether pre-trauma neuroticism is related to pre-trauma arousal symptoms, and c) whether the relation between neuroticism and PTSD symptoms after pregnancy loss still stands after statistically controlling for pre-trauma arousal symptoms. We also controlled for prior life events, because these have been linked to neuroticism (Clark et al., 1994) and PTSD (Breslau, Chilcoat, Kessler, \& Davis, 1999). The results presented here are part of a larger study, as described in detail elsewhere (Engelhard, van den Hout, \& Artnz, 2001; Engelhard, van den Hout, Kindt, Arntz, \& Schouten, 2002). In brief, we conducted a prospective study of the effects of pregnancy loss, with a study design similar to Janssen et al. (1997). A large sample of women completed several questionnaires in early pregnancy, and was followed for every two months thereafter until one month after the due date of birth. Of these, 1.18 had a pregnancy loss and about $25 \%$ of them met the criteria for PTSD one month later (Engellhard et al., 2001). The present paper focuses on neuroticism, arousal symptoms, and prior life events assessed in early pregnancy in relation to PTSD symptom severity one month after pregnancy loss. Although pregnancy might be stressful itself (Cox \& Reading, 1989), arousal in early pregnancy was used as a 'baseline' measure, since we were interested in rises in these symptoms after pregnancy loss. Posttraumatic stress was conceptualized as a continuous variable, because PTSD criteria are still under examination, and we aimed to distinguish between the symptom-clusters.

\section{METHOD}

Participants and procedure. About 1370 women within 12 weeks of pregnancy responded to ads in family magazines, recruiting participants for a study of pregnancyexperiences. In order to limit a selection bias, this study was embedded in a larger study of pregnancy experiences. Respondents were immediately sent baseline questionnaires, including measures for neuroticism, baseline arousal symptoms, and 
prior life events. For every two months thereafter until one month after the due date of birth, they were sent short surveys. These included pregnancy-related questions (e.g., 'how often do you dream of your child'), but also asked participants to inform the researchers if they had experienced pregnancy loss. Women with a pregnancy loss were sent follow-up questionnaires for PTSD symptoms about one month later. Of the original sample, 126 women $(9 \%)$ had a loss, and 8 of them dropped out of the study (drop-out $=6 \%$ ). The remaining 118 women were about 31 years $(\mathrm{SD}=4.2$ ). Nearly all of them graduated from high school, $40 \%$ was college-educated, and about one-third was childless. The mean gestational age was 8 weeks $(\mathrm{SD}=1.9)$ at enrollment, and 12 weeks ( $\mathrm{SD}=6.4$, range $5-40$ ) at the time of the loss. The baseline questionnaires were completed prior to pregnancy loss.

Measures. Neuroticism was assessed with the widely used Eysenck Personality Questionnaire (EPQ; Eysenck \& Eysenck, 1975). The neuroticism scale is reported only (range $=0-22$ ). PTSD symptoms were assessed with the Posttraumatic Symptom Scalle (PSS-SR; Foa, Riggs, Dancu, \& Rothbaum, 1993; Arntz, 1993) in which the severity of the 17 DSM-IV (APA, 1994) PTSD symptoms was rated (0 = not at all, 3 malmost always), for the prior month, in relation to pregnancy loss. Ratings were summed to yield a severity score of the three subscales of reexperiencing (range $=0$ 15 ), avoidance and numbing (range $=0-21$ ), and arousal (range $=0-15$ ), and of total PTSD symptoms (range $=0-51$ ). Baseline arousal was assessed with the arousalsubscale of the PSS-SR. These iterns do not refer to a specific event (e.g., "having trouble falling or staying asleep', 'feeling irritable or having fits of anger'), and were also rated for the prior month. Prior life events were measured with the Negative Life Events and Trauma Questionnaire (Morgan \& Janoff-Bulman, 1994). Events included verbal, physical, and sexual abuse, parental death, serious accidents, serious illness, and natural disasters. Lifetime negative events were calculated.

\section{Results}

The distribution of the $\mathrm{EPQ}-\mathrm{N}(M=7.3, S D=4.6)$ was in the normal range of a community sample of Dutch women (Sanderman, Eysenck, \& Arrindell, 1991). The mean score on the pre-trauma arousal-scale was 3.7 $(S D=2.6)$. The average PSS-SR score was $18.1(S D=9.1)$. Means for the reexperiencing, avoiclance and numbing, and arousal subscales were $5.5(S D=3.2), 7.5(S D=3.9)$, and $5.1(S D=3.6)$, respectively. Prior life events were skewed to the left $(M=3.0, S D=2.6)$ and $\log$-transformed to normality for analyses. First, we tested whether pre-trauma neuroticism predicts PTSD symptoms. This was the case: neuroticism in early pregnancy was strongly related to PTSD symptoms after pregnancy loss, $r(118)=.25, p<.01$, and particularly to the PTSD arousal symptoms, $r=.34, p<.01$. Neuroticism was moderately related to PTSD avoidance and numbing symptoms, $r=.19, p<.05$, and was non-significantly related to PTSD reexperiencing symptoms, $r=.12, N S$. Second, we tested whether 


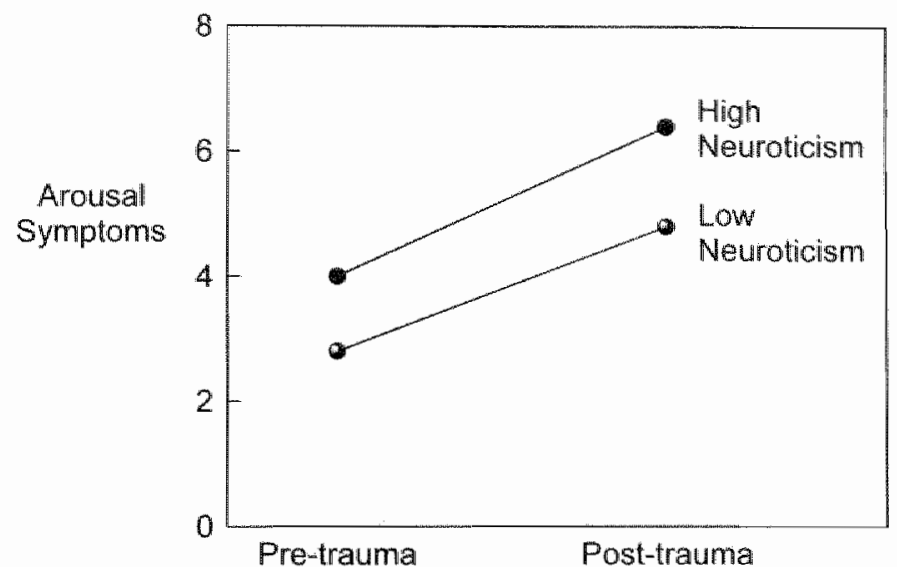

Figure 1. Mean severity of arousal-symptoms as measured with the Postraumatic Symptom Scalle for individuals high and low in neuroticism before and after pregnancy loss.

neuroticism was related to pre-trauma arousal symptoms, which was also the case, $r$ $(118)=.44, p<.01$. A paired-t-test showed that women reported more arousal symptoms after pregnancy loss than before, $t(117)=5.0, p<.001$. Finally, we tested whether the relationship between neuroticism and PTSD symptoms would still stand after controlling for pre-trauma arousal symptoms. Partial correlations indicated that the relationship between neuroticism and PTSD symptoms was no longer significant after controlling for pre-trauma arousal, $r p(118)=.08$, NS. More specilically, neuroticism was no longer significantly related to PTSD arousal symptoms, $r p(118)=$ $.12, N S$, or PTSD avoidance symptoms, $r p(118)=.11, N S$. In other words, neuroticism was not related to increases in arousal symptoms from before to after pregnancy loss. This is illustrated in Figure 1 by similar slopes in arousal symptoms for individuals high and low in neuroticism (based on a median split of EPQ-N).

Finally, forward multiple regression analyses tested the relative contribution of neuroticism, baseline arousal, and prior life events in predicting PTSD symptoms. First, neuroticism, $\beta=.25, t=2.81, p=.006$, accounted for $6 \%$ of the variance of PTSD symptoms, $F(1,116)=7.92, p=.006$. Second, when baseline arousal was added, the relationship between neuroticism and PTSD symptoms was no longer intact: baseline arousal, $\beta=.39, t=4.2, p<.001$, accounted for $19 \%$ of the variance of PTSD symptoms, and neuroticism, $\beta=.08, t=.88, p=.38$, was non-significant, $F(2,115)=$ $13.35, p<.001$. Third, prior life events were added and explained independent 
variance: baseline arousal, $\beta=.37, t=4.17, p<.001$, and prior life events, $\beta=.17, t=$ $2.12, p=.04$, accounted for $28 \%$ of the variance of PTSD symptoms, $F(3,114)=$ $14.52, p<.001$.

\section{DISCUSSION}

In this prospective study, pre-trauma neuroticism predicted PTSD symptoms, and particularly PTSD arousal symptoms, after pregnancy loss. This replicates earlier retrospective findings (e.g., Roca et al., 1992). While this suggests that neuroticism predicts the development of post-trauma symptoms (e.g., see Janssen et all, 1997; Kelly et al. 1998), this was not the case in our study: neuroticism was also strongly related to pre-trauma arousal symptoms, and it did not predict rises in these symptoms after pregnancy loss.

Although the constructs of PTSD and neuroticism are clearly different, the former being a reaction to a particular event and the latter being a temperamental disposition, there is overlap in symptoms. In line with Clark and Watson's (1991) model of anxiety, we found that both constructs involve symptoms of general distress. Does that render the findings tautological? On face value, the arousal-subscale appears related to items of a neuroticism-scale, and indeed the correlation between neuroticism and pre-trauma arousal was .44. However, the noteworthy thing is that this "tautology" could so easily be created. Although items of pre-trauma arousal were identical to PTSD arousal items (e.g., irritability, anger-outbursts, and sleeping problems), symptom-endorsement easily became a manifestation of neuroticism. The findings suggest that this content overlap parsimoniously explains the relationship between neuroticism and post-trauma morbidity. While the existence of content-overlap was quite obvious, it does not imply that arousal symptoms are somehow less relevant to PTSD. In fact, pregnancy loss was attended by sharp increases in arousal, which attests to the fact that increased arousal is highly common after a stressful life event.

Earlier observations of the relation between neuroticism and PTSD symptoms might inspire to find out why individuals high in neuroticism are more likely to develop PTSD symptoms. The present findings, however, suggest that this question may be somewhat beside the point. Individuals high in neuroticism start with a higher baseline level, but the increase in PTSD arousal symptoms after pregnancy loss was equal for individuals with high and low neuroticism. Clinically, these findings may have important implications. Individuals high in newroticism may be more likely to meet the PTSD diagnosis because they have higher baseline levels of arousal. Some of the anxicty symptoms that do not dissipate after treatment may very well be part of the Finally, there are two limitations to the data. First, the data are based on self-reports. Second, neuroticism may not have a direct etiological role, but may modify the course of postraumatic morbidity (McFarlane, 1989). That is, the spontaneous decay in symptom severity may be less or slower in individuals with high neuroticism. 
Previously, neuroticism was related to avoidant coping (McCrae \& Costa, 1986), which is important in the persistence of PTSD symptoms (Ehlers \& Clark, 2000). Obviously this is an empirical issue that awaits further study.

\section{ACKNOWLEDGEMENTS}

The authors gratefully acknowledge Richard J. MoNally for a helpful discussion and comments on an earlier version of the manuscript. This paper was presented at the annual meeting (November 2000) of the International Society for Traumatic Stress Studies (ISTSS), San Antonio, USA.

\section{REFERENCES}

American Psychiatric Association (1994). Diagnostic and statistical manual of mental disorders (4th ed.). Washington, DC: Author.

Arntz, A. (1993) Nederlandse vertaling van de PSS-SR. Universiteit Maastricht, the Netherlands: Author.

Bowman, M.L. (1999). Individual differences in posttraumatic stress: Problems with the DSM-IV model. Canadian Journal of Psychiarry, 44, 21-33.

Breslau, N., Chilcoat, H.D., Kessler, R.C., \& Davis, G.C. (1999). Previous exposure to trauma and PTSD effects of subsequent trauma: Results from the Detroit Area Survey of Trauma. American Joumal of Psychiatry. 156, 902-907.

Breslau, N., Davis, G.C., Andreski, P., \& Peterson, E. (1991). Traumatic events and posttraumatic stress disorder in an urban population of young adults. Archives of General Psychiatry, 48,216-222.

Casella, L., \& Motta, R.W. (1990). Comparison of characteristics of Vietnam veterans with and without posttraumatic stress disorder. Psychological Reports, 67, 595-605.

Charlton, P.F.C., \& Thompson, J.A. (1996). Ways of coping with psychological distress after trauma. British Journal of Clinical Psychology, 35, 517-530.

Chung, M.C., Easthope, Y., Chung, C., \& Clark-Carter, D. (1999). The relationship between trauma and personality in victims of the Boeing $737-2 \mathrm{D} 6 \mathrm{C}$ crash in Coventry. Journal of Clinical Psychology, 55, 617-629.

Clark, L.A., \& Watson, D. (1991). Tripartite model of anxiety and depression: Psychometric evidence and taxonomic implications. Journal of Abnormal Psychology, 100, 316-336.

Clark, L.A., Watson, D., \& Mineka, S. (1994). Temperament, personality, and the mood and anxiety disorders. Joumal of Abnomal Psychology. 103, 103-116.

Costa, P.T., Jr., \& McCrae, R.R. (1987). Neuroticism, somatic complaints, and disease: Is the bark worse than the bite? Joumal of Personality, 55, 299-316.

Cox, D.N., \& Reading, A.E. (1989). Fluctuations in state anxiety over the course of pregnancy and the relationship to outcome. Journal of Psychosomatic Obstetrics and Gynaecology, 10,71-78. 
Ehlers, A., \& Clark, D.M. (2000). A cognitive model of posttraumatic stress disorder. Behaviour Research and Therapy, 38,319-345.

Engelhard, I.M., van den Hout, M.A., \& Arntz, A. (2001). Posttraumatic stress disorder after pregnancy loss. General Hospital Psychiatry, 23, 62-66.

Engelhard, I.M, van den Hout, M.A., Kindt, M., Arntz, A., \& Schouten, E. (2002). Peritraumatic dissociation and posttraumatic stress after pregnancy loss: A prospective study. Behaviour Research and Therapy, in press.

Eysenck, H.J., \& Eysenck, S.B.G. (1975). Mamual of the Eysenck Personality Questionnaire. San Diego, CA: Educational and Industrial Testing Service.

Foa, E.B., Riggs, D.S., Dancu, C.V., \& Rothbaum, B.O. (1993). Reliability and validity of a brief instrument for assessing post-traumatic stress disorder. Joumal of Traumatic Stress, 6, 459-473.

Frost, M., \& Condon, J.T. (1996). The psychological sequelae of miscarriage: A critical review of the literature. Australian and New Zealand Jaurnal of Psychiatry, $30,54-62$.

Hyer, L., Braswell, L., Albrecht, B., Boyd, S., Boudewyns, P., \& Talbert, S. (1994). Relationship of NEO-PI to personality styles and severity of trauma in chronic PTSD victims. Joumal of Clinical Psychology, 50, 699-707.

Janssen, H.J.E.M. (1995). A longitudinal prospective study of the psychological impact of pregnancy loss on women. Unpublished doctorate dissertation, Katholieke Universiteit Nijmegen, the Netherlands.

Janssen, H.J.E.M., Cuisinier, M.C.J., de Graauw, K.P.H.M., \& Hoogduin, K.A.L. (1997). A prospective study of risk factors predicting grief intensity following pregnancy loss. Archives of General Psychiarry, 54, 56-61.

Jones, J.C., \& Barlow, D.H. (1990). The etiology of posttraumatic stress disorder. Clinical Psychology Review, 10, 299-328.

Kelly, B., Raphael, B., Judd, F., Kernutt, G., Burnett, P., \& Burrows, G. (1998). Posttraumatic stress disorder in response to HIV infection. Gemeral Hospital Psychiatry. 20,345-352.

Lewin, T.J., Carr, V.J., \& Webster, R.A. (1998). Recovery from post-earthquake psychological morbidity: who suffers and who recovers? Australian and New Zealand Joumal of Psychiatry, 32, 15-20.

McCrae, R.R., \& Costa, P.T., Jr. (1986). Personality, coping, and coping effectiveness in an adult sample. Joumal of Personalio: 54, 385-405.

McFarlane, A.C. (1989). The aetiology of post-traumatic morbidity: Predisposing, precipitating and perpetuating factors. British Journal of Psychiatry, 154, 221-228.

McFarlane, A.C. (1992). Avoidance and intrusion in posttraumatic stress disorder. The Journal of Nervous and Menral Disease, 180, 439-445.

McNally, R.J. (1992). Psychopathology of posttraumatic stress disorder (PTSD): Boundaries of the syndrome. In M. Basoglu (Ed.), Torture and its consequences: Current treatment approaches (pp. 229-252). Cambridge: CUP. 
Mook, J., Schreuder, B.J.N., van der Ploeg, H.M., Bramsen, I., van Tiel-Kadiks, G.W., \& Feenstra, W. (1997). Psychological complaints and characteristics in postwar children of Dutch World War II victims: Those seeking treatment as compared with their siblings. Psychotherapy and Psychosomatics, 66, 268-275.

Morgan, H.J., \& Janoff-Bulman, R. (1994). Positive and negative self-complexity: Patterns of adjustment following traumatic versus non-traumatic life experiences. Journal of Social and Clinical Psychology, 13, 63-85.

Ormel, J., \& Wohlfarth, T. (1991). How neuroticism, long-term difficulties, and life situation change influence psychological distress: A longitudinal model. Journal of Personality and Social Psychology, 60, 744-755.

Roca, R.P., Spence, R.J., \& Munster, A.M. (1992). Posttraumatic adaptation and distress among adult burn survivors. American Jownal of Psychiatry, 149,1234 1238.

Sanderman, R., Eysenck, S.B., \& Arrindell, W.A. (1991). Cross-cultural comparisons of personality: The Netherlands and England. Psychological Reports, 69, $1091-$ 1096.

Watson, D., \& Pennebaker, J.W. (1989). Health complaints, stress, and distress: Exploring the central role of negative affectivity. Psychological Review, 96, 234254. 



\title{
CHAPTER 4
}

\section{Peritraumatic Dissociation and Posttraumatic Stress after Pregnancy Loss: A prospective study}

\begin{abstract}
This study examined (1) predictors for peritraumatic dissociation, (2) its relations with acute and chronic symptoms of posttraumatic stress disorder (PTSD), and (3) pathways: regarding these relations in response to pregnancy loss. In early pregnancy, about 1370 women volunteers completed questionnaires for neuroticism, control over emotions, dissociative tendencies, absorption, and prior life events. Of these, 126 subsequently experienced pregnancy loss and most of them completed measures one month $(n=$ $118)$ and four months $(n=104)$ later. At one month, peritraumatic dissociation, memory of pregnancy loss (degree of fragmentation, sensory impressions, and emotional intensity), thought suppression, and PTSD symptoms were assessed, and at four nonths, PTSD symptoms were re-assessed. Petitraumatic dissociation was predicted by prior low control over emotions, dissociative tendencies, and lower education. It was not predicted by neuroticism, absorption, and prior life events. Peritraumatic dissociation was related to acute PTSD symptoms and LISREL analyses indicated that self-reported menory fragmentation and thought suppression of pregnancy loss mediated this relation. It also predicted chronic PTSD symptoms, and this relation was mediated by acute PTSD symptoms.
\end{abstract}

*Engethard, 1.M., van den Hout, M.A., Kindt, M., Arntz, A., Scllouten, E. (in press). Bchesviour Rewearch and Therapy. 


\section{INTRODUCION}

Peritraumatic dissociation involves acute alterations in cognitive and perceptual functioning at the time of a traumatic event. It includes depersonalization, derealization, narrowing of attention, time distortion, and confusion (Marmar, Weiss, \& Metzler, 1997; Spiegel \& Cardeña, 1991). Longitudinal studies strongly linked peritraumatic dissociation to posttraumatic stress disorder (PTSD) after various traumatic events (e.g., Ehlers, Mayou, \& Bryant, 1998; Koopman, Classen, \& Spiegel, 1994; Shalev, Peri, Canetti, \& Schreiber, 1996; Ursano et al., 1999). This was independent of objective markers of trauma severity, initial $(<1$ week) PTSD symptoms, (Shalev et al., 1996), and prior PTSD (Ursano et al., 1999).

In fact, peritraumatic dissociation is considered one of the most important predictors for PTSD (Marmar et al,, 1997). The question is what are its determinants? Peritraumatic dissociation relates to peritraumatic perceived threat (Griffin, Resick, \& Mechanic, 1997; Marmar, Weiss, Metzler, \& Delucchi, 1996), and dissociative reactions are related to hyperarousal (Rainey et al., 1987; Southwick et al., 1993). However, research of its premorbid psychological determinants is scant. This is partly because prospective trauma studies are difficult to do. Generally, potential premorbid factors are assessed after trauna, although effects of the event or memory distortions might contaminate such reports. Nevertheless, cross-sectional studies identified potential determinants. Fullerton and colleagues (2000) found that prior depression was related to peritraumatic dissociation in response to a motor vehicle accident (MVA). Marmar and colleagues (1996) assessed emergency workers after critical incident exposure and found that traits similar to neuroticism related to peritraumatic dissociation. This suggests that neuroticism, which predicts PTSD symptoms (McFarlane, 1989, but see also Engelhard, van den Hout, \& Kindt, submitted), increases risk for peritraumatic dissociation. Marmar and colleagues (1996) also found external locus of control to be a strong correlate. Low control over emotions is involved in PTSD (Jones \& Barlow, 1990), and might lead to more disorganizing effects of panic during threat. Moreover, general dissociative tendencies and "absorption", that is, openness to self-altering experiences (see Kihlstrom, Glisky, \& Angiulo, 1994) bear a close phenomenological resemblance to peritraumatic dissociation (absorption correlates with hypnotizability; see Roch \& McConkey, 1990). These tendencies relate to PTSD (Spiegel, Hunt, \& Dondershine, 1988; Stutman \& Bliss, 1985 ) and may enhance spontaneous dissociation during trauma. It has also been suggested that prior traumatic events, particularly before adulthood, lower the threshold for acute dissociation (van der Kolk, van der Hart, \& Marmar, 1996). Prior trauma predicts PTSD (Breslau, Chilcoat, Kessler, \& Davis, 1999), but recently, lower intelligence strongly predicts PTSD, beyond objective trauma exposure (Macklin 
et al., 1998). Fewer cognitive resources might render individuals more overwhelmed during threat.

Furthermore, little is understood about the processes by which peritraumatic dissociation results in PTSD. For a better understanding, it might be useful to distinguish processes leading to acute and chronic (> 3 months; APA, 1994) PTSD. To begin with, regarding the onset of PTSD, peritraumatic dissociation might explain the nature of trauma representations that are later involuntary re-experienced (van der Kolk \& Fisler, 1995). Traumatic memories related to PTSD appear different in structure and content from traumatic memories unrelated to PTSD. Intentional recall of the former is fragmented and disorganized, rather than whole and coherent (Foa, Molnar, \& Cashman, 1995; Harvey \& Bryant, 1999). For example, trauma-narratives reported by individuals with acute stress disorder (ASD) involve more disjointed, confused, and repetitive elements than those reported by individuals without ASD (Harvey \& Bryant, 1999), and decreased fragmentation is related to reduced PTSD symptoms (Foa et al., 1995). Moreover, sensory and emotional impressions rather than thoughts typically characterize re-experiencing phenomena (Ehlers \& Steil, 1995; Ehlers \& Clark, 2000). Dissociation during trauma may be responsible for incoherence of events at the time of encoding, resulting in memory fragmentation at the time of recall, and may overlap with the processing of sensory and emotional impressions of the event rather than its meaning.

Peritraumatic dissociation might also predict acute PTSD by being an early marker for disengagement with the traumatic event. In the aftermath of a traumatic event, oscillation occurs between intrusions and cognitive avoidance (Horowitz, Wilner, Kaltreider, \& Alvarez, 1980). The more memories evoke emotions, the more the individual attempts to suppress them. However, for individuals who develop PTSD, avoidance increases with time (Shalev et al., 1996). There is evidence that peritraumatic dissociation strongly relates to avoidance (Griffin et al., 1997) and escape coping (Marmar et al., 1996). Moreover, it relates to less physiological reactivity during re-exposure to trauma-related material (Griffin et al., 1997). Possibly, individuals with high dissociation during trauma are more likely to use avoidance strategies to deal with traumatic memories. The tendency to suppress thoughts is particularly relevant as it paradoxically increases their recurrence (e.g., Lavy \& van den Hout, 1990).

Regarding the maintenance of PTSD, studies showed that the longer PTSD persists, the less trauma exposure explains symptoms (McFarlane \& Yehuda, 1996). Once symptoms have emerged, the way the individual interprets them appears more critical in determining their course (Ehlers et al.4 1998; Steil \& Ehlers, 2000). For example, Ehlers et al. (1998) found that peritraumatic dissociation and negative interpretations of intrusions at three months predicted PTSD symptoms at one year. After controlling for PTSD symptoms at three months, peritraumatic dissociation was no longer significant, whereas negative interpretations remained significant. This suggests that the relation 
between peritraumatic dissociation and chronic PTSD is mediated by acute PTSD symptoms.

In sum, peritraumatic dissociation appears related to neuroticism, emotional control, general dissociative tendencies, absorption, prior trauma, and lower intelligence. Note that these may not be independently associated. In order to elucidate their relative importance and degree of interdependence, the first goal of this study was to measure all factors in a prospective study. We also studied the magnitude of peritraumatic dissociation and these factors in predicting acute PTSD symptoms. Second, we investigated whether traumatic memory characteristics (fragmentation, sensory impressions and emotional intensity) and thought suppression mediate the relation between peritraumatic dissociation and acute PTSD symptoms. Finally, we examined whether acute PTSD symptoms mediate the relation between peritraumatic dissociation and chronic PTSD symptoms. Earlier, we reported a prospective longitudinal study of PTSD symptoms after pregnancy loss (Engelhard, van den Hout, \& Arntz, 2001; Engelhard et al., 2001), which prowided us with a way to measure premorbid factors before pregnancy loss. The results presented here are part of that study. Participants were sent questionnaires by mail. In early pregnancy, they completed measures for neuroticism, expected emotional control in case of pregnancy loss, general dissociative tendencies, absorption, and prior negative events. Highest level of education attained was used as a proxy measure of intelligence. There are no Dutch measures of intelligence to be administered by mail and the two are highly related in the Netherlands. For example, Bögels, Notermans, Arntz, \& van den Hout (2001) found a correlation of $r=.62$ between highest level of education and gender and age-controlled IQ. One month after pregnancy loss, participants completed measures for peritraumatic dissociation, memory (degree of fragmentation, sensory impressions, and emotional intensity), thought suppression, and PTSD symptoms. Af four months, PTSD symptoms were re-assessed.

\section{Mertion}

Participants. As described in detail elsewhere (Engelhard et al., 2001), about 1370 pregnant women responded to ads in Dutch family magazines recruiting participants ( $\leq$ 12 weeks pregnant) for study of pregnancy experiences. They completed baselline questionnaires at about 8 weeks of pregnancy. For every 2 months thereafter until 1 month after the due-date of birth, they completed pregnancy-related surveys that allso asked them to inform the researchers if they had a pregnancy loss. A total of $118 \%$ out of 126 women ( $9 \%$ ) who had a pregnancy loss completed questionnaires about 1 month later (response $=94 \%)$. Respondents were 31 years $(S D=4)$, nearly all were married or cohabited, about $40 \%$ was college-educated, and about $30 \%$ was childless. The mean age of the loss was 12 weeks ( $S D=6$; range $5-40$ ), and $95 \%$ was before the 20 th week.

\footnotetext{
* 5 women were not included in our prevous report as they enrolied at at ate stage and experienced alate loss
} 
A total of 104 women (88\%) also completed measures at 4 months. Relative to completers, the 14 drop-outs reported more peritraumatic dissociation, $M=21.2$ vs $M$ $=26.0, F(1,116)=5.1, p=.03$, and acute PTSD symptoms, $M=17.3$ vs $M=24.4, F$ $(1,116)=7.9, p<.01$. They did not differ in age and pregnancy length.

\section{MEASURES.}

Neuroticism was assessed with the widely used Eysenck Personality Questionnaire (EPQ-N; Eysenck \& Eysenck, 1975).

Perceived control over emotional reactions was measured with the following item: "If my pregnancy does not turn out well, I will definitely be able to completely control my emotions", rated on a 5 -point scale ( $1=$ absolutely not, $5=$ absolutely).

General dissociative tendencies were measured with an adapted form of the Peritraumatic Dissociative Experiences Questionnaire (PDEQ; see below) in which all items were rewritten to general terms. Participants rated to which extent each item characterized their experiences (e.g., "I find myself acting on "automatic pilot", "I have moments of losing track of what is going on", "What happens to me seems unreal to me, like I am in a dream or watching a movie or play", using a 5-point scale ( $1=$ not at all, $5=$ extremely). Cronbach's alpha was .75 .

Absorption was measured with the 34-item Tellegen Absorption Scale (TAS, Tellegen \& Atkinson, 1974). Items are scored on a true or false format (e.g., "My thoughts often occur as images rather than words"), and 'true' responses are summed. Prior research supports the reliability and validity of the TAS (Roche \& McConkey, 1990).

Negative life events were assessed with a scale of 21 discrete events (e.g., verbal, physical, and sexual abuse, serious accidents, and disaster), and an open-ended question for events not included (Morgan \& Janoff-Bulman, 1994). For each negative event participants had experienced, they reported how many times it occurred and their age at the time. Negative lifetime events and events before adulthood ( $<18$ years) were calculated.

Highest level of education attained was assessed with a 7 -point scale ( $1=$ elementary school, 7 = graduate school).

Dissociation at the time of pregnancy loss was measured with the 10-item PDEQ (Marmar et al., 1997). Each item (e.g., "I had moments of losing track of what was going on") is rated on a 5-point scalle $(1=$ not at all true, $5=$ extremely true $)$ and ratings are summed to generate severity of peritraumatic dissociation. A matching rater-administered version of this scale has established internal consistency and validity (Marmar et al, 1997).

Memory of pregnancy loss was rated for fragmentation (How much does your memory of the event exist of fragmented pieces as opposed to a whole entity?'), sensory impressions (i.e., visual images, sounds, smells, taste, and bodily sensations; e.g." "How much does your memory of the event exist of visual images"), and emotional 
intensity ('How intense are emotions in your memory of the event?'). Items were rated on a 7 -point scale $(1=$ not at all, $7=$ extremely), and sensory-impressions were summed. Thought suppression was measured with 4 items of the White Bear Suppression Inventory (WBSI; Wegner \& Zanakos, 1994) that measure individual differences in the tendency to suppress unwanted thoughts (see Muris, Merckelbach, \& Horselenberg, 1996). These were rated for the suppression of pregnancy-related thoughts, using a 5point scale $(1=$ strongly disagree, $5=$ strongly agree $)$. Cronbach's alpha for these items was 73 .

PTSD symptom severity was assessed with the PTSD Symptom Scale (PSS; Foa, Riggs, Dancu, \& Rothbaum, 1993), which comprises the 17 DSM-IV (APA, 1994) symptoms for PTSD. Items are rated on a 4-point severity scale $(0=$ not at all, $3=$ almost always). The PSS has established reliability and validity (Foa et al., 1993).

Data analysis. SPSS 10.0 .5 estimated the few missing values by regression with residual estimation adjustment. Pregnancy length and life events were skewed to the left and log-transformed for analyses. Pearson correlations were computed between the variables and multiple regression tested the relative contribution of predictors. The PRELIS 2.30 program computed polychoric, polyserial, and product moment correlations, and LISREL 8.0 evaluated the degree to which hypothesized pathways were consistent with the data, with the weighted least squares method. Several model fit criteria were used (Schumacker \& Lomax, 1996). The Goodness-of-Fit Index (GFI) and Non-Normed Fit Index (NNFI) do not explicitly depend on sample size and values above 90 represent a good fit. The Root-Mean-Square Residual Error of Approximation (RMSEA) considers the error of approximation in the population and precision of the fit measure itself. A value up to .08 reflects an acceptable error. $\mathrm{A} \chi^{2}$ difference test compared hypothesized pathways with an alternative and indicates whether the improvement in fit for an additional relationship is sufficient to warrant the cost of one degree of freedom. The significance level was $5 \%$.

\section{RESULTS}

Table I displays means, standard deviations, and intercorrelations of the variables. Most participants ( $70 \%$ ) reported at least one item on the PDEQ (rated $\geq 4$, "intense"). The most common were being on automatic pilot $(27 \%)$, distorted body $(23 \%)$, feeling as though watching a movie or play (23\%), time change (18\%), and losing track of what was going on (17\%). Residual symptoms were endorsed by $6-15 \%$. First, we studied predictors of peritraumatic dissociation. Negative lifetime events and events before adulthood were strongly related $[r(118)=.73, p<.001]$ and we only report negative events before adulthood. Neuroticism, absorption, and prior negative events did not significantly predict peritraumatic dissociation. In contrast, expected emotional control $(\beta=-.17, t=2.03, p=.045)$, general dissociative tendencies $(\beta=.27, t=3.21$, 


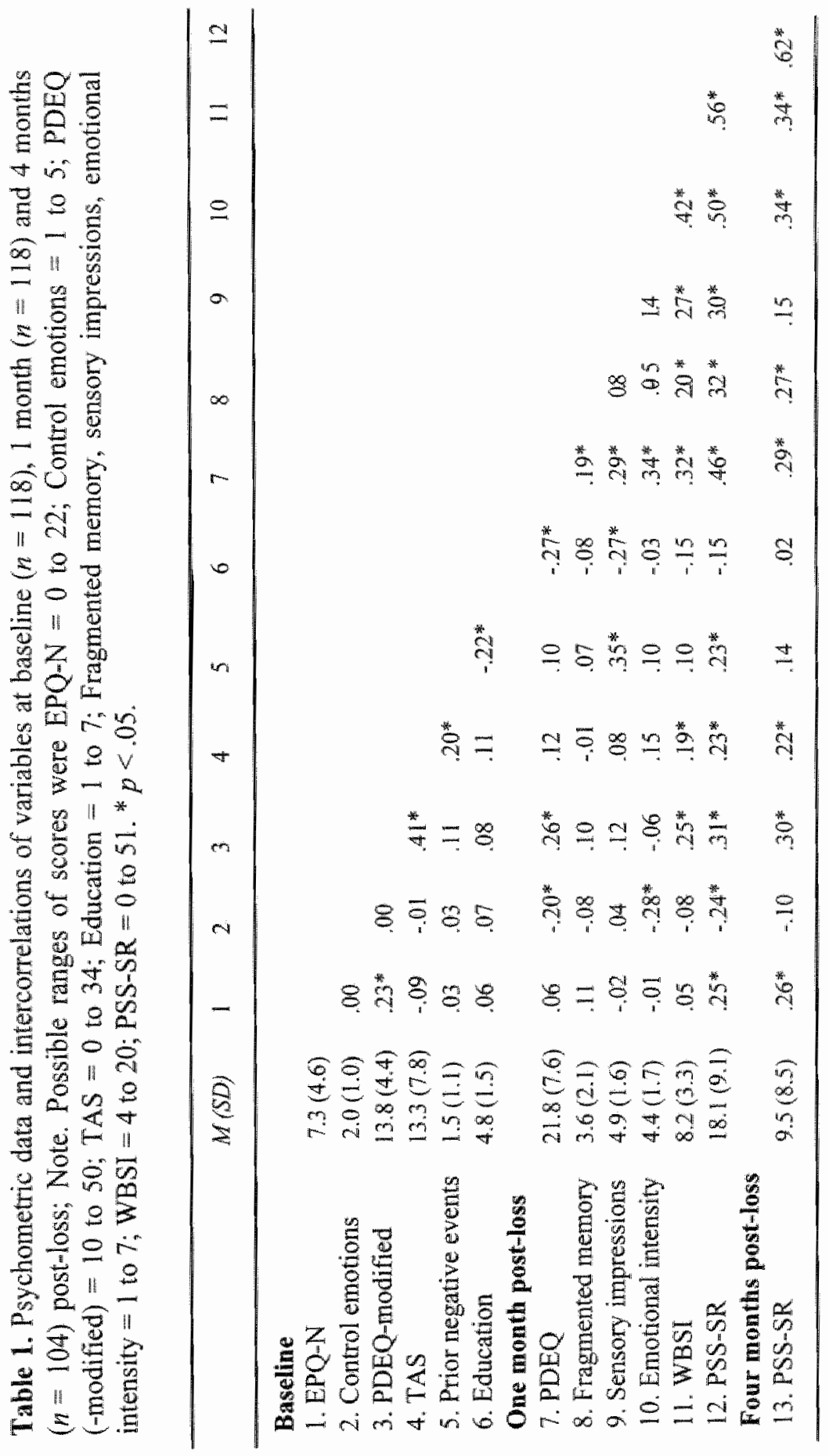


$\beta=.002)$, and education $(\beta=-.28, t=3.23, p=.002)$ independently predicted peritraumatic dissociation, accounting for $18 \%$ of its variance, $F(3,114)=8.17, p<$ .001 . Next, these predictors were studied in relation to acute PTSD symptoms. Neuroticism $(\beta=.22, t=2.54, p=.013)$, emotional control $(\beta=-.24, t=2.96, p=$ $.004)$, general dissociative tendencies $(\beta=.18, t=1.94, p=.054)$, and prior negative events $(\beta=.19, t=2.33, p=.022)$ accounted for $23 \%$ of acute PTSD symptoms, $F(4$, $113)=8.54, p<.001^{*}$. Absorption $(\beta=.14, t=1.55, p=.124)$ was not significant. Then peritraumatic dissociation was included. Peritraumatic dissociation $(\beta=36, t=$ $4.48, p<.001)$, neuroticism $(\beta=.22, t=2.75, p=.007)$, emotional control $(\beta=-.17, t$ $=2.23, p=.028)$, and negative events $(\beta=.16, t=2.13, p=.035)$ accounted for $33 \%$ of acute PTSD symptoms, $F(4,113)=13.67, p<.001$. General dissociative tendencies $(\beta=.10, t=1.08, p=.282)$ and absorption $(\beta=.14, t=1.64, p=.103)$ were not significant. Finally, the pathways linking peritraumatic dissociation to PTSD symptoms at 1 month $[r(118)=.46, p<.001]$ and 4 months $[r(104)=.29, p=.003]$ were investigated (see Figure 1 for $\beta$ weights). To begin with, peritraumatic dissociation was allowed to have an indirect relationship with acute PTSD symptoms through memory fragmentation, sensory impressions, emotional intensity, and thought suppression of pregnancy loss. This model fit well to the data, $\mathrm{GFI}=.97, \mathrm{NNFI}=.97$, RMSEA $=.04$, and explained $46 \%$ of the variance of acute PTSD symptoms. However, sensory impressions and emotional intensity were not significantly linked to PTSD, and emotional intensity appeared related to PTSD through thought suppression. Then, a direct link between peritraumatic dissociation and acute PTSD symptoms was added to the model. This direct link $(\beta=.19, t=.64)$ and the difference between the models with and without this link was not statistically significant $\left[\Delta \chi^{2}(1)=.40, p=.53\right]$. We concluded that the relationship between peritraumatic dissociation and acute PTSD symptoms was mainly mediated by fragmented memory and thought suppression of pregnancy loss. Next, we allowed the relationship between peritraumatic dissociation and chronic PTSD symptoms to be mediated by acute symptoms, GFI $=.97, \mathrm{NNFI}=$ 1.01 , RMSEA $=0.0$, which fit well to the data, and explained $37 \%$ of chronic PTSD symptoms. Then, we also included a direct link between peritraumatic dissociation and chronic symptoms in the model. This direct link $(\beta=.07, p=.82)$ and the difference between the models with and without this link $\left[\Delta \chi^{2}(1)=.77, p=.38\right]$ were not statistically significant. We concluded that the relationship between peritraumatic dissociation and chronic PTSD symptoms was mediated by acute symptoms. Finally, we included a relationship between acute and chronic PTSD symptoms in the model for acute PTSD, which fit well, GFI $=.98, \mathrm{NNFI}=1.09, \mathrm{RMSEA}=.0$.

The mediators of acute PTSD symptoms were each allowed to directly relate to chronic PTSD symptoms, but none of these links (largest $\beta=.2$, largest $t=.67$ ) were significant.

\footnotetext{
"Pregnancy length was significantly rolated to acute PTSD symptoms $\left(y^{\circ}=31, p=.001\right)$, but not to peritranmatic dissociation $\left(p^{s}=.08, p=.37\right)$.
} 


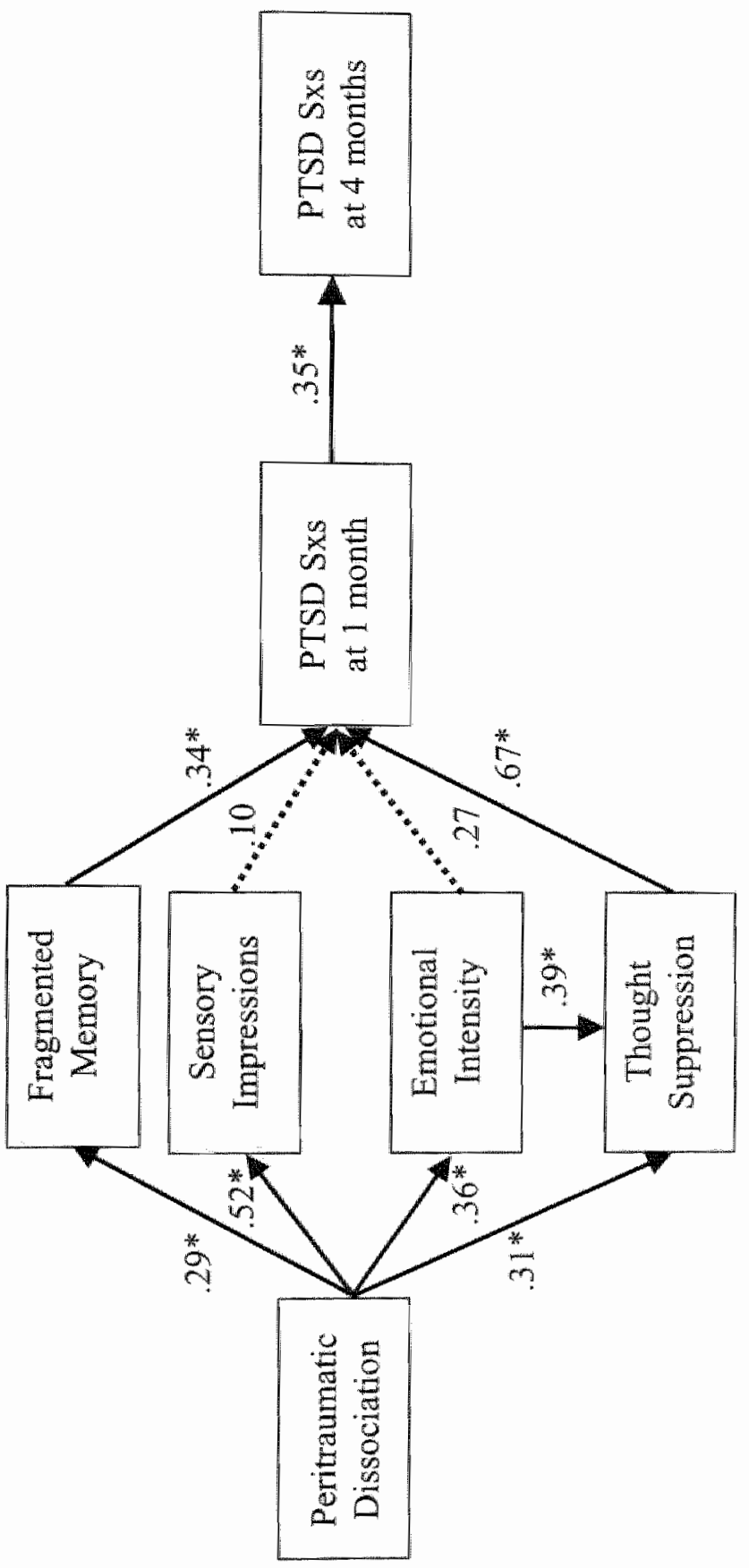




\section{Discussion}

The results of this study can be summarized as follows. Peritraumatic dissociation was commonly reported $(70 \%)$ after pregnancy loss, which was comparable to studies of MVA (79\%; Ursano et al., 1999) and civilian injury (50\%; Shalev et al., 1996). It strongly related to acute and chronic PTSD symptoms, which is consistent with other longitudinall studies. Its determinants were less control over emotions, dissociative tendencies, and lower education. Peritraumatic dissociation related to acute PTSD symptoms even after controlling for premorbid neuroticism, emotional control, general dissociative tendencies, absorption, and negative events. This relation was largely mediated by memory fragmentation and thought suppression, and the relation between peritraumatic dissociation and chronic PTSD symptoms was mediated by acute symptoms.

Previously, dissociation was associated with physiological hyperarousal (Rainey et all, 1987; Southwick et al., 1993). Although the construct of peritraumatic dissociation is poorly defined, taken together, the cluster of symptoms might be conceived of as a marker for the individual's inability to tolerate acute and later arousal and intrusions. The highest level of education negatively predicted peritraumatic dissociation but did not predict PTSD. Shalev et al. (1996) found the opposite for total years of education. It is unclear what is responsible for this. Highest level of education still might be too crude a proxy measure of intelligence, since lower intelligence was previously found to be a strong predictor of PTSD in Vietnam veterans (Macklin et al., 1998). Peritraumatic dissociation was not predicted by neuroticism, which was inconsistent with cross-sectional data of Marmar et al. (1996), and it was not predicted by absorption. In contrast, both factors predicted PTSD symptoms. The nature of the link between neuroticism and PTSD is unclear (Engelhard et al., 2001). To our knowledge, this is the first prospective study linking absorption to PTSD. Although imagery is thought to play an important role in PTSD (Brett \& Ostroff, 1985), absorption did not predict PTSD beyond the contribution of general dissociative tendencies. This was not entirely surprising, given that absorption is a subset of dissociative tendencies. Finally, prior life events did not predict peritraumatic dissociation, which was in line with recent findings of Fullerton et al. (2000), but did directly predict acute PTSD symptoms.

Peritraumatic dissociation related to acute PTSD symptoms through fragmentation and suppression of memories of pregnancy loss. The data are silent about causality, given the cross-sectional nature of these relations. However, theory suggesis that fragmented memories impair the organization of memories and their connection with existing schemas, and excessive avoidance is thought to impede this integration further (Foa \& Riggs. 1993). Prior studies showed that suppression of unwanted thoughts increases the frequency of such thoughts (e.g., Lavy \& van den Hout, 1990). Moreover, after instructed suppression of trauma-related thoughts, individuals with PTSD, relative to 
non-PTSD traumatized controls, reported a drastic increase in trauma-related thoughts (Shipherd \& Beck, 1999). Possibly, the inability to suppress trauma-related thoughts predisposes to persistent symptoms. Self-reported sensory impressions were unrelated to PTSD symptoms. This may be attributed to the nature of memory measurement. That is, we assessed evaluation of memory ("meta"-memory) rather than memory content. Perceptual memories relevant to PTSD might not be deliberately accessed (Brewin, 2001). Future studies with more comprehensive measures might clarify this issue further. Sensory impressions might also have been measured too early. Most individuals report sensory impressions and intrusive recollections immediately after trauma and initial intrusions are not a good predictor of PTSD (Ehlers \& Steil, 1995). The significance of sensory impressions might be different at a later stage. Dissociation at the time of pregnancy loss did not predict chronic PTSD symptoms beyond acute PTSD symptoms. Holen (1993) also found that peritraumatic dissociation was more important in predicting short term rather than long term adjustment. As noted by Marmar et al. (1997), reports of peritraumatic dissociation months or years later might be confounded by current distress, resulting in stronger relationships with PTSD.

The results are in line with cognitive models of PTSD (e.g., Foa \& Riggs, 1993; Ehlers \& Clark, 2000) that underscore the importance of elaboration of fragmented trauma memory into coherence and alteration of avoidance strategies. However, many questions remain. For example, how can be assessed when integration of the trauma memory has occurred? When are avoidance strategies dysfunctional, and what factors determine them? Finally, several limitations of this study need to be taken into account. First, the LISREL analyses were partly cross-sectional and do not elucidate causality. Future longitudinal studies ought to use shorter assessment intervals to clarify causality. Second, there were several imperfections in measures. Although showing good internal consistency, general dissociative tendencies were measured with an unvalidated modified PDEQ and thought suppression was measured with only part of the WBSI. Moreover, memory measures were not validated. Third, pregnancy loss is generally a brief event and it is unclear how the results relate to more severe or prolonged events. Risk factors for PTSD at low exposure levels may lose significance at high exposure, although the dose-response model generally does not withstand scrutiny (Bowman, 1999). Strengths of the study were the prospective assessment of predictors and rather homogeneous traumatic event. However, further study is needed to establish causal pathways between peritraumatic dissociation and acute PTSD symptoms.

\section{ACKNOWLEDGEMENTS}

We thank Richard J. McNally for commenting on a previous draft of this paper. This paper was presented at the World Congress of Behavioral and Cognitive Therapies (July 2001), Vancouver, Canada. 


\section{REFLRENCES}

American Psychiatric Association (1994). Diagnostic and statistical manual of mental disorders (4th ed.). Washington, DC: Author.

Bögels, S.M., Notermans, M., Arntz, A., \& van den Hout, M.A. (2001). IQ and the effectiveness of behoviour versus cognitive therapy for anxiety disorders. Manuscript in preparation.

Bowman, M.L. (1999). Individual differences in posttraumatic distress: Problems with the DSM-IV model. Canadian Joumal of Psychiary, 44, $21-33$.

Breslau, N., Chilcoat, H.D., Kessler, R.C., \& Davis, G.C. (1999). Previous exposure to trauma and PTSD effects of subsequent trauma: Results from the Detroit Area Survey of Trauma. American Journal of Psychiatry, 156, 902-907.

Brett, E.A., \& Ostroff, R. (1985). Imagery and posttraumatic stress disorder: An overview. American Journal of Psychiatry, 142, 417-24.

Brewin, C.R. (2001). A cognitive neuroscience account of posttraumatic stress disorder and its treatment. Behoviour Research and Therapy, 39, 373-393.

Ehlers, A., \& Clark, D.M. (2000). A cognitive model of posttraumatic stress disorder. Behaviour Research and Therapy, 38, 319-345.

Ehlers, A., Mayou, R.A., \& Bryant, B. (1998). Psychological predictors of chronic posttraumatic stress disorder after motor vehicle accidents. Joumal of Abnormal Psychology, 107, 508-5.19.

Ellers, A., \& Steil, R. (1995). Maintenance of intrusive memories in posttraumatic stress disorder: A cognitive approach. Behavioural and Cognitive Psychotherapy, $23,217-249$.

Engelhard, I.M., van den Hout, M.A., \& Arntz, A. (2001). Posttraumatic stress disorder after pregnancy loss. General Hospital Psychiatry, 23, 62-66.

Engellhard, I.M., van den Hout, M.A., \& Kindt, M. (2001). Neuroticisim and the development of postratumatic stress symptoms: A prospective study. Manuscript submitted for publication.

Eysenck, H.J., E Eysenck, S.B.G. (1975). Manual of the Eysenck Personality Questionnaire. San Diego, CA: Educational and Industrial. Testing Service.

Foa, E.B., Molnar, C., \& Cashman, L. (1995). Change in rape narratives during exposure therapy for posttraumatic stress disorder. Joumal of Trawmatic Stress, 8, 675-690.

Foa, E.B., \& Riggs, D.S. (1993). Posttraumatic stress disorder and rape. In J. Oldham, M.B. Riba, \& A. Tasman (Eds.), Annual review of psychiatry, Vol. 12 (pp. 273303). Washington DC: American Psychiatric Association.

Foa, E.B., Riggs, D.S., Dancu, C.V., \& Rothbaum, B.O. (1993). Reliability and validity of a brief instrument for assessing posttraumatic stress disorder. Joumal of Traumatic Stress, $6,459-473$.

Fullerton, C.S., Ursano, R.J., Epstein, R.S., Crowley, B., Vance, K.L., Kao, T.-C., \& Baum, A. (2000). Peritraumatic dissociation following motor vehicle accidents. The Jounnal of Nervous and Mental Disease, 188, 267-272. 
Griffin, M.G., Resick, P.A., \& Mechanic, M.B. (1997). Objective assessment of peritraumatic dissociation: Psychophysiological indicators. American Jourmal of Psychiatry, 154, 1081-1088.

Harvey, A.G., \& Bryant, R.A. (1999). A qualitative investigation of the organization of traumatic memories. British Jowrnal of Clinical Psychology, 38, 401-405.

Holen, A. (1993). The North Sea oil rig disaster. In J.P. Wilson, \& B. Raphael (Eds.), International handbook of traumatic stress syndromes (pp. 471-478). New York: Plenum Press

Horowitz, M.J., Wilner, N., Kaltreider, N., \& Alvarez, W. (1980). Signs and symptoms of posttraumatic stress disorder. Archives of General Psychiatry, 37, 85-92.

Jones, J.C., \& Barlow, D.H. (1990). The etiology of posttraumatic stress disorder. Clinical Psychology Review, 10, 299-328.

Kihlstrom, J.F., Glisky, M.L., \& Angiulo, M.J. (1994). Dissociative tendencies and dissociative disorders. Journal of Abnormal Psychology, 103, 117-124.

Koopman, C., Classen, C., \& Spiegel, D. (1994). Predictors of posttraumatic stress symptoms among survivors of the Oakland/Berkeley, Calif., firestorm. American Journal of Psychiatry, 151,888-894.

Lavy, E.H., \& van den Hout, M.A. (1990). Thought suppression induces intrusions. Behavioural Psychotherapy, 18, 251-258.

Macklin, M.L., Metzger, L.J., Litz, B.T., McNally, R.J., Lasko, N.B., Orr, S.P., \& Pitman, R.K. (1998). Lower precombat intelligence is a risk factor for posttraumatic stress disorder. Joumal of Consulting and Clinical Psychology, 66, 323-326.

Marmar, C.R., Weiss, D.S., Metzler, T.J., \& Delucchi, K. (1996). Characteristics of emergency services personnel related to peritraumatic dissociation during critical incident exposure. American Journal of Psychiatry, 153, 94-102.

Marmar, C.R., Weiss, D.S., \& Metzler, T.J. (1997). The Peritranmatic Dissociative Experiences Questionnaire. In J.P. Wilson, \& T.M. Keane (Eds.), Assessing psychological trauma and PTSD: A practitioner's handbook (pp. 412-428). New York: Guilford Press.

McFarlane, A.C., \& Yehuda, R. (1996). Resilience, vulnerability, and the course of posttraumatic reactions. In B.A. van der Kolk, A.C. McFarlane, \& L. Weisaeth (Eds.), Traumatic stress: The effects of overwhelming experience on mind, body, and sociery (pp. 155-181). New York: Guilford Press.

McFarlane, A.C. (1989). The aetiology of post-traumatic morbidity: Predisposing, precipitating and perpetuating factors. British Joumal of Psychiatry, 154, 221-228.

Morgan, H.J., \& Janoff-Bulman, R. (1994). Positive and negative self-complexity: Patterns of adjustment following traumatic versus non-traumatic life experiences. Journal of Social and Clinical Psychology, 13, 63-85.

Muris, P., Merckelbach, H., \& Horselenberg, R. (1996). Individual differences in thought suppression. The white bear suppression inventory: Factor structure, reliability, validity, and correlates. Behaviour Research and Therapy, 34, 501-513. 
Rainey, Jr., J.M, Aleem, A., Ortiz, A., Yeragani, V., Pohlm R., \& Berchou, R. (1987). A laboratory procedure for the induction of flashbacks. American Journal of Psychiatry, 144, 1317-1319.

Roche, S.M., \& McCorkey, K.M. (1990). Absorption: Nature, assessment, and correlates. Joumal of Personality and Social Psychology, 59, 91-101.

Schumacker, R.E., \& Lomax, R.G. (1996). A begiwner's guide to structural equation modeling. Mahwah, NJ: Lawrence Erlbaum Associates.

Shalev, A.Y., Peri, T., Canetti, L., \& Schreiber, S. (1996). Predictors of PTSD in injured trauma survivors: A prospective study. American Journal of Psychiatry, 153,219-225.

Shipherd, J.C.. \& Beck, J.G. (1999). The effects of suppressing trauma-related thoughts on women with rape-related posttraumatic stress disorder. Behoviour Research and Therapy, 37, 99-112.

Southwick, S.M., Krystal, J.H., Morgan, A., Johnson, D., Nagy, L.M., Nicolaou, A., Heninger, G.R., \& Chamey, D.S. (1993). Abnormal noradrenergic function in posttraumatic stress disorder. Archives of General Psychiatry, 50, 266-274.

Spiegel, D., \& Cardefia, E. (1991). Disintegrated experience: The dissociative disorders revisited. Joumal of Abnormal Psychology, 100, 366-378.

Spiegel, D., Hunt, T., \& Dondershine, H.E. (1988). Dissociation and hypnotizability in posttraumatic stress disorder. American Joumal of Psychiatry, 145, 301--305.

Steil, R., \& Ehlers, A. (2000). Dysfunctional meaning of posttraumatic intrusions in chronic PTSD. Behaviour Research and Therapy, 38, 537-558.

Stutman, R.K., \& Bliss, E.L. (1985). Posttraumatic stress disorder, hypnotizability, and imagery. American Journal of Psychiatry, 142,741-743.

Tellegen, A., \& Atkinson, G. (1974). Openness to absorbing and self-altering experiences ("absorption"), a trait related to hypnotic susceptibility. Journal of Abnormal Psychology, 83, 268-277.

Ursano, R.J., Fullerton, C.S., Epstein, R.S., Crowley, B., Vance, K., Kao, T.C., Baum, A. (1999). Peritraumatic dissociation and posttraumatic stress disorder following motor vehicle accidents. American Joumal of Psychiatry, 156, 1808-1810.

Van der Kolk, B.A., \& Fisler, R. (1995). Dissociation and the fragmentary nature of traumatic memories: Overview and exploratory study. Journal of Traumatic Stress, $8,505-525$.

Van der Kolk, B., van der Hart, O., \& Marmar, C.R. (1996). Dissociation and information processing in posttraumatic stress disorder. In B.A. van der Kolk, A.C. McFarlane, \& L. Weisaeth (Eds.), Troumatic stress: The effects of ovenwelming experience on mind, body, and society (pp. 303-327). New York: Guilford Press.

Wegner, D.M., \& Zanakos, S. (1994). Chronic thought suppression. Journal of Personality, 62, 615-640. 


\title{
CHAPTER 5
}

\section{The Sense of Coherence in Early Pregnancy and Crisis Support and Posttraumatic Stress after Pregnancy Loss}

\begin{abstract}
Antonovsky (1987) defined the sense of coherence (SOC) as the ability to perceive a stressor as comprehensible, manageable, and meaningful. In this prospective study of pregnant women, the relationships were tested between the SOC in early pregnancy and crisis support and symptoms of psychological trauma after pregnancy loss. One thousand three hundred and seventy-two women completed questionnaires in early pregnancy, including measures for the SOC and depressive symptoms, and were followed for every 2 months thereafter until 1 month after the due-date of birth. Of them, 126 women had a pregnancy loss, and 118 completed measures for crisis support and symptoms of posttraumatic stress disorder (PTSD) and depression about one month later. The results showed that a stronger SOC in early pregnancy significantly, but modestly, predicted less PTSD symptoms after pregnancy loss. The SOC also predicted less depressive symptoms after pregnancy loss, over and above depressive symptoms in early pregnancy. Crisis support partly mediated the relation between the SOC and PTSD symptoms. The findings suggest that a stronger SOC renders women somewhat resilient to psychological trauma after pregnancy loss, which appears partly due to the mobilization of crisis support.
\end{abstract}

*Engelhard, I.M., wan den Host, M.A., \& Vlaeyen, J.W.S. (Manuseript under review). 


\section{INTRODUCTION}

Pregnancy loss occurs in at least 15 percent of known pregnancies (Alberman, 1988), and it is increasingly recognized that it may have strong effects on emotional well being (e.g., Frost \& Condon, 1996; Lee \& Slade, 1996; Speckhard, 1997). Pregnancy loss may trigger symptoms of depression (Frost \& Condon, 1996), and, recently, we found that it may result in symptoms of posttraumatic stress disorder [(PTSD); Engelhard, van den Hout, \& Arntz, 2001]. PTSD involves reexperiencing the traumatic event (e.g., intrusive recollections, nightmares, being upset when reminded), avoidance of its reminders/ numbing (e.g, behavioral avoidance, cognitive avoidance, feeling cutoff from others), and hyperarousal (e.g., irritability, sleeping problems; APA, 1994). Consistent with the general PTSD literature (e.g., Bowman, 1999), we found considerable individual differences in PTSD symptom severity, and only part of the variance was explained by the gestational age of the loss.

What factors render women resilient to PTSD symptoms after pregnancy loss? Ehlers and Clark (2000) proposed that individuals recover from a traumatic event when (1) memory for the event is integrated into the context of other experiences, (2) avoidance strategies are dropped, and (3) negative appraisals of the event and its aftermath are modified. These propositions are supported by cross-sectional and longitudinal studies after several stressful events (see Ehlers \& Clark, 2000). Interestingly, these factors bear a close resemblance to the "sense of coherence" (SOC) concept introduced by Antonovsky (1987). Antonovsky (1987, p. 19) defined the SOC as the ability to perceive a stressor as (1) comprehensible (stimuli are viewed as structured, predictable, and explicable), (2) manageable (resources are available to meet associated demands), and (3) meaningful (demands are challenges, worthy of investment and engagement). Individuals with this natural inclination might be at an advantage in coming to terms with pregnancy loss. Several retrospective studies report an association between a high SOC and less postraumatic stress after various traumatic events (e.g., Eriksson \& Lundin, 1996; Frommberger et al., 1999; Kaiser, Sattler, Bellack, \& Dersin, 1996). For example. Frommberger and colleagues (1999) found that the SOC and PTSD symptoms were strongly correlated 6 months after a traffic accident, $r(51)=-.50, p<$ .001 . However, in these previous studies, the SOC was assessed after the traumatic event took place, which does not establish causal order: the SOC may affect PTSD symptoms, it may be the other way around, or both. Although the SOC is fairly stable over time (Feldt, Leskinen, Kinnunen, \& Mauno, 2000), it may be influenced by stressful events, particularly when efforts at mastery fail (Geyer, 1997).

The SOC may not specifically protect against PTSD symptoms: it has also been negatively linked with other psychological symptoms after life events (e.g., Anson, Carmel, Levenson, Bonneh, \& Maoz, 1993). Depressive symptoms may be of particular importance, because these are common after pregnancy loss, often co-occur with PTSD (APA, 1994), and are related to the SOC in the normal population (Geyer, 
1997). However, depressive symptoms are also common during pregnancy (Komstein, 2001), and it is unclear whether a weaker SOC predicts an increase in depressive symptoms from before to after pregnancy loss.

How might the SOC protect against PTSD symptoms? Antonovsky (1987) suggested that higher levels of the SOC enable an individual to mobilize resources, such as social support, to cope with a stressor. More crisis support predicts less postraumatic reactions after pregnancy loss (Lee \& Slade, 1996) and other stressful events (e.g., Flannery, 1990; Joseph, 1999). Important aspects of support appear to be confiding in others and active emotional and practical support (e.g., Joseph, 1999). For example, discussing the traumatic event with others (McFarlane, 1988) and using social interactions (e.g., "I ask my friends if they have similar thoughts") to manage upsetting memories (Bryant, Moulds, \& Guthrie, 2001) are related to less symptoms. It is unclear whether the SOC predicts the mobilization of crisis support after pregnancy loss. In fact, support is often deficient after pregnancy loss, particularly after a miscarriage. Friends and family may not even have known about the pregnancy (Day \& Hooks, 1987), the woman's partner may deal with the loss differently (DeFrain, Millspaugh, \& Xie, 1996), and people, including doctors, often underestimate its psychological impact (Cuisinier, Kuijpers, Hoogduin, de Graauw, \& Janssen, 1993).

It is difficult to examine resilience for PTSD, because experimental studies cannot replicate real-life threat and prospective studies are nearly unfeasible due to the randomness of traumatic events. In our previously reported study of PTSD after pregnancy loss (Engelhard et al., 2001), participants enrolled in the study in early pregnancy, which enabled us to measure the SOC and depressive symptoms before pregnancy loss. The present paper is part of that study and focuses on (1.) the relation between the SOC in early pregnancy and PTSD symptoms after pregnancy loss, (2) the relation between the $\mathrm{SOC}$ and depressive symptoms after pregnancy loss after: statistically controlling for pre-loss depressive symptoms, and (3) crisis support as a mediator between the SOC and PTSD symptoms. To our knowledge, this is the first prospective study of the SOC and PTSD symptoms.

\section{METHOD}

Participants. As reported in detail elsewhere (Engelhard et al., 2001; Engelhard, van den Hout, Kindt, Antz, \& Schouten, 2002), 1372 pregnant women responded to ads in family magazines recruiting women in early pregnancy ( $<3$ months) for a study of pregnancy experiences. Of the original sample, 33 women did not complete the baseline questionnaires and dropped out of the study. Baseline questionnaires included the SOC Scale (SOC-13; Antonovsky, 1987, 1993) and Beck Depression Inventory (BDI; Beck, Rush, Shaw, \& Emery, 1979). For every 2 months thereafter until 1 month after the due date of birth, they completed short pregnancy-related surveys that also asked them to inform the researchers if they had a pregnancy loss. One hundred and twenty six women (9\%) had a pregnancy loss, and 118 of them completed the PTSD 
Symptom Scale (PSS-SR; Foa, Riggs, Dancu, \& Rothbaum, 1993), BDI, and Crisis Support Scale (CSS; Joseph, Andrews, Williams, \& Yule, 1992) about 1 month later (response rate $=94 \%$ ). However, one of them did not complete the SOC, therefore the results are based on the remaining 117 women. All questionnaires were sent by mail with a postage-paid return envelope. Respondents were on average 31 years old (SD $=$ 4), nearly all were married or cohabiting, about $40 \%$ was college-educated, and $30 \%$ was childless. The mean gestational age was 8 weeks $(S D=2.0)$ at the time of enrollment in the study. It was 12 weeks $(S D=6$; range 5-40) at the time of the loss, and $95 \%$ was before the $20^{\text {th }}$ week.

Measures. The SOC-13 contains 13 items (e.g., Do you often have very mixed-up feelings and ideas? How often do you have the feeling that there's little meaning in the things you do in your daily life?), that are rated on a 7-point scale. Ratings are summed (higher scores reflect higher coherence). The PSS-SR includes the 17 DSM-IV (APA, 1994) symptoms for PTSD that are scored on a 4-point severity scale $(0=$ not at all, $3=$ almost always). Five items pertain to the "re-experiencing" symptoms, 7 tap "avoidance", and 5 measure 'hyperarousal'. These subscales can be combined to yield overall PTSD symptom severity. The widely used BDI comprises 21 symptoms of depression that are rated on a 4-point severity scale. In the present study we excluded one item related to weight loss. The CSS is a 6-item self-report scale of received crisis support, which refers to (a) the availability of others, (b) confiding in others, (c) emotional support, (d) practical support, (e) being let down (reverse scored), and ( $\mathrm{f}$ ) contact with others who had a similar experience. Participants rated the first 5 items separately for their partner, family and friends, and doctor. Items were rated on a 7 point scale ranging from never (1) to always (7). Crisis support was operationalized as the average ratings of these 3 groups of people. Contact with peers (item f) was calculated separately.

\section{RESULTS}

The means and intercorrelations of psychometric measures and gestational age at the time of pregnancy loss are displayed in table 1. Gestational age was skewed to the left and log-transformed for analyses. Note that the number of participants varied slightly due to missing values on some scales. The internal consistency of the SOC-13 (Cronbach's $\alpha=.76$ ), CSS (Cronbach's $\alpha=.76, .73$, and .76 for friends/family, partner, and doctor, respectively), and PSS-SR (Cronbach's $\alpha=.86$ ) were satisfactory. Comparisons with available norms indicated that the sample was in the normal range of the SOC (Antonovsky, 1993) and pre-loss depressive symptoms (Kendall, Hollon, Beck, Hammen, \& Ingram, 1987). The significance level was 5\%. 
Table 1. Psychometric data and intercorrelations of the SOC- 13 and BDL in early pregnancy, gestational age of pregnancy loss (wks), the PSS-SR, BDI, and CSS one month after pregnancy loss.

\begin{tabular}{llllllll}
\hline Characteristic & $N$ & $M(S D)$ & 1 & 2 & 3 & 4 & 5 \\
\hline EarlyPregnancy & & & & & & & \\
1. SOC-1.3 & 117 & $65.1(9.6)$ & & & & \\
2. BDI & 117 & $7.9(5.4)$ & $-.39^{* *}$ & & & & \\
After Pregnancy Loss & & & & & & & \\
3. Gestational age & 117 & $12.1(6.4)$ & -.07 & .03 & & & \\
4. PSS-SR & 117 & $18.3(9.0)$ & $-.25^{* *}$ & $.34 * *$ & $.31^{* *}$ & & \\
5. BDI & 117 & $6.6(6.3)$ & $-.37^{* *}$ & $.45^{* *}$ & $.40^{* *}$ & $61^{* *}$ & \\
6. CSS & 117 & $27.2(4.0)$ & $.21^{*}$ & $-.19^{*}$ & $.19^{*}$ & $-.26^{* *}$ & -.14 \\
$\quad$ Partner & 115 & $29.8(4.8)$ & .10 & $-.21^{*}$ & .13 & -.07 & -.07 \\
Family/friends & 116 & $27.0(5.2)$ & .17 & -.15 & .07 & $-.36^{* *}$ & $-.22^{*}$ \\
Physician & 110 & $24.6(7.6)$ & .17 & -.07 & $.20 *$ & -.13 & -.01 \\
$\quad$ Contact with peers & 116 & $4.4(2.3)$ & .00 & .05 & -.02 & -.13 & -.13
\end{tabular}

Possible ranges are: SOC-13 (Sense of Coherence Scale) $=13$ to 91 , BDI (Beck Depression Inventory) $=0$ 10 60 (exchuding weight-loss item), PSS-SR (Postramatic Symptom Scale) $=0$ to $\$ 1$. and CSS (Crisis Support Scale) $=5$ to 35 , Contact with peers $=1$ to 7 .

** $p<.01 ; * p<.05$ (two-tailed).

As shown in table 1 , the $\mathrm{SOC}$ in early pregnancy was negatively related to PTSD symptoms one month after pregnancy loss. More specifically, the SOC was significantly related to PTSD avoidance, $r(117)=-.24, p=.008$, and arousal symptoms, $r$ $(117)=-.27, p=.004$, but not to reexperiencing symptoms, $z^{m}(117)=-.10, p=.27$. The SOC was also negatively linked to depressive symptoms both before and after pregnancy loss. After statistically controlling for depressive symptoms before pregnancy loss, the relationship between the $\mathrm{SOC}$ and depressive symptoms after pregnancy loss was still significant, $p(114)=-.24, p=.009$, indicating that a weaker $S O C$ predicts a rise in depressive symptoms after pregnancy loss.

Finally, the $\mathrm{SOC}$ was also positively related to crisis support. A closer examination of the aspects of crisis support showed that the SOC was significantly related to confiding in others $(r=.23, p=.018)$ and emotional support $(r=.23, p=.016)$. Crisis support, particularly confiding in others $(r=-.24, p=.012)$ and being let down $(r=.29, p=$ .002), was also significantly associated with PTSD symptoms. To test whether crisis support mediated the relation between the SOC and PTSD symptoms, three regression equations were tested (see Baron \& Kenny, 1986): (1) crisis support was regressed on the SOC, (2) PTSD symptoms were regressed on the SOC, and (3) PTSD symptoms were regressed on both the $\mathrm{SOC}$ and crisis support. Mediation is established when the 
effect of the SOC on PTSD symptoms is less in equation (3) than in (2). Gestational age of the loss was also included in the equations. First, the $\operatorname{SOC}(\beta=.22, t=2.46, p=$ $.015)$ and gestational age $(\beta=.20, t=2.25, p=.027)$ together accounted for $8 \%$ of the variance of crisis support. Second, the $\operatorname{SOC}(\beta=-.23, t=2.59, p=.011)$ and gestational age $(\beta=.29, t=3.33, p=.001)$ accounted for $14 \%$ of the variance of PTSD symptoms. Third, crisis support $(\beta=-.30, t=3.42, p<.001)$ and gestational age $(\beta=$ $.35, t=4.11, p<.001)$ accounted for $20 \%$ of the variance of PTSD symptoms, $F(2$, $114)=14.21, p<.001$. The $\operatorname{SOC}(\beta=-.16, t=1.87, p=.06)$ was no longer significant, which appears to support the mediation hypothesis.

\section{DISCUSSION}

In this prospective study, a stronger SOC in early pregnancy predicted lesS PTSD symptoms after pregnancy loss, which is consistent with theories of SOC (Antonovsky, 1987) and psychotrauma (Ehlers \& Clark, 2000). However, the present correlations were modest and weaker relative to earlier retrospective studies. This may be due to different study designs: the SOC and PTSD assessed at the same time may result in spuriously inflated correlations. The SOC was predictive of PTSD avoidance and arousal symptoms. Avoidance symptoms are less common than reexperiencing and arousal symptoms after a traumatic event and appear critical in PTSD diagnosis (McMillen, North, \& Smith, 2000). Avoidance symptoms increase with time for individuals who Jater develop PTSD (Shalev, Peri, Canetti, \& Schreiber, 1996), and early avoidance strategies are related to later PTSD (Bryant \& Harvey, 1995). Theoretically, avoidance prevents assimilation (changing prior beliefs to take event into account) and accommodation (incorporating the event into prior beliefs). A stronger $\mathrm{SOC}$ was also related to less depressive symptoms after pregnancy loss, even after controlling for depressive symptoms in early pregnancy, which suggests that the $\mathrm{SOC}$ is a general rather than specific resilience factor for symptomatology after pregnancy loss.

Antonovsky (1987) proposed that individuals with a strong SOC select and mobilize appropriate resources to deal with stressful events. In line with this suggestion, we observed that crisis support statistically mediated between SOC and PTSD symptoms. However, this 'mediating' role should be interpreted with some caution. Crisis support and PTSD symptoms were assessed simultaneously and it cannot be ruled out that PTSD severity influenced the degree of crisis support. After all, social withdrawal is considered a PTSD symptom. Additionally, the notion of the SOC suggests that individuals with a higher SOC actively try to adjust their representation of the world to changing circumstances and strive for coherence. This successful cognitive integration may stimulate more and better social contacts, which may have been tapped by the measure of crisis support. Of course this is not to say that social support in times of crisis is not helpful. Although some aspects of social support may be harmful (e.g., emotional over-involvement; Flannery, 1990), there is growing evidence for the 
protective role of social support after trauma (e.g., see Joseph, 1999). Confiding may reduce negative affect and enhance the understanding and assimilation of the event (Pennebaker, 1989) and active emotional support may provide information that enables an individual to reassess the event (Ehlers \& Clark, 2000).

The data also showed that support from medical workers was (modestly) related to gestational age. Particularly after a miscarriage, women often reported that they received little empathy and information. For example, one woman said: "I often wonder why this happened to me. Could I have prevented this?" (loss at 13 weeks). After a stillbirth, a woman said: "So many questions go through my mind. Will I ever have a baby? What will happen the next time? I've lost confidence in myself" ( 32 weeks). Another woman said: "The lack of information upsets me. I couldn'r comprehend what the gynecologist said. Too much was going through my mind 26 weeks)". Coming to terms with pregnancy loss may be facilitated if clinicians structure the experience, give (written) information about medical and psychological aspects, and offer follow-up appointments.

In an earlier report of the present study, we (Engelhard et al., 2002) focused on acute dissociative reactions to pregnancy loss and found that these predicted PTSD symptoms. It might be speculated that the link between the SOC and PTSD symptoms was mediated by acute dissociative reactions. This was, however, not the case: the correlation between the SOC and peritraumatic dissociative symptoms was $r=-.13$, NS.

Limitations of this study were the reliance on self-report measures and the simultaneous assessment of crisis support and PTSD symptoms. Furthermore, to increase our understanding of the impact of pregnancy loss, the cultural context ought to be taken into account (de Vries, 1996). This involves the meaning assigned to pregnancy loss (by the woman, society, and the medical system), religion, and culturally accepted rituals (e.g, condolence cards or a funeral) and customs (e.g., emotional expression). Strengths were the prospective design, large sample, and relatively homogeneous traumatic event, which is important because the event itself is involved in the etiology of PTSD. In sum then, there was a significant association between the SOC in early pregnancy and severity of PTSD symptoms after pregnancy loss. This association disappeared after controlling for crisis support, but it remains to be seen that SOC affects PTSD severity via crisis support and that crisis support is not an epiphenomenon of the SOC.

\section{REFERENCES}

Alberman, E. (1988). The epidemiology of repeated abortion. In: R.W. Beard, \& F. Sharp (Eds.), Pregnancy loss: Mechanisms and treatment (pp. 9-17). London: Springer-Verslag.

American Psychiatric Association (1994). Diagnostic and statistical manual of mental disorders $\left(4^{\text {th }} \mathrm{ed}\right.$ ). Washington, DC: Author. 
Anson, O., Carmel, S., Levenson, A., Bonneh, D.Y., \& Maoz, B. (1993). Coping with recent life events: The interplay of personal and collective resources. Behavioral Medecine, 18, 159-166.

Antonovsky, A. (1987). Unraveling the mystery of health. How people manage stress and stay well. San Francisco: Jossey-Bass.

Antonovsky, A. (1993). The structure and properties of the sense of coherence scalle. Social Science and Medicine, 36, 725-733.

Baron, R.M., \& Kenny, D.A. (1986). The moderator-mediator variable distinction in social psychological research: conceptual, strategic, and statistical considerations. Jourmal of Personality and Social Psychology, 51, 1173-1182.

Beck, A.T., Rush, A.J., Shaw, B.F., \& Emery, G. (1979). Cognitive therapy of depression (pp. 389-399). New York: Wiley \& Sons.

Bowman, M.L. (1999). Individual differences in posttraumatic distress: Problems with the DSM-IV model. Canadian Journal of Psychiatry, 44, 21-33.

Bryant, R.A. \& Harvey, A.G. (1995). Avoidant coping style and post-traumatic stress following motor vehicle accidents. Behaviour Research and Therapy, 33, 631-635.

Bryant, R.A., Moulds, M., \& Guthrie, R.M. (2001). Cognitive strategies and the resolution of acute stress disorder. Joumal of Traumatic Stress, 14, 213-219.

Cuisinier, M.C.J., Kuijpers, J.C., Hoogduin, C.A.L., de Graauw, C.P.H.M., \& Janssen, H.J.E.M. (1993). Miscarriage and stillbirth: Time since the loss, grief intensity and satisfaction with care. European Journal of Obsetrics and Gynecology, 52, 163-168.

Day, R.D., \& Hooks, D. (1987). Miscarriage: A special type of family crisis. Family Relations, 36, 305-310.

DeFrain, J., Millspaugh, E., \& Xie, X. (1996). The psychosocial effects of miscarriage: Implications for health professionals. Families, Systems and Healih, 14, 331-347.

DeVries, M.W. (1996). Trauma in cultural perspective. In B.A. van der Kolk, A.C. McFarlane, \& L. Weisaeth (Eds.), Traumatic stress: The effects of overwhelming experience on mind, body, and society (pp. 398-413). New York: Guilford Press.

Ehlers, A. \& Clark, D.M. (2000). A cognitive model of posttraumatic stress disorder. Behaviour Research and Therapy, 38,319-345.

Engelhard. I.M., van den Hout, M.A., \& Arntz, A. (2001). Posttraumatic stress disorder after pregnancy loss. General Hospiral Psychiatry, 23, 62-66.

Engelhard, I.M., van den Hout, M.A., Kindt, M., Arntz, A., \& Schouten, E. (2002). Peritraumatic dissociation and posttraumatic stress after pregnancy loss: A prospective study. Behaviour Research and Therapy, in press.

Eriksson, N. \& Lundin, T. (1996). Early traumatic stress reactions among Swedish survivors of the m/s Estonia disaster. British Jourmal of Psychiatry. 169, 713-716.

Feldt, T., Leskinen, E., Kinnunen, U., \& Mauno, S. (2000). Longitudinal factor analysis models in the assessment of the stability of sense of coherence. Personality and Individual Differences, 28, 239-257.

Flannery, R.B. (1990). Social support and psychological trauma: A methodological review. Joumal of Traumatic Stress, 3, 593-611. 
Foa, E.B., Riggs, D.S., Dancu, C.V., \& Rothbaum, B.O. (1993). Reliability and validity of a brief instrument for assessing post-traumatic stress disorder. Journal of Traumatic Stress, 6, 459-473.

Frommberger, U., Stieglitz, R-D., Straub, S., Nyberg, E., Schlickewei, W., Kuner, E., \& Berger, M. (1999). The concept of "sense of coherence" and the development of posttraumatic stress disorder in traffic accident victims. Joumal of Psychosomatic Research, 46, 343-348.

Frost, M., \& Condon, J.T. (1996). The psychological sequelae of miscarriage: A critical review of the literature. Australian and New Zealand Journal of Psychiarry. $30,54-62$.

Geyer, S. (1997). Some conceptual considerations on the sense of coherence. Social Science and Medicine, 44, 1771-1779.

Joseph, S. (1999). Social support and mental health following trauma. In W. Yule (Ed.), Post-traumatic stress disorders (pp. 71-91). New York: Wiley \& Sons.

Joseph, S., Andrews, B., Williams, R., \& Yule, W. (1992). Crisis support and psychiatric symptomatology in adult survivors of the Jupiter cruise ship disaster. British Journal of Clinical Psychology, 31, 63-73.

Kaiser, C.F., Sattler, D.N., Bellack, D.R., \& Dersin, J. (1996). A conservation of resources approach to a natural disaster: Sense of coherence and psychological distress. Journal of Social Behovior and Personality, 11, 459-476.

Kendall, P.C., Hollon, S.D., Beck, A.T., Hammen, C.L., Ingram, R.E. (1987). Issues and recommendations regarding use of the Beck Depression Inventory. Cognifive Therapy and Research, 11, 289-299.

Kornstein, S.G. (2001). The evaluation and management of depression in women across the life span. Journal of Clinical Psychiatry, 62, 11-17.

Lee, C., \& Slade, P. (1996). Miscarriage as a traumatic event: A review of the literature and new implications for intervention. Journal of Psychosomatic Research, 3, 235244.

McFarlane, A.C. (1988). The longitudinal course of posttraumatic morbidity: The range of outcomes and their predictors. Journal of Nervous and Mental Disease, $176,30-39$.

McMillen, J.C., North, C.S., \& Smith, E.M. (2000). What parts of PTSD are normal: Intrusion, avoidance, or arousal? Data from the Northridge, California, earthquake. Jounal of Troumatic Stress, 13, 57-75.

Pennebaker, J.W. (1989). Confession, inhibition, and disease. Advances in Experimental Social Psychology, 22, $211-244$.

Shalev, A.Y., Peri, T., Canetti, L., \& Schreiber, S. (1996). Predictors of PTSD in injured trauma survivors: A prospective study. American Journal of Psychiatry, 153, 219-225.

Speckhard, A. (1997). Traumatic death in pregnancy: The significance of meaning and attachment. In: C.R. Figley, B.E. Bride, \& N. Mazza (Eds.), Death and trauma: The traumatology of grieving (pp. 67-100). Washington, DC: Taylor \& Francis. 



\title{
CHAPTER 6
}

\section{"Emotion and Intrusion-based Reasoning" in Vietnam Veterans with and without Chronic Posttraumatic Stress Disorder}

\begin{abstract}
Patients suffering from anxiety disorders other than postraumatic stress disorder (PTSD) interpret anxiety responses themselves as evidence that threat is impending if anxiety, then threat" (Arntz, Rauner, \& van den Hout, 1995). This "enotion-based reasoning (ER) may render a disorder self-perpetuating. Analogous to $E R$, danger might also be inferred from the presence of intrusions: intrusion-based reasoning? (IR). The aims of this study were to test whether ER and IR are involved in chronic PTSD, Vietnam combat veterats with or without PTSD or other anxiety disorders rated perceived danger of brief scenarios in which information about objective danger (danger vs. safety) and response (anxiety/intrusions vs, non-distressing emotion) was systematically varied. Two series were administered. ER-scenarios were non-specific for PTSD and IR-scenarios were specific for PTSD. Relative to control participants, PTSD patients engaged in both ER and IR. whereas veterans without PTSD inferred the danger of scenarios from objective stimulus information, veterans with PTSD also inferred danger from the presence of anxiety or intrusions. Further analyses showed that these effects were largely mediated by perceived uncontrollability.
\end{abstract}

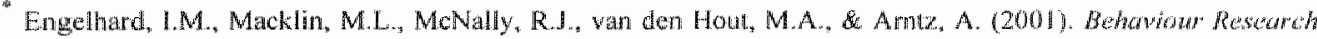
cond Therapy, 39, 1339-1348. This article was awarded the "Artikelprijs EPp", acadenic year 1909-2000 by the Dutch school for research and postgraduate education Experimental Psychopabology. A poster presentation of this study wass awarded the $2^{\text {nd }}$ prize of the Student Poster A wards at the annual meeting of the Internationat Society for Tramatic Stress Studies assembled in San Antonio, November. 2000. 


\section{INTRODUCTION}

Whereas the prevalence of posttraumatic stress disorder (PTSD) varies by type of traumatic event, the course of the disorder is similar for different trauma populations. $A$ minority of victims develops PTSD within three months following the event (APA, 1994) and for about half of them, the disorder persists for at least a year (Breslau \& Davis, 1992). In fact, PTSD may persist for many years (Kessler, Sonnega, Bromet, Hughes, \& Nelson, 1995). For example, three and a half years following an Australian bushfire, half of the firefighters who reported PTSD after 8 months were still symptomatic (McFarlane, 1988). Even 14 years after the Buffalo Creek dam collapse, $25 \%$ of survivors still had PTSD related to the disaster (Green, Lindy, Grace, \& Leonard, 1992). About 17 years post-crime, 17\% of rape victims had PTSD (Kilpatrick, Saunders, Veronen, Best, \& Von, 1987). Similarly, 19 years after combat exposure, $15 \%$ of male Vietnam War veterans were suffering from PTSD (Kulka, Schlenger, Fairbank, Hough, Jordan, Marmar, \& Weiss, 1990). What psychological mechanisms are responsible for this persistence of posttraumatic symptoms and of a sense of threat?

Patients suffering from PTSD and other anxiety disorders tend to prioritize the processing of threatening information. That is, relative to non-PTSD trauma victims, or non-trauma controls, PTSD patients tend to attend selectively to trauma-related information (McNally, 1998; McNally, Luedke, Besyner, Peterson, Bohm, \& Lips, 1987; Trandel \& McNally, 1987). This tendency has been significantly related to the severity of PTSD (McNally, Kaspi, Riemann, \& Zeitlin, 1990) but less to the degree of trauma-exposure (Chemtob, Roitblat, Hamada, Muraoka, Carlson, \& Bauer, 1999; McNally et al, 1990). PTSD patients also tend to selectively store and recall threatening information (McNally, Metzger, Lasko, Clancy, \& Pitman, 1998).

Interestingly, other anxiety patients not only prioritize threat information, but also take the occurrence of anxiety responses themselves as evidence that threat is impending. Whereas non-anxious individuals infer danger from objective information about situations, anxious patients also infer it from their own anxious responses: "if anxiety, then threat". This "emotion-based reasoning' (ER) tendency has been reported for spider phobia, panic disorder, social phobia, and a group of other anxiety disorders $(\mathrm{n}=$ 31 , of which only 5 were diagnosed with PTSD). Furthermore, it was not limited to disorder-specific situations (Arntz, Rauner, \& van den Hout, 1995).

Such a phenomenon might also be involved in chronic PTSD. Once PTSD symptoms have emerged, the individual's appraisals of them may be critical. Recently, Ehlers and Clark (2000) proposed that negative appraisals of initial PTSD symptoms might incite a sense of current threat, thus fostering symptom persistence. This threat may be internal ("I'm going crazy") or external ("the world is dangerous"). It may render the disorder self-perpetuating by amplifying distress and fostering avoidance strategies (see also Ehlers \& Steil, 1995). There is empirical support for several propositions of 
this model. For example, PTSD patients are characterized by high anxiety sensitivity, i.e. fear of anxiety symptoms arising from beliefs about their negative implications (Taylor, Koch, \& McNally, 1992). Prospective (Ehlers, Mayou, \& Bryant, 1998) and cross-sectional (Clohessy \& Ehlers, 1999; Dunmore, Clark, \& Ehlers, 1999; Steil \& Ehlers, 2000) studies showed that the negative interpretation of PTSD symptoms was strongly linked to chronic PTSD, independently of trauma-severity and the frequency of symptoms. Moreover, it was strongly associated with the distress caused by symptoms and the use of avoidance strategies. However, these negative appraisals of symptoms primarily involved references to internal threat (i.e., threat to physical or mental well being), and it is unclear whether PTSD patients also perceive more external threat (i.e., outside danger) on the basis of such symptoms.

The aim of this study was twofold. First, we tested whether individuals with chronic PTSD exhibit the ER tendency that Arntz et al. (1995) found in other anxiety patients, i.e., whether they infer danger from the presence of anxiety responses themselves. Second, we tested whether they exhibit a similar tendency based on PTSD-related intrusions, i.e., inferring danger from the presence of intrusions. Analogous to ER, we refer to this as 'intrusion-based reasoning' (IR). Vietnam War combat veterans withl combat-related PTSD were compared with combat veterans who had never PTSD or other anxiety disorders. Particjpants rated perceived danger of two series of brief scenarios: ER-scenarios that were specific for other anxiety disorders, taken from the Arntz et al. study, and IR-scenarios that were specific for combat-related PTSD. Information about objective danger (danger vs. safety) and response (anxiety/distressing intrusions vs. non-distressing emotional response) was systematically varied. Extrapolating from the Antz et al. data, we expected that participants without PTSD would infer danger from objective danger cues, and that participants with PTSD would also infer danger from the presence of anxiety responses. We expected the same pattern for the presence of intrusions. Furthermore, we examined whether these expected effects remained after adjusting for the influence of perceived uncontrollability, anxiety, and outcome expectations of scenarios. Finally, we explored the link between ER and IR, and whether they were each associated with trait anxiety, anxiety sensitivity, the negative interpretation of posttrauma symptoms, and intelligence.

\section{METHOD}

Participants and procedure. Thirty male Vietnam War combat veterans participated in this study: 15 veterans who met DSM-IV (APA, 1994) criteria for PTSD and 15 veterans with no history of PTSD or other anxiety disorder (see table 1 for ages). The 'reasoning' paradigms were conducted over the telephone, and corresponding rating scales and questionnaires were sent beforehand by mail. Participants were asked to return everything within a week, and they received $\$ 20$ for participating. 
Measures. The ER/IR paradigms consisted of brief scenarios that were read to participants over the telephone by an experimenter who was blind to psychiatric status. Each scenario was rated on visual analogue scales (VASs). ER was measured with three scenarios that were specific for panic disorder, social phobia, and spider phobia, taken from Arntz et al. (1995). There were four versions of each scenario that started identically but ended differently: (1) with objective danger information and an anxiety response; (2) with objective danger and a non-anxiety emotional response; (3) with objective safety and anxiety; and (4) with objective safety and a non-anxiety emotional response. IR was assessed with four PTSD specific scenarios that were based on casereports of Vietnam War veterans (Chalsma, 1998, p.122; Kline \& Rausch, 1985; Schacter, 1996, p.210; Smith, 1985, p. 130). These were similarly varied except that response information involved distressing intrusions instead of anxiety. An example of a PTSD scenario was as follows:

It's a fourth of July holiday, and you 're on your way to meet some friends. You're looking forward to seeing them, but you're running late. As you're driving your car, several children toss firecrackers under the wheels of your car.

The version of danger and intrusions continued:

You hit the accelerator, but lose control of the wheel. The car stalls in the wrong lane. The oncoming traffic moves quickly towards you. You hear more firecrackers. The sudden noise triggers upsetting thoughts about Vietnam.

The version of danger and no intrusions was:

You hit the accelerator, but lose control of the wheel. The car stalls in the wrong lane. The oncoming traffic moves quickly towards you. You hear more firecrackers. The sudden noise makes you angry, but then you laughto yourself and think: 'Well, at least f've got a good excuse now for being late."

The version of safety and intrusions was:

The sudden noise triggers upsetring thoughts about Viemam.

The version of safety and no intrusions was:

The sudden noise makes you angry, but then you laugh to yourself and think: 'Well, at leasit I've got a good excuse now for being late.

IR-scenarios were administered first, followed by the ER-scenarios. Each series was randomly ordered with the restriction that all versions and scenarios were represented in each set of four. Participants were instructed to identify themselves as well as possible with the main character of each individual scenario, and to rate five $100 \mathrm{mms}$ VASs that were printed in a booklet form. The first scale was the degree of danger of the scenario, which was the dependent variable. The other scales represented safety, 
uncontrollability, anxiety, and positive vs. negative outcome. These served to explore effects on the danger ratings.

Participants also completed the following questionnaires: the Posttraumatic Symptom Scale (PSS-SR; Foa, Riggs, Dancu, \& Rothbaum, 1993), the Trait scale of the StateTrait Anxiety Inventory (STAI-T; Spielberger, Gorsuch, Lushene, Vagg, \& Jacobs, 1983), and the Anxiety Sensitivity Index (ASI; Reiss, Peterson, Gursky, \& MoNally, 1986). In addition, the 14-item modified version (Ehlers, personal communication, December 23, 1997) of the Interpretation of Symptoms Questionnaire (ISQ; Dunmore, Clark, \& Ehlers, 1999) was used to measure the negative appraisals of posttrauma symptoms. The Combat Exposure Scale (CES; Keane, Fairbank, Caddell, Zimering, Taylor, \& Mora, 1989) and the Shipley Institute of Living Scale (Zachary, 1991; data were missing for 6 participants per group) had already been administered. Shipley scores were converted with the scale's conversion table to estimate full-scale intelligence.

\section{RESULTS}

Age and Psychometric data. One-way analyses of variance were conducted on age and the psychometric data (see table 1 for means and standard deviations). There were no significant differences between the groups in combat exposure (CES) and estimated IQ. However, the PTSD group was younger, reported more PTSD symptoms (PSSSR), trait anxiety (STAI-T), more negative interpretation of symptoms (ISQ), and higher anxiety sensitivity (ASI) compared to the non-PTSD group.

Table 1. Age and psychometric data

\begin{tabular}{|c|c|c|c|c|}
\hline \multirow[b]{2}{*}{ Characteristic } & \multicolumn{2}{|c|}{ Group } & \multirow[b]{2}{*}{ F } & \multirow[b]{2}{*}{$p$} \\
\hline & PTSD & Non-PTSD & & \\
\hline Age & $51.86(2.11)$ & $54.13(3.38)$ & 4.66 & .04 \\
\hline PSS-SR & $38.13(10.18)$ & $6.00(7.04)$ & 101.05 & .00 \\
\hline STAl-T & $60.50(10.35)$ & $32.50(7.72)$ & 65.85 & .00 \\
\hline ASI & $32.20(8.95)$ & $16.13(9.83)$ & 21.89 & .00 \\
\hline $\mathrm{ISQ}$ & $32.13(10.11)$ & $2.67(4.78)$ & 104.13 & .00 \\
\hline CES & $26.21(11.22)$ & $18.08(11.54)$ & 3.31 & .08 \\
\hline 19 & $108.89(14.46)$ & $117.00(12.18)$ & 166 & .22 \\
\hline
\end{tabular}

Note. Possible ranges of scores were PSS-SR $=0$ to $51, \mathrm{STAL} I=20$ to $80 ; \mathrm{ASI}=01064 ; 1 \mathrm{SO}=010$ 56; $\mathrm{CES}=0$ to 41 . Standard deviations are in parentheses. 
ER/IR-danger ratings. For the ER-scenarios, three-way analyses of variance (ANOVAs) for repeated measures (see figure it for danger ratings) revealed a trend for Group, $F(1,28)=4.04, p=.054$, and main effects for Danger, $F(1,28)=37.88, p<$ .001 , and Response, $F(1,28)=28.21, p<.001)$. The crucial Group x Response interaction was significant, $F(1,28)=6.20, p=.019$, indicating that, compared to the control group, the PTSD group showed higher danger ratings on scenarios with anxiety information relative to scenarios without anxiety. The three-way Group $x$ Danger $x$ Response interaction was nonsignificant. For the IR-scenarios, there were main effects for Group, $F(1,28)=18.35, p<.001$, for Danger, $F(1,28)=60.40, p<.00$, and Response, $F(1,28)=29.86, p<.001$. Again, the crucial Group $x$ Response interaction was significant, $F(1,28)=8.25, p=.008$, indicating that, compared to the control group, the PTSD group showed higher danger ratings on scenarios with intrusions relative to scenarios without intrusions. The three-way Group $x$. Danger $x$ Response interaction was nonsignificant. Next, we examined whether the observed effects remained intact when adjusting for VAS-ratings of uncontrollability, anxiety, and outcome expectations. The same analyses were repeated with these variables as covariates. The observed effects remained intact after controlling for anxiety and outcome expectations. However, after adjustment for uncontrollability, the observed Group $\times$ Response interaction for ER-scenarios dropped from $6.20, p=.019$, to $2.83, p$ $=.104$. This was also the case for IR scenarios: the $F$-value dropped from $8.25, p=$ .008 , to $3.93, p=.058$. The effect size of $\mathrm{ER}$ after adjusting for uncontrollability dropped from $f=.47$ to .32 , and the effect size of IR dropped from $f=.54$ to .37 . These effect sizes remained substantial, which suggests that the observed ER and IR effects were only partly due to perceptions of uncontrollability.

Exploratory analyses. ER and IR were defined as the difference in danger ratings between scenarios with and without information about anxiety and intrusions, respectively, and these variables were moderately related, $r(30)=.35, p=.055$. We also explored the link between ER and IR on the one hand, and the ISQ, ASI, STAI-T, and IQ on the other hand by computing Spearman correlation coefficients for the PTSD group. The $1 Q$ estimate was significantly related to $I R, r(9)=-.89, p=.001$. None of the psychometric variables, including IQ $(r=. \| 4)$ was significantly linked to ER. 


\section{With PTSD}
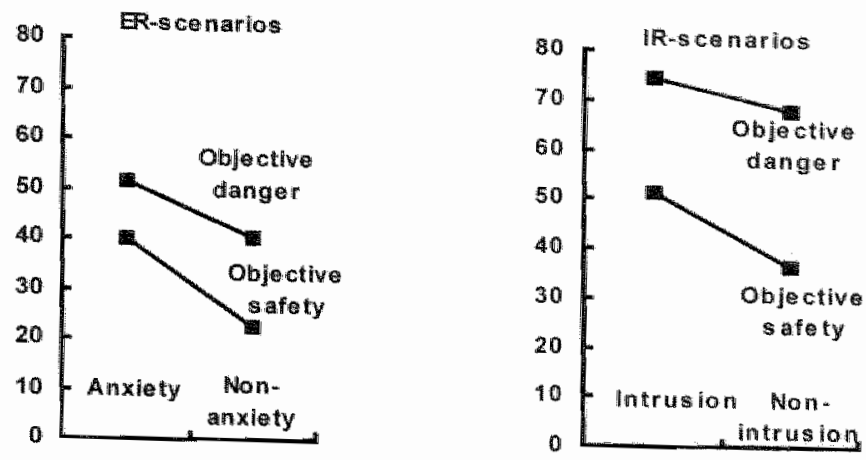

\section{Without PTSD}
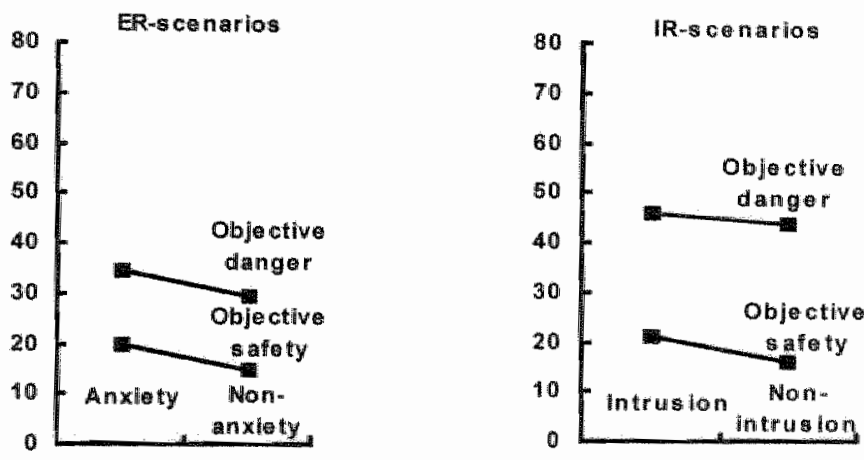

Figure 1. Mean danger ratings of participants with and without PTSD for ER-scenarios and IRscenarios as a function of objective danger information (danger $v$ s. safety) and response information (anxiety/intrusions $v$ s, non-distressing response). The ER/R tendencies shown by the PTSD group are reflected by steeper slopes relative to the non-PTSD group, due to higher danger ratings on scenarios with anxiety/intrusion response information.

\section{Discussion}

Consistent with Arntz et al. (1995), we found that, compared to healthy combat veterans, Vietnam combat veterans with PTSD interpret anxiety responses themselves harbingers of impending threat. A similar pattern occurred for PTSD-intrusions, confirming predictions of Ehlers and Clark (2000). The two tendencies were linked 
only modestlly suggesting that they are loosely coupled phenomena. Note meanwhile that $\mathbb{E R}$ and $I R$ were not measured with standardized and independently validated instruments, and that the moderate correlation may in part be explicable by measurement imperfection. Although participants with PTSD exhibited both ER and $I R$, there were some differences in ratings of the two types of scenarios. First, the $I R$ effects were smaller, perhaps attributable to the mild formulations of intrusions in these scenarios (e.g., "upsetting thoughts about Vietnam" or "being upset and reminded of Vietnam") compared to the anxiety response information of the other scenarios (e.g., "being scared to death" and "suddenly becoming very anxious"). In addition, all versions of the IR-scenarios included triggers for intrusions (e.g., 'sudden noise' and "the smell of blood"), while these were followed by a non-anxious emotional response in control scenarios. During the debriefing, many participants with PTSD reported that they found it difficult to relate to these control scenarios because such triggers typically evoked intrusions and fear. Second, the PTSD group rated all IR scenarios as more dangerous than did the non-PTSD group, consistent with research showing that PTSD patients have difficulty suppressing the meaning of traumarrelated words, once activated (McNally, 1998).

The data seem to rule out that ER and IR resulted from trauma exposure as such, since they were not associated with combat experiences. In addition, it seems unlikely that while participants were asked to rate danger of scenarios, the PTSD group interpreted this as internal rather than external threat. Participants with PTSD scored higher on the ASI and ISQ relative to participants without PTSD. However, the correlations between ER/IR and the ASI and ISQ were non-significant. Two explanations may account for part of the ER/IR effects. First, the ER/IR effects were reduced after adjusting for perceptions of uncontrollability. Jones and Barlow (1990) suggested that the crucial step to PTSD is the development of anxious apprehension about anxiety and associated traumatic memories. Individuals who perceive such symptoms as unpredictable and uncontrollable may believe that lack of control over emotional responses renders them vulnerable to external threat during such emotional episodes. Studying the relation between perceived control over intemal anxiety reactions and external events (e.g., as measured with the Anxiety Control Questionnaire; Rapee, Craske, Brown, \& Barlow, 1996) may clarify this issue further. Second, although the exploratory analyses were based on a small sample size, they indicated that $I R$ was strongly associated with lower intelligence. Lower pre-trauma intelligence strongly predicts chronic PTSD severity, independently of trauma exposure and current intelligence (Macklin, Metzger, Litz, MeNally, Lasko, Orr, \& Pitman, 1998). Fewer cognitive resources, such as abstract thinking and higher order reasoning skills, may impede coping with acute PTSD symptoms and may make trauma victims more vulnerable to IR. Lower IQ may increase the risk for PTSD in part because low IQ is related to IR-like reasoning styles. Still, it is acknowledged that somewhat inconsistent with this argument, IQ was not related $E R$. 
ER and IR were specifically related to PTSD but since the study was cross-sectional we cannot determine whether they foster persistence of PTSD, result from PTSD, or both. In favor of the first view, Sijsenaar (1996) found that healthy individuals high in ER had more difficulty distinguishing safety signals from danger signals in a conditioning paradigm compared to individuals low in ER. There are several ways in which ER and IR may contribute to the persistence of PTSD. First, they may promote persistence because the common experiences of intrusions and anxiety are taken as evidence that doom is (still or again) impending and that the world is unsafe. Second, they may foster avoidance of cues that lead to the experience of anxiety. Although avoidance strategies may reduce arousal, they also impede emotional processing (Rachman, 1980) and modification of the fear structure (Foa \& Kozak, 1986). Third, they may amplify distress, which increases the frequency of intrusive thoughts (De Silva \& Marks, 1999). Fourth, given that people tend to confirm rather than disconfirm prior beliefs about threat, ER and IR may motivate PTSD patients to search selectively for dangerconfirming information.

This study had several limitations. The number of participants was relatively small. Consequently, all scenarios were administered to each participant. Although scenarios were randomized, there still may have been carry-over effects. Finally, the data are silent about the crucial issue of causality. If ER/IR are causal, it follows that prospective studies will show that newly traumatized victims who interpret initial symptoms as signs of threat are at risk for chronic morbidity. However, the strongest test for causality is intervention research. If ER/IR are causal to the development of chronic PTSD, it follows that prevention of ER/IR after trauma will prevent chronic PTSD. Such intervention studies would be interesting theoretically as well as clinically.

\section{ACKNOWLEDGMENTS}

This project was supported in part with a Fulbright scholarship awarded to the first author, for study at Harvard University, by the Netherlands America Commission for Educational Exchange (NACEE), Amsterdam, The Netherlands. The authors gratefully acknowledge the participants for their time and emotional involvement. Special thanks are also due to Roger K. Pitman and Scott P. Orr for their help with this project. This paper was presented at the annual meeting (November 2000) of the International Society for Traumatic Stress Studies, San Antonio, TX.

\section{REFERENCES}

American Psychiatric Association (1994). Diagnostic and statistical mantal of mental disorders (4th ed.). Washington, DC: Author.

Arntz, A., Rauner, M., \& van den Hout, M. (1995). "If I feel anxious, there must be danger": Ex-consequentia reasoning in inferring danger in anxiety disorders. Behaviour Research and Therapy, 33, 917-925. 
Breslau, N.. \& Davis, G.C. (1992). Posttraumatic stress disorder in an urban population of young adults: Risk factors for chronicity. American Joumal of Psychiatry, 149, $671-675$.

Chalsma, H.W. (1998). The chambers of memory" PTSD in the life stories of U.S. Vietnam veterans. New Jersey: Jason Aronson.

Chemtob, C.M., Roiblat, H.L., Hamada, R.S., Muraoka, M.Y., Carlson, J.G., \& Bauer; G.B. (1999). Compelled attention: The effects of viewing trauma-related stimuli on concurrent task performance in posttramatic stress disorder. Jommal of Trammatic Stress, 12, 309-326.

Clohessy, S., \& Ehlers, A. (1999). PTSD symptoms, response to intrusive memories and coping in ambulance service workers. British Jounal of Clinical Psychology, $38,251-265$.

De Silva, P., \& Marks, M. (1999). Intrusive thinking in post-traumatic stress disorder. In Yule, W. (Ed.). Post-traumatic stress disorders: Concepts and therapy (pp. $161-$ 175). London: Wiley.

Dunmore, E., Clark, D.M., \& Ehlers, A. (1999). Cognitive factors involved in the onset and maintenance of posttraumatic stress disorder (PTSD) after physical or sexual assault. Behaviour Research and Therapy, 37,809-829.

Ehlers, A., \& Clark, D.M. (2000). A cognitive model of postraumatic stress disorder. Behaviour Research and Therapy, 38, 319-345.

Ehlers, A., Mayou, R.A., \& Bryant, B. (1998). Psychological predictors of chronic posttraumatic stress disordar after motor vehicle accidents. Jownal of Abnomal Psychology, 107, 508-519.

Ehlers, A. \& Steil, R. (1995). Maintenance of intrusive memories in posttraumatic stress disorder: A cognilive approach. Behaviownal and Cogmitive Psychotherapy. $23,217-249$.

Foa, E.B., \& Kozak, M.J. (1986). Emotional processing of fear: Exposure to corrective information. Psychological Bulletin, $99,20-35$.

Foa, E.B., Riggs, D.S., Dancu, C.V., \& Rothbaum, B.O. (1993). Reliability and validity of a brief instrument for assessing post-traumatic stress disorder. Jounal of Trammatic Stress, $6,459-473$.

Green, B.L., Lindy, J.D., Grace, M.C., \& Leonard, A.C. (1992). Chronic postraumatic stress disorder and diagnostic comorbidity in a disaster sample. Jowmal of Nervous and Mental Disease, $180,760-766$.

Jones, J.C., \& Barlow, D.H. (1990). The etiology of posttraumatic stress disorder. Clinical Psychology Review, 10, 299-328.

Keane, T.M., Fairbank, J.A., Caddell, J.M., Zimering, R.T., Taylor, K.L., \& Mora, C.A. (1989). Clinical evaluation of a measure to assess combat exposure. Psychological Assessment, 1, 53-55.

Kessler, R.C., Sonnega, A.* Bromet, E., Hughes, M., \& Nelson, C.B. (1995). Posttraumatic stress disonder in the National Comorbidity Survey. Archives of General Psychiatiy, 52, 1048-1060. 
Kilpatrick, D.G., Saunders, B.E., Veronen, L.J., Best, C.L., \& Von, J.M. (1987). Criminal victimization: Lifetime prevalence, reporting to police, and psychological impact. Crime and Delinquency, 33, 479-489.

Kline, N.A., \& Rausch, J.L. (1985). Olfactory precipitants of flashbacks in posttraumatic stress disorder: Case reports. Journal of Clinical Psychiamy, 46, 383-w 384.

Kulka, R.A., Schlenger, W.E., Fairbank, J.A., Hough, R.L., Jordan, B.K., Marmar, C.R., \& Weiss, D.S. (1990). Trauma and the Viemam War generation: Report of findings from the National Viemam Veterans Readjusiment Study. New York: Brunner/Mazel.

Macklin, M.L., Metzger, L.J., Litz, B.T., McNally, R.J., Lasko, N.B., Orr, S.P., \& Pitman, R.K. (1998). Lower precombat intelligence is a risk factor for posttraumatic stress disorder. Journal of Consulting and Clinical Psychology, 66, 323-326.

McFarlane, A.C. (1988). The phenomenology of posttraumatic stress disorders following a natural disaster. The Joumal of Nervous and Mental Disease, 176, 2229.

McNally, R.J. (1998). Experimental approaches to cognitive abnormality in posttraumatic stress disorder. Clinical Psychology Review, 18, 971-982.

McNally, R.J., Kaspi, S.P., Riemann, B.C., \& Zeitlin, S.B. (1990). Selective processing of threat cues in posttraumatic stress disorder. Joumal of Abnormal Psychology, 99, $398-402$

McNally, R.J., Luedke, D.L., Besyner, J.K., Peterson, R.A., Bohm, K., \& Lips, O.J. (1987). Sensitivity to stress-relevant stimuli in posttraumatic stress disorder. Journal of Anxiety Disorders, 1, 105-116.

McNally, R.J., Metzger, L.J., Lasko, N.B., Clancy, S.A., \& Pitman, R.K. (1998). Directed forgetting of trauma cues in adult survivors of childhood of sexual abuse with and without posttraumatic stress disorder. Journal of Abnormal Psychology. 107, 596-601.

Rachman, S. (1980). Emotional processing. Behaviour Research and Therapy, 18, 51 60.

Rapee, R.M., Craske, M.G., Brown, T.A., \& Barlow, D.H. (1996). Measurement of perceived control over anxiety-related events. Behavior Therapy, 27, 279-293.

Reiss, S., Peterson, R.A., Gursky, D.M., \& McNally, R.I. (1986). Anxiety sensitivity, anxiety frequency and the prediction of fearfulness. Behoviour Research and Therapy, 24, 1-8.

Schacter, D. L. (1996). Searching for memory: The brain, the mind, and the past. New York: BasicBooks.

Sijsenaar, M. (1996). Kijken door een gekleurde bril: Een onderzoek naar de rol van emorional reasoning bij het ontstaan van angstklachten [Looking through colored glasses: A study of emotional reasoning in the etiology of anxiety symptoms]. Masters thesis, Maastricht University. 
Smith, J.R. (1985). Individual psychotherapy with Viet Nam veterans. In S.M. Sonnenberg, A.S. Blank, Jr., \& Talbott, J.A. (Eds.). The trauma of war: Stress and recovery in Viet Nam veterans (pp. 127-163). Washington, DC: American Psychiatric Press.

Spielberger, C.D., Gorsuch, R.L., Lushene, R., Vagg, P.R., \& Jacobs, G.A. (1983). Manual for the State-Trait Anxiety Inventory. Palo Alto, CA: Consulting Psychologists Press.

Steil, R. \& Ehlers, A. (2000). Dysfunctional meaning of posttraumatic intrusions in chronic PTSD. Behoviour Research and Therapy, 38, 537-558.

Taylor, S., Koch, W.L., \& McNally, R.J. (1992). How does anxiety sensitivity vary across the anxiety disorders? Journal of Anxiety Disorders, 6, 249-259.

Trandel, D.V., \& McNally, R.J. (1987). Perception of threat cues in post-traumatic stress disorder: Semantic processing without awareness? Behaviour Research and Therapy, 25, 469-476.

Zachary, R.A. (1991). Shipley Institute of Living Scale: Revised manual. Los Angeles: Western Psychological Services. 


\section{CHAPTER 7}

\section{"Intrusion-based Reasoning" and Posttraumatic Stress Disorder after Exposure to a Train Disaster: A Longitudinal Study "}

\section{ABSTRACT}

Previously, we found that chronic PTSD relates to "intrusion-based reasoning" (IR), i.e. the tendency to interpret distressing intrusions themselves as evidence that danger is impending, regardless of objective danger information (Engelhard, Macklin, MeNally, van den Hout, \& Arntz, 2001). This study was intended to elucidate the causal status of this relation. Twenty-nine residents of a Belgian town witnessed a train crash and were assessed for IR and PTSD symptoms within 1 nonth and were reassessed for PTSD at 3.5 months. Founteen control residents did not witness the erast and were also tested for $I R$. The IR paradign involved rating the danger of brief scenarios in which objective danger and presence of intrusions about the crash were systematically varied. The directly exposed residents showed greater danger ratings to scenarios in which intrusions were included than did the controls. IR was strongly related to both acute and chronic PTSD symptoms. It did not significantly predict chronic PTSD symptoms after controlling for acute symptoms, although the partial correlation $(r p=26, p=09)$ was in the expected direction. The data suggest that IR is involved in the onset and maintenance of PTSD symptoms, but nore clarity about causality awaits future larger and experimental studies.

\footnotetext{
Engelthard, I.M., van den Houl, M.A., Antz, A., MeNally, R.J. (in press). Behcryour Restewch and Therctpy. A poster presentation of this study was awarded the $1^{\text {sh }}$ prize of the Studient Poster Awards at the annual meeting of the International Society for Traumatic Stress Studies assembled in New Orleans. Decenber, 2001.
} 


\section{INTRODUCTION}

After an extremely stressful event, many individuals experience psychological distress, but only a minority develops posttraumatic stress disorder (PTSD). PTSD consists of persistent reexperiencing of the event, avoidance of reminders and numbing, and increased arousal. It is diagnosed when a minimum of these symptoms is present for more than one month, and is regarded chronic if it persists for more than three months (APA, 1994). Initial symptoms of anxiety and intrusive recollections are common after trauma (McFarlane \& Yehuda, 1996). However, there appears to be a critical phase in which these symptoms dissipate in some individuals, but continue in others. McFarlane (2000) reported a study of acute symptoms after a motor vehicle accident (MVA) and PTSD six months later. On the first day after the accident, anxiety symptoms did not differ between individuals with and without later PTSD. Differences emerged on the tenth day: whereas anxiety increased in individuals with later PTSD, it started to decrease in individuals who did not develop the disorder. Shalev, Peri, Canetti, and Schreiber (1996) studied symptoms one week and six months after a MVA, and found that initial anxiety, as well as intrusions, remained elevated for individuals with PTSD at six months, but dropped for individuals without PTSD at six months. In contrast, avoidance symptoms increased with time for the former group and remained low for the latter.

Why does the acute stress response fail to resolve in some individuals? PTSD prevalence often-mut not always (Bowman, 1999)--increases with increasing stressor severity (March, 1993). However, the longer the disorder persists, the less trauma exposure explains symptoms (McFarlane \& Yehuda, 1996). What might be critical are the individual's appraisals of acute symptoms. Recently, Ehlers and Clark (2000) proposed that PTSD becomes self-perpetuating when the traumatic event or its sequelae, such as initial symptoms, are processed in a way that produces a sense of current threat (e.g., "My reactions mean I'm going crazy" or ". . I'm losing control"), as this amplifies distress and avoidance strategies. Prospective and cross-sectional studies after various traumatic events (see Ehlers \& Clark, 2000) supported the importance of negative appraisals of initial PTSD symptoms in the maintenance of PTSD. For example, Ehlers, Mayou, \& Bryant (1998) found that negative appraisals of PTSD symptoms assessed three months after a MVA predicted PTSD symptoms at one year, independently of trauma-severity and frequency of initial symptoms.

Earlier, we found that chronic PTSD was also related to "intrusion-based reasoning" (IR), i.e, the tendency to infer danger not only from the presence of objective danger, but also from the presence of intrusions (Engelhard, Macklin, McNally, van den Hout, \& Arntz, 2001). Whereas Vietnam veterans without PTSD inferred danger from objective information about situations, veterans with PTSD also inferred danger from the presence of intrusions: 'if intrusions, then threat'. A similar "emotion-based reasoning" tendency was found for anxiety responses unrelated to PTSD (Engelhard et 
al., 2001), which has also been found in other anxiety disorders (Arntz, Rauner, \& van den Hout, 1995). This points to an intriguing parallel between PTSD and other anxiety disorders: all may persist because symptoms (i.e. intrusions in case of PTSD) are processed in a way that confirms danger inferences. However, former findings do not imply that IR independently predicts later PTSD: IR might render PTSD selfperpetuating, might result from PTSD, or both.

This study was intended to (1) replicate previous IR findings of Vietnam veterans in an acutely traumatized sample, and (2) elucidate causality. Residents of a Belgian town who witnessed a tragic train crash were administered a modified IR paradigm within one month post-trauma and were re-assessed for PTSD at three and a half months. Control residents who did not witness the crash, but lived in the same community, were also tested for IR. We expected that the directly exposed individuals would display IR to a greater degree than would controls, and that greater IR would be related to more acute PTSD symptoms. Furthermore, we expected that the early tendency to allow distressing intrusions to influence danger inferences would predict the presence and intensity of chronic PTSD.

\section{METHOD}

Background. On March 27, 2001, two trains collided in Pécrot, a Belgian town located between the university cities of Leuven and Louvain-la-Neuve. Around $8.40 \mathrm{a} . \mathrm{m}$., a driver of an empty passenger train ignored a stop signal and went the wrong side of two tracks. With a ticket collector, but without passengers on the train, he approached a commuter train carrying 24 schoolchildren, students, and rush hour commuters. Dispatchers realized what had happened, but could not get in touch with the drivers because the trains were not equipped with radios or cellular telephones and stations along the route were unmanned. After 7 minutes, power to the line was cut. Shortly thereafter, the two trains crashed head-on at about $55 \mathrm{mph}$. This happened on an embankment in Pécrot where residents live on both sides. The havoc and chaos were enormous, leaving wreckage and human remains scattered throughout the area. The first car of the commuter train was crushed and flipped backward onto the second car, with the first car of the other train piled on top and pointed skywards. Eight people died instantly and twelve were seriously injured (Delepierre, 2001; Gollin, 2001). Local residents heard a loud crash followed by a brief 'eerie' silence. For a moment, the air was filled with dust and fibers. Many residents immediately went outside and heard and saw passengers moaning and crying for help. Some tried to help victims out of the wreckage (e.g., with ladders they got from their homes), and several telephoned emergency services, their partners, or relatives. The previous train carried 60 to 70 schoolchildren, and several mothers and grandmothers called schools or frantically ran to the trains to ensure that their children were safe. Then they watched the scene, talked to neighbors, or received emergency workers, survivors, relatives, and the press in their homes. Some homes were evacuated because the upper car was in danger of collapsing, 
and because rescue workers and police dogs had to recover human remains. It took hours to rernove victims from the train, but the wreckage was cleared the next moming.

Participants and procedure. Two groups of residents of Pécrot participated in this study. One group consisted of individuals directly exposed to the train collision and the other (control) group comprised individuals indirectly exposed to the collision. Thirty directly exposed residents participated, but 1 was excluded from analyses due to invalid ratings, resulting in 29 participants (19 women). Of those, 22 saw or heard the accident happen, 3 arrived shortly thereafter, and 4 arrived later, but lived very close to the scene. Five refused participation ( 2 women) because they did not want to be confronted with the experience, resulting in a response-rate of $85 \%(29 / 34)$. Fourteen (4 women) controls participated, who arrived about 8 hours after the collision. Their mean age was 53 years $(S D=17)$ and they lived in Pécrot for about 30 years $(S D=$ 24). Most were married or cohabitating $(83 \%)$ and were college-educated $(72 \%)$. About half was employed, $30 \%$ was retired, and 10\% was homemaker. These characteristics did not significantly differ between the two groups. Information was not collected from (direct crash) victims or their families. Participants were recruited about 3 weeks after the crash through "snowball sampling'. The locall general practitioner helped identify those willing to participate. After participants gave written informed consent, they were assessed in their homes for IR, trauma exposure, and PTSD. All directly exposed individuals were re-assessed for PTSD at 3.5 months. Participants were not compensated and their participation was voluntary.

Measures. The IR paradigm consisted of 4 descriptive scenarios presented in a booklet form, in which the variables of (a) objective danger information and (b) the presence of intrusions of the train crash were crossed. Thus, there were 4 versions of each scenario that started identically, but ended differently: (1) with objective danger information and distressing intrusions; (2) with objective danger and no distressing intrusions; (3) with objective safety and distressing intrusions; and (4) with objective safety and no distressing intrusions. An example was as follows:

It's a summer night, and you're taking a walk in Lewen. It's quiet and you're alone. Suddenly, you hear someone crying...

Objective danger and intrusions version:

... You wrm around and see that a young woman is being mugged. As she's crying for help, the robber turns rowards you. The crying reminds you of the train crash. You are scared to death...

Objective danger without intrusions:

...You turn around and see that a young woman is being mugged. As she's crying for help, the robber turns towards you. You take a deep breath and feel calm ... 
Objective safety and intrusions:

... You tum around and see that a young woman is argung with her boyfriend. The crying reminds you of the train crash. You are scared to death...

Objective safety without intrusions:

... You turn around and see that a young woman is arguing with her boyfriend. You take a deep breath and feel calm...

Order of presentation of the 16 scenarios was random with the restriction that each set of 4 included all versions and scenarios. Participants were told to identify themselves as well as possible with the main character of each scenario. After reading each scenario, they rated their perceived danger on a $100 \mathrm{~mm}$ visual analogue scale. A trauma-exposure scale designed for this study and the Posttraumatic Symptom Scale (PSS; Foa, Riggs, Dancu, \& Rothbaum, 1993) were also administered. The traumaexposure scale included immediate emotional reactions of horror, fear, or helplessness (i.e., the DSM-IV stressor criterion), that were rated on a 5-point scale ( $1=$ "not at all", $5=$ "extreme"). The PSS corresponds to the 17 DSM-IV symptoms of PTSD. Respondents rated the severity of each symptom during the prior three weeks ( $1^{\text {st }}$ assessment) or month ( $2^{\text {nd }}$ assessment), using a 4-point scale $(0=$ "not at all", $3=$ "almost always"). Foa et al. (1993) reported good reliability and concurrent validity with other PTSD measures. A PTSD symptom was considered present if rated at least 2 ("half the time").

\section{RESULTS}

PTSD symptoms. Of the group directly exposed to the train crash, $82 \%$ reported intense (rated $\geq 4$ ) helplessness, $62 \%$ reported intense fear, and $40 \%$ reported intense horror at the time. At 3 weeks, $28 \%(8 / 29)$ met the symptom criteria for a PTSD diagnosis, and $38 \%$ (11/29) met criteria for partial PTSD (i.e., 2 out of 3 symptomclusters, see Carlier \& Gersons, 1995). More specifically, 97\% met criteria for 'reexperiencing", $31 \%$ for "avoidance and numbing", and $69 \%$ for "increased arousal". The overall mean PSS was $23.6(S D=9.9)$, which was similar to Dutch PTSD outpatients, $M=25.8, S D=10.5$ (Antz, Tiesema, \& Kindt, 2001). The most common symptoms were intrusive recollections $(86 \%$; particularly sounds of the crash and of victims, images of human remains and of injured and dead victims, and thoughts of the ones who died and their relatives), distress when reminded $(66 \%)$, cognitive avoidance $(66 \%)$, hypervigilance $(62 \%)$, physiological reactivity when reminded $(48 \%)$, sleeping problems $(48 \%)$, and exaggerated startle $(45 \%)$. The least common were detachment from others $(14 \%)$ and psychogenic amnesia $(28 \%)$.

At 3.5 months, $24 \%(7 / 29)$ of the directly exposed group met the criteria for PTSD (63\% of them met PTSD symptom-criteria at 3 weeks), $17 \%(5 / 29)$ met criteria for partial PTSD (due to not meeting avoidance criteria), and $59 \%$ was without (partial) 
PTSD. More specifically, 69\% met criteria for "reexperiencing", $24 \%$ for "avoidance and numbing", and $48 \%$ for "increased arousal". The mean PSS was $14.8(S D=12.5)$, and the most common symptoms were hypervigilance $(66 \%)$, intrusive recollections $(59 \%)$, psychological distress when reminded $(41 \%)$, cognitive avoidance $(41 \%)$, and exaggerated startle $(38 \%)$. The least common were numbness (10\%), nightmares $(14 \%)$, and detachment from others $(17 \%)$.

At 3 weeks, residents indirectly exposed to the crash had a mean PSS of $4.9(\mathrm{SD}=3.7)$. They reported intrusive recollections $(36 \% ; n=5)$, cognitive avoidance $(14 \% ; n=2)$, diminished interest $(14 \%)$, irritability $(7 \%)$, and distress when reminded $(7 \%)$. No other PTSD symptoms were reported.

IR. First, danger ratings were compared between the directly exposed and controls. Data were analyzed with three-way analysis of variance for repeated measures comparing Group (acutely traumatized versus controls), Danger (objective danger wersus safety), and Response (intrusions versus no intrusions). Figure 1 displays danger ratings of controls and directly exposed individuals with and without (partial) PTSD at 3.5 months. It suggests that the directly exposed group shows the IR phenomenon, which is reflected by steeper slopes relative to the controls due to greater ratings of danger to scenarios in which intrusions were included. Analyses revealed main effects for Group, $F(1,41)=8.77, p=.005$, Danger, $F(1,41)=105.76, p<.001$, and Response, $F(1,41)=4.22, p=.046$. The crucial Group $x$ Response interaction was significant, $F(1,41)=5.48, p=.024$, indicating that, relative to the controls, the directly exposed group showed greater ratings of danger to scenarios in which intrusions were included relative to the same scenarios in which intrusions were exchuded. The three-way Group x Danger $x$ Response interaction was not significant, $F$ $(1,4)=.47, p=.499$.

Second, IR was defined as the intra-individual difference in danger ratings dependent on the presence of intrusions. Acute and chronic PTSD symptom severity scores and IR were skewed to the left and were transformed to normality, with log and square root respectively. One-tailed significance levels are reported. IR was significantly related to acute PTSD symptoms, $r(29)=.42, p=.002$, and to chronic PTSD symptoms, $r(29)=$ $.49, p=.002$, and the latter two were strongly related, $w=.65, p<.001$. The partial correlation between IR and chronic PTSD symptoms, when controlling for acute PTSD symptoms, was $r=.26, p=.09$. Stepwise multiple regression indicated that IR accounted for $24 \%$ of the variance of chronic PTSD symptoms: individuals who showed more IR at 3 weeks reported higher levels of chronic PTSD symptoms at 3 and a half months, $\beta=.49, t=2.91, p=.004, F(1,27)=8.49, p=.004$. With the addition of acute PrTSD symptom severity $(\beta=.54, t=3.22, p=.002)$, 46\% of the variance was accounted for, but the contribution of IR was no longer statistically significant $(\beta=.23$, $t=1.35, p=.09), F(2,26)=10.91, p<.001$. 

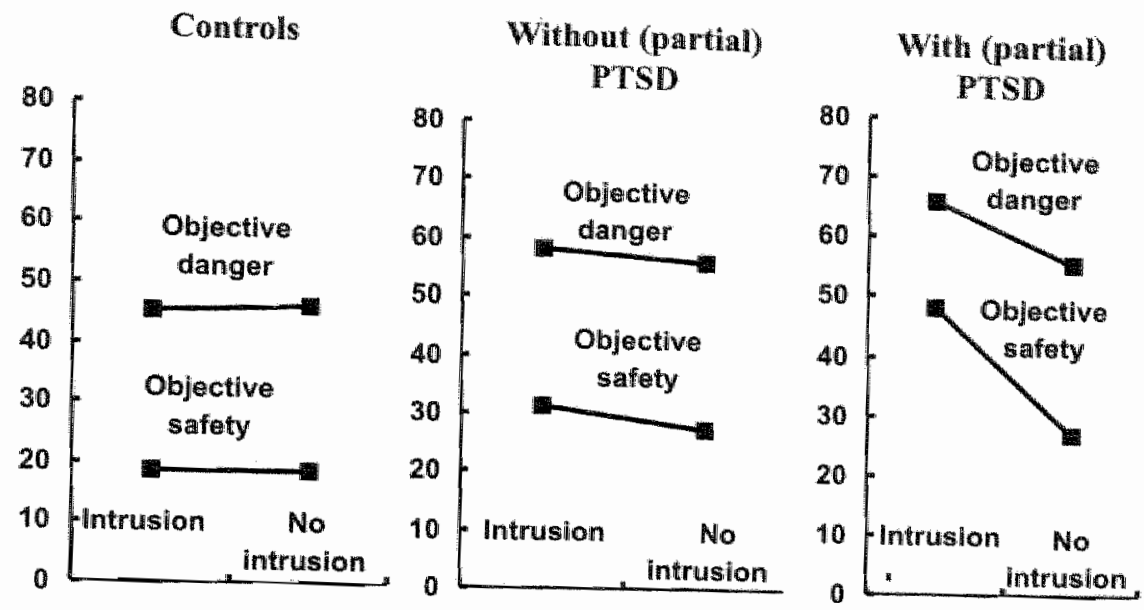

Figure 1. Danger ratings at 3 weeks, for controls and individuals with and without (partial) PTSD at 3.5 months, as a function of objective danger info. (danger vs. safety) and responses (intrusions vs, no intrusions). The IR-tendency is reffected by steeper slopes due to higher ratings on scenarios with intrusions relative to scenarios without intrusions.

\section{Discussion}

Acute and chronic PTSD symptoms were highly prevalent among residents directly exposed to the train crash. This is consistent with other studies reporting PTSD symptoms in local residents exposed to events in which others were harmed, sucla as a train collision (Chung, Werrett, Farmer, Easthope, \& Chung, 2000), an airplane crash (Chung, Easthope, Eaton, \& McHugh, 1999), and a football stadium disaster (Wright, Binney, \& Kunkler, 1994). About one-fourth of directly exposed residents had PTSD at 3.5 months, which is comparable to the $22 \%$ obtained in residents 4106 months after exposure to the Hillsborough football stadium disaster (Wright et al., 1994). Avoidance and numbing symptoms were uncommon in the present sample, possibly because residents lived nearby the scene of the crash and because a disaster affecting a small village might be more of a defining event to the community itself. Many residents stated they felt closer to others. Acute reexperiencing symtoms were common, which is consistent with studies of other traumatic events (e.g., Bryant \& Harvey, 1996: Shalev, 1992; Shalev et al., 1996).

Cognitive theorists generally agree that memory of the traumatic event tends to reappear until emotional processing has been completed (see Brewin, Dalgleish, \& 
Joseph, 1996). These symptoms mainly serve to accommodate (i.e., responding to the event with beliefs already available) and assimilate (e.g., changing prior beliefs and experiences to the event). The presence of early intrusions is often not a good predictor of PTSD (see Brewin et al., 1996; Ehlers \& Steil, 1995). What appears important, based on the work of Ehlers's group (e.g., Ehlers \& Steil, 1995; Dunmore, Clark, \& Ehlers, 2001; Ehlers et al., 1998; Steil \& Ehlers, 2000), is whether individuals interpret such symptoms themselves negatively. Our present and earlier findings (Engelhard et al., 2001; see also Arntz et al., 1995) suggest what might also be important is whether individuals interpret situations differently based on the presence of intrusions. Note that the IR phenomenon is slightly different from the catastrophic interpretations of symptoms studied by Ehlers and colleagues. By catastrophically interpreting symptoms like intrusions, such symptoms themselves are seen as predictors of harm. The present data suggest that intrusions may also serve as contextual cues (Hall \& Honey, 1994), indicating that a different stimulus predicts harm: when having intrusions about the train disaster (e.g., sight of blood, sounds of crying), the situation is held to be more dangerous relative to the absence of intrusions.

IR did not significantly contribute to chronic PTSD over and above acute PTSD symptoms, although the partial correlation was $r p=.26(p=.09)$. This might be nonsignificant due to a power problem resulting from the small sample size $(\mathbb{N}=29)$. Indeed, the strength of this association fits nicely into the range of associations reported by Ehlers's group between negative interpretations of initial PTSD symptoms themselves and chronic PTSD symptoms controlled for initial symptoms: from .10 (Ehlers et al., 1998) to .36 (Dunmore, Clark, \& Ehlers, 2001).

Besides the small sample size, another limitation of this study was that IR assessed within 1 month post-trauma might be contaminated by the development of PTSD. Acute and chronic PTSD symptoms were strongly linked, $r=65$, leaving little room in variance for other risk factors. There is also a potential limitation of the findings of the control group. If control subjects are not experiencing any intrusions, might this effect how they respond on the $\mathbb{R}$ task? More generally, is it necessary for someone to have experienced intrusions for the IR task to be a valid measure? On the other hand, the "emotion-based reasoning" (ER) effects have been reported for several anxiety disorders (spider phobia, panic disorder, and social phobia), and were not limited to disorder-specific situations (Amtz et al., 1995). Thus, just like an individual does not have to be a spider phobic to show ER with regard to spiders, one may not have to experience intrusions for the IR effect to materialize. Strengths of this study were the longitudinal design, non-clinical sample, and non-selective dropout. The suggestion that IR might play a role in the causation and maintenance of PTSD is in line with other recent findings. In a laboratory classical conditioning study with participants without psychopathology, Arntz (2001) demonstrated that participants high in ER showed greater danger expectation ratings to the CS- than did participants low in ER, whereas their danger expectations to a CS+ were comparable. In other words, participants high in ER poorly discriminated safety from danger signals. Other 
evidence for the role of ER in the causation of emotional disorders stems from clinical findings that anxiety patients high in residual $E R$ after $C B T$ had a higher risk to relapse at follow-up measurement after treatment than participants with lower ER (Arntz, 2001).

In sum, then, although the correlation of IR with chronic PTSD symptoms was attenuated by acute PTSD symptoms, the correlations of IR with both acute and chromic PTSD symptoms were quite robust and suggest a strong relationship.

\section{ACKNOWLEDGEMENTS}

We thank Fred J. Engelhard and Jean-Paul Hoton for help in getting this project started, Marian A. Ramakers-van Kuijk for assisting in the data collection, the participants for sharing their experiences, and an anonymous reviewer for helpful comments on an earlier version of this paper. This study was presented at the annual meeting (December 2001) of the International Society for Traumatic Stress Studies, New Orleans, USA.

\section{REFERENCES}

American Psychiatric Association (1994). Diagnostic and statistical manual of mental disorders ( $4^{\text {th }}$ ed.). Washington, DC: Author.

Arntz, A. (2001). Emotional reasoning and anxiety disorders. Paper presented at the World Congress of Behavioral and Cognitive Therapies, July 17-21, 2001, Vancouver.

Arntz, A., Rauner, M., \& van den Hout, M. (1995). "If I feel anxious, there must be danger": Ex-consequentia reasoning in inferring danger in anxiety disorders. Behowiour Research and Therapy, 33, 917-925.

Arntz, A., Tiesema, M., \& Kindt, M. (2001). Imaginal exposure with and without imagery rescripting as treatment of PTSD. Submitted for publication.

Bowman, M. L. (1999). Individual differences in posttraumatic distress: Problems with the DSM-IV model. Canadian Joumal of Psychiatry, 44, $21-33$.

Brewin, C.R., Dalgleish, T., \& Joseph, S. (1996). A dual representation theory of posttraumatic stress disorder. Psychological Review, 103, 670-686.

Bryant, R.A., \& Harvey, A.G. (1996). Initial post-traumatic stress responses following motor vehicle accidents. Journal of Traumatic Stress, 9, 223-234.

Carlier, I.V.E. \& Gersons, B.P.R. (1995). Partial PTSD: The issue of psychological scars and the occurrence of PTSD symptoms. Joumal of Nervous and Mental Disease, 183, 107-109.

Chung, M.C., Easthope, Y., Eaton, B., \& McHugh, C. (1999). Describing traumatic responses and distress of community residents directly and indirectly exposed to an aircraft crash. Psychiatry, 62, 125-137.

Chung, M.C., Werrett, J., Farmer, S., Easthope, Y., \& Chung, C. (2000). Responses to traumatic stress among community residents exposed to a train collision. Stress Medicine, $16,17-25$. 
Delepierre, F. (2001, March 29). Catastrophe ferroviaire. Le Soir, pp. 2, 20.

Dunmore, E., Clark, D.M., \& Ehlers, A. (2001). A prospective investigation of the role of cognitive factors in persistent posttraumatic stress disorder (PTSD) after physical or sexual assault. Behaviour Research and Therapy, 39, 1063-1084.

Ehlers, A., \& Clark, D.M. (2000). A cognitive model of posttraumatic stress disorder. Behaviour Research and Therapy, 38, 319-345.

Ehlers, A., Mayou, R.A.y \& Bryant, B. (1998). Psychological predictors of chronic posttraumatic stress disorder after motor vehicle accidents. Journal of Abnormal Psychology, 107, 508-519.

Ehlers, A., \& Steil, R. (1995). Maintenance of intrusive memories in posttraumatic stress disorder: A cognitive approach. Behovioural and Cognitive Psychorherapy, 23, $217-249$.

Engelhard, I.M., Macklin, M.L., McNally, R.J., van den Hout, M.A., \& Arntz, A. (2001). Emotion- and intrusion-based reasoning in Vietnam veterans with and without chronic posttraumatic stress disorder. Behaviour Research and Therapy, 39, $1139-1348$.

Foa, E.B., Riggs, D.S., Dancu, C.V., \& Rothbaum, B.O. (1993). Reliability and validity of a brief instrument for assessing post-traumatic stress disorder. Joumal of Traumatic Stress, 6, 459-473.

Gollin, R. (2001, March 28). Acht kilometer op het verkeerde spoor. De Volkskrant, p.5.

Hall, G., \& Honey, R.C. (1990). Context-specific conditioning in the conditionedemotional-response procedure. Journal of Experimental Psychology: Animal Behavior Processes, 16, 271-278.

March J.S. (1993). What constitutes a stressor? The "criterion A" issue. In: J.R.T. Davidson \& E.B. Foa (Eds.), Postraumatic stress disorder: DSM-IV and beyond (pp. 37-54). Washington, DC: American Psychiatric Press.

McFarlane, A.C. (2000). Posttraumatic stress disorder: A model of the longitudinal course and the role of risk factors. Jounal of Clinical Psychiatry, 61, 15-20.

McFarlane, A.C., \& Yehuda, R. (1996). Resilience, vulnerability, and the course of posttraumatic reactions. In B.A. van der Kolk, A.C. McFarlane, \& L. Weisaeth (Eds.), Traumatic stress: The effects of overwhelming experience on mind, body, and society (pp. 155-181). New York: Guilford Press.

Shalev, A.Y. (1992). Posttraumatic stress disorder among injured survivors of a terrorist attack: Predictive value of early intrusion and avoidance symptoms. Journal of Nervous and Mental Disease, 180,505-509.

Shalev, A.Y., Peri, "T., Canetti, L., \& Schreiber, S. (1996). Predictors of PTSD in injured trauma survivors: A prospective study. American Joumal of Psychiatry, 153, 219-225.

Steil, R. \& Ehlers, A. (2000). Dysfunctional meaning of posttraumatic intrusions in chronic PTSD. Behaviour Research and Therapy, 38,537-558.

Wright, J.C., Binney, V., \& Kunkler, J. (1994). Psychological distress in the local Hillsborough or 'host' community following the Hillsborough football stadium disaster. Joumal of Community and Applied Social Psychology, 4, 77-89. 


\section{PART III GENERAL DISCUSSION}

\section{The main results}

$\mathrm{T}$ he main results are discussed next. These are presented with respect to the four domains described in the introduction.

\section{The stressor}

As to the stressor, several findings are noteworthy. Striking findings were that the estimates of PTSD caseness after preeclampsia and pregnancy loss resembled that found after the train crash (about 25\%). PTSD estimates were, however, based on selfreport measures and should not be taken as full clinical diagnosis, which requires a diagnostic interview. The symptom-severity of PTSD after pregnancy loss was similar to that reported by clinical PTSD patients, but after the train crash, it was higher". PTSD subsided within months after pregnancy loss and tended to be chronic after the train crash. Furthermore, PTSD symptoms were strongly associated with depressive symptoms. Finally, objective stressor severity accounted for a small but significant portion of the variance of PTSD symptoms.

Although one may wonder if PTSD is valid after preeclampsia and pregnancy loss, there is no a priori reason to assume that it is not. The diagnostic instrument used correctly identifies $86 \%$ of PTSD cases (counting a symptom rated $\geq 1$ as present: Foa, Riggs, Dancu, \& Rothbaum, 1993), and has been previously used to generate PTSD diagnosis (e.g., Brewin, Andrews, Rose, \& Kirk, 1999; Brewin, Andrews, \& Rose, 2000a; Ehlers, Mayou, \& Bryant, 1998). Moreover, the DSM-IV criteria were used and there is a wide consensus over the utility of the PTSD concept (APA, 1994). Initially, PTSD was exclusively related to war, assault, and disasters, but it is increasingly recognized that threatening medical events may lead to the same constellation of symptoms. Recent studies documented clinical PTSD levels after HIV diagnosis (Kelly et al. 1998), myocardial infarction (Shemesh et al. 2001), spinal cord injury (Binks,

\footnotetext{
Mean PSS scores were $36.13(S D=9.29)$ at 3 weeks and $33.57(S D=8.62)$ at 3.5 months
} 
Radnitz, Moran, \& Vinciguerra, 1997), medical and surgical events (Shalev, Schreiber, Galai, \& Melmed, 1993), and breast cancer (Pitman et al., 2001). In fact, the study of Pitman and colleagues (2001) provides psychophysiological support for the proposition that breast cancer can cause PTSD. Breast cancer patients with PTSD showed significantly higher physiologic responses during recollection of their personal breast cancer experiences than did patients without the disorder. These elevated responses were comparable to PTSD patients from other events, such as military combat, terrorist attacks, and physical assault. Testing whether preeclampsia and pregnancy loss evoke psychophysiologically responsive PTSD may add objectivity to the evaluation of PTSD.

However, the nature of the stressor might determine different subtypes of the disorder. Research about this issue is scant. Studies typically report "full-blown" diagnosis or "partial" levels rather than the types and nature of symptoms. Nevertheless, there is some evidence that different subtypes of PTSD exist (Elhai, Frueh, Davis, \& Hamner, 2001). We explored this issue by testing for differences between the symptom-profiles of participants meeting the symptom-criteria for acute PTSD after pregnancy loss $(n=$ 28 ) and the train crash $(n=9)$. Obviously, this should be interpreted with great caution due to the small samples and group differences in terms of gender, education, age, and so forth. Chi ${ }^{2}$ tests showed that after the train crash, the following symptoms were more common: nightmares, reliving, physiological distress at reminders, behavioral avoidance, hypervigilance, and startle reactions, which are distinctive for PTSD (McNally, 1992). In contrast, after pregnancy loss, diminished interest, foreshortened future, and concentration problems were more common, which overlap with major depression (McNally, 1992). Although both groups comprised individuals with clinical levels of PTSD based on the same diagnostic scheme, the symptom-profiles may differ and represent a physiologically responsive and depressive subtype.

The nature of reexperiencing symptoms may also differ. For example, after road accidents, Steil and Ehlers (2000) reported that intrusive recollections manifested as visual images, sounds or smells, bodily sensations, and thoughts. After exposure to the train crash, these manifested as sounds, images, and thoughts. A stressor that poses less immediate threat, such as being diagnosed with a life-threatening illness, these may mainly manifest as ruminative thoughts. The symptoms may be accompanied by different emotions, such as anxiety or numbing (de Silva \& Marks, 1999). These issues may be clarified further if studies include the types and qualitative nature of symptoms. Are the results regarding etiological factors generalizable to other discrete events? There might be a threshold in the etiology of PTSD: some studies found risk factors that were significantly related to PTSD at low exposure levels, but lost significance at high exposure (see March, 1990; Jones \& Barlow, 1990).

Nevertheless, PTSD may follow different types of discrete events and the similarities in symptoms far outweigh the differences (Blank, 1993). This suggests that similar processes mediate between the event and disorder, regardless of the type of event. There is no a priori reason to assume that different processes are involved for different 
types of events. Our data also suggest that predictors for acute and chronic PTSD are $s$ valid across different traumatized groups. Most knowledge about correlates of PTSD symptoms comes from studies of military combat, crime, or accidents (Brewin, Andrews, \& Valentine, 2000b). These factors assessed prior to pregnancy loss predicted acute PTSD symptoms after pregnancy loss. Moreover, regarding the persistence of symptoms, the Vietnam combat and train crash studies suggest that reasoning on the basis of symptoms is important, irrespectively of their quality.

\section{Pretraumatic factors}

Regarding pretraumatic factors, we found that newroticism, prior negative life events, less emotional control, and dissociative tendencies were salient independent predictors of acute PTSD symptoms after pregnancy loss, accounting for $23 \%$ of the variance. In addition, a higher sense of coherence (SOC) predicted less PTSD symptoms, accounting for $5 \%$ of the variance.

Does neuroticism render individuals more vulnerable to PTSD symptoms? After pregnancy loss, pretrauma neuroticism indeed predicted PTSD symptoms, and particularly arousal symptoms. While this suggests that individuals high in neuroticism are more likely to develop these symptoms after pregnancy loss, this was not the case. Neuroticism was also strongly related to arousall symptoms before pregnancy loss and it did not significantly predict PTSD symptoms after controlling for these baseline symptoms. Thus, overlap in symptoms of general distress explained the relationship between neuroticism and PTSD symptoms. Measures that are just symptom-based and do not tie arousal symptoms to the trauma (e.g., the PTSD Symptom Scale, PSS-SR, M-PTSD), may assess preexisting general distress, which may be part of the characteristic level rather than being diagnostic of PTSD.

The findings suggest that individuals with a stronger $S O C$ are at a small advantage in receiving crisis support and coming to terms with pregnancy loss. However, since the pregnancy loss study was split into smaller units, it is unclear whether the $\mathrm{SOC}$ and other pretraumatic predictors are independently related to PTSD symptoms. Therefore, a regression analysis was repeated including the $\mathrm{SOC}$ and these factors. Emotional control $(\beta=-.27, t=3.21, p=.002)$, general dissociative tendencies $(\beta=.26,1=1.94$, $p=.054)$, and prior negative events $(\beta=.23, t=2.79, p=.006)$ remained indepenclent predictors of acute PTSD symptoms. However, neuroticism $(\beta=.15, t=1.40, p=.16)$ and the $\operatorname{SOC}(\beta=-.03, t=.23, p=.81)$ were no longer significant. Neuroticism and the SOC were in fact strongly related, $r=-.65, p<.001$, and appear to tap the same phenomenon.

The pregnancy loss study suggests that a range of pretraumatic factors influences the onset of PTSD, as is the case with other psychiatric disorders. Although knowledge about correlates of PTSD symptons is mainly derived from retrospective studies, this study provides support that these factors have predictive value when assessed prospectively. In the meta-analysis of mainly retrospective studies, Brewin and 
colleagues (2000b) conclude that greater social, educational, and intellectual disadvantages, psychiatric history, and prior adversity enhance the risk of PTSD reliably, with weighted average effect sizes $r$ ranging from .10 to .19 . In our study, the effect sizes $r$ for personality traits, prior adversity, and prior emotional control ranged from .23 to .25 .

\section{Peritraumatic factors}

With respect to peritranmatic dissociation, the results showed that this was predicted by previously assessed lower emotional control, greater dissociative tendencies, and lower education. Adding peritraumatic dissociation to the regression equation of pretraumatic predictors of acute PTSD symptoms, led to an increase in the variance explained, showing an independent role. However, in the prediction of PTSD at 4 months, the best predictor was PTSD at 1 month. Finally, cross-sectional analysis suggested that the relationship between peritraumatic dissociation and acute PTSD symptoms was mainly mediated by self-reported fragmented memory and thought suppression.

Individuals who perceived less emotional control and had lower education reported more peritraumatic dissociative experiences. The degree of peritraumatic dissociation was also predicted by dissociative tendencies, which was not entirely surprising given that these tendencies were measured with an adapted version of the same instrument. In other words, the same variable was used to predict itself. Surprisingly, neuroticism, prior negative events, and gestational age at the loss were non-significantly related to peritraumatic dissociation. Cross-sectional analyses also showed that peritraumatic dissociation was significantly associated with avoidance of traumatic memories, suggesting it is an early indicator for disengagement with the traumatic event.

There has been a long-standing debate as to whether memories for traumatic events differ from other experiences (see Shobe \& Kihlstrom, 1997). According to some cognitive theorists, fragmented memories of the traumatic experience serve a causal tole in the development of PTSD (e.g., Foa \& Riggs, 1993; Ehlers \& Clark, 2000). Peritraumatic dissociation is thought to cause this memory fragmentation. Traumatic memories are also thought to be different from other memories in that they contain more sensory components and higher levels of emotion. However, are trauma memories really that special? Obviously they are more emotionally evocative, but are they more fragmented? The vast majority of studies show that traumatic memories are remembered very well (Shobe \& Kihlstrom, 1997), and there is evidence that traumatic memories do not differ from other memories in terms of self-reported sensory components or objectively assessed fragmentation (e.g., Porter \& Birt, 2001). After pregnancy loss, peritraumatic dissociation was significantly associated with selfreported sensory modalities, but this was not a strong and independent predictor of PTSD symptoms. There is also a lack of evidence for the relation between peritraumatic dissociation and memory fragmentation. A problem with fragmented 
trauma memories is how they should be operationalized, that is, fragmented as compared to what? In the pregnancy loss study, we found that the degree of fragmentation as reported by the individual was associated with PTSD symptoms. However, there are serious problems in interpreting this finding. An analogue experimental study, in which participants were exposed to a stressful movie, did not observe fragmentation in actual memory performance, although a link was reported between self-reported dissociation during the movie and meta-memory fragmentation. The authors suggested that dissociation does not fragmentize actual memory, but leaves individuals with the subjective experience of fragmentation (Kindt \& van den Hout, 2002). Moreover, Gray and Lombardo (2001) showed that "fragmented" memory reports of trauma are wholly accounted for once one controls for cognitive ability. Finally, "elaboration and integration" of the traumatic memory into autobiographical memory is considered crucial in the development of PTSD. However, it is unclear what is meant by this. How can be determined when this has occurred?

The preeclampsia study showed that peritraumatic distress and dissociation independently predicted PTSD symptoms over and above objective stressor severity. which is consistent with other studies (e.g., Bernat et al., 1998; Shalev et al., 1996). Thus, extreme emotional reactions and the absence of reactions were related to PTSD symptoms. Is this a paradox? As noted by Kleber and van der Hart (1998), it is possible that extreme reactions, either in responsiveness or non-responsiveness, hinder adaptation. There are also indications that dissociative reactions and hyperarousal are related (e.g., Southwick et al., 1993), but this topic has not received much research attention.

\section{Posttraumatic factors}

Cross-sectional analyses suggested that negative appraisals of PTSD symptoms and thought suppression were significantly related to PTSD symptoms after preeclampsia. Furthermore, we found that PTSD in Vietnam combat veterans was related to the tendency to draw invalid conclusions about other situations on the basis of anxiety ("emotion-based reasoning"; ER) and intrusions ("intrusion-based reasoning"; IR). In the train crash study, we replicated these resuits in acutely traumatized individuals and also attempted to clarify the crucial issue of causality by re-assessing PTSD symptoms at 3.5 months. IR indeed predicted chronic PTSD symptoms, even after controlling for acute PTSD symptoms, but this was not statistically significant $(r p=.26, p=09)$. Furthermore, thought suppression was strongly associated with acute PTSD symptoms after pregnancy loss, but it did not predict PTSD symptoms at 4 months beyond the effects of acute symptoms. Finally, more crisis support after pregnancy loss was associated with less PTSD symptoms.

The rellation between negative appraisals of symptoms and PTSD symptoms has allso been found among other trauma victims (e.g, Dunmore, Clark, \& Ehlers, 1999). How should this relation be interpreted? According to Ehlers and Clark (2000), negative 
appraisals of postraumatic symptoms intensify PTSD. Although the actual threat of the trauma is long gone, such appraisals may continue a sense of threat, which is accompanied by distress and motivates avoidance strategies. There is empirical support for this model (see Ehlers \& Clark, 2000). Other anxiety disorders also appear to persist because individuals catastrophize the meaning of particular symptoms (e.g., Ehlers, Margraf, \& Roth, 1988), and it is of interest that current effective treatments for PTSD (Rothbaum, Meadows, Resick, \& Foy, 2000) and other anxiety disorders (e.g.. Clark et al. 1994) include components that are likely to normalize symptoms. However, if negative appraisals are critical, what causes such appraisals? As discussed by $\mathrm{McNally}$ (2001), invoking catastrophic interpretations for the causes of anxiety disorders is the beginning and not the end of inquiry.

In addition to negative appraisals of symptoms themselves, we found that the presence of anxiety or intrusions may bias the interpretation of other events. The ER bias shown by Vietnam veterans with chronic PTSD was not situation specific and was previously reported in social phobia, panic disorder, and specific phobia patients (Arntz, Rauner, van den Hout, 1995). This also draws a parallel between PTSD and other anxiety disorders in that ER may be a risk factor for developing the disorder. According to cognitive theories of anxiety disorders, distorted beliefs about danger of certain situations and/or internal stimuli maintain anxiety disorders. Studies have indeed shown that anxiety patients overestimate danger of various stimuli (Clark, 1999). Why do these beliefs persist? One maintaining process may be ER. The use of subjective reactions to discriminate between safety and danger may not be problematic in case of real threat. However, when threat is irrational, this may start a vicious circle in which subjective fear responses are used to erroneously validate thoughts of impending doom, which amplifies distress, etc. In other words, false alarms are not recognized (Jones $\&$ Barlow, 1990), and irrational beliefs are maintained (Clark, 1999). Yet PTSD is also characterized by reexperiencing the traumatic event and veterans with chronic PTSD also showed $I R$. Intrusive recollections are very common in the initial post-trauma aftermath. Appraising these as signs of impending danger may also amplify distress and render PTSD symptoms self-perpetuating. ER and IR were only modestly related and might represent two pathways that increase risk of persistent PTSD. Does the IR inclination render acutely traumatized individuals more prone to develop chronic PTSD symptoms? IR was strongly correlated with both acute and chronic PTSD symptoms, but its relationship with chronic PTSD symptoms was attenuated by acute symptoms. This may be due to the small sample size $(n=29)$ and the late first assessment ( 3 weeks post-trauma), that is, at a time when acute symptoms tended to remain chronic. Recent findings by Arntz (2001) suggest that ER and IR may increase risk for PTSD. First, ER is related to poorer discrimination between danger and safety signals in a conditioning paradigm. Second, ER is reduced by cognitive treatment for anxiety disotders, but remains stable after non-cognitive (e.g., behavioral and interpersonal) treatment. Residual $\mathbb{E}$ predicts short-term relapse beyond residual symptoms. 
Why did thought suppression at about 1 month not significantly predict PTSD symptoms at 4 months after controlling for acute PTSD symptoms? It is generally accepted that in the normal course of trauma, oscillation occurs between intrusions and cognitive avoidance, the latter presumably serving to prevent the individual from becoming overwhelmed by rauma memories (Horowitz, Wilner, Kaltreider, \& Alvarez, 1980). Shipherd and Beck (1999) found that individuals with PTSD, relative to non-PTSD traumatized controls, reported less control over trauma-related thoughts while they were instructed to temporarily suppress these thoughts. During instructed suppression, they had a low frequency of trauma-related thoughts, but subsequently, when they were allowed to think about anything, they had a drastic increase in the frequency of trauma-related thoughts. Non-PTSD traumatized controls, in contrast, reported high control over thoughts during instructed suppression and did not experience such a rebound of to be suppressed thoughts. In general, individuals differ in how successful they suppress thoughts (Merckelbach, Muris, van den Hout, \& de Jong, 1991). Possibly, perceived uncontrollability over intrusions and the extent to which suppression of initial intrusions does not last predisposes to chronic PTSD symptoms.

Crisis support, particularly confiding in others and not being let down, was associated with less PTSD symptoms after pregnancy loss. Although it cannot be ruled out that PTSD symptom severity influenced the degree of crisis support (e.g., sociall withdrawal is a PTSD symptom), there is evidence for the protective role of social support (loseph, 1999). Although emotional support (e.g." confiding, receiving information and guidance) was associated with less PTSD symptoms after pregnancy loss, other aspects of support (e.g., practical support, such as material resources and financial aid) may also be beneficial, depending on the impact of the event (Joseph, 1999).

In our longitudinal studies, the effect sizes $y^{*}$ of peritraumatic dissociation, crisis support, and IR on acute PTSD symptoms ranged from .26 10.42. This is consistent with Brewin et al. (2000b) who concluded that factors during or after the trauma show somewhat larger effects on PTSD symptoms, ranging from .23 to 40 , relative to pretraumatic factors.

\section{FUTURE RESEARCH}

There are several areas of interest for future research. To begin with, what is the cohesiveness of the stressor criterion in different traumatized populations? Can PTSD result from events that do not involve threat (e.g, events that primarily pertain to loss)? How does a broadened criterion (i.e., defined by subjective interpretation) affect the heterogeneity in symptoms and the distinction between PTSD and other disorders? More studies are needed of low magnitude events that address the qualitative and quantitative factors related to PTSD phenomenology.

The currently accepted view is that the similarities of trama-responses outweigh the differences. However, the time has come to focus on the differences between different 
groups of trauma victims. Knowledge is scant with regard to the qualitative nature of acute and chronic reactions for different groups and the course of reactions in the immediate post-trauma period. Future studies should include the types and nature of symptoms, and not just "full-blown" diagnosis or "partial" levels. The nature of the stressor might determine subtypes of PTSD. According to O'Donohue and Elliott (1990), subtyping by precipitating event may produce more homogeneous classes.

PTSD is conceptualized by the DSM-IV as a stressor-driven disorder. Accordingly, it is important to distinguish symptoms that originated before and after the stressor, which can be difficult. After the train crash, avoidance and numbing symptoms were scarce. This was previously reported after other large-scale disasters, and may be due to media exposure, community cohesion, and the location of participants" homes (along the crash site). It may also be difficult to operationalize some of these symptoms, because individuals may not be aware of their avoidance behavior (Solomon \& Canino" 1990), and these symptoms may develop later. Nonetheless, the requirement of at least three avoidance / numbing symptoms may exclude individuals from treatment who need it. The effects of varying the required number of avoidance symptoms after a large-scale trauma needs further study. Likewise, little is known about the positive effects of avoidance in the acute trauma phase. Acute trauma interventions often show adverse effects and one explanation for this is that they hinder initial avoidance, which may be adaptive (Rose \& Bisson, 1998). After large-scale trauma, there are limited opportunities to avoid memories of the event. When and for whom are avoidance strategies functional? What are the boundaries between functional and dysfunctional avoidance?

With respect to vulnerability and resilience factors, the challenge is to take account of factors at different time points. Although the longitudinal course of PTSD needs to be understood as a process, few researchers differentiate factors involved in the onset and persistence of the disorder. It is also unclear whether vulnerability and resilience factors for PTSD symptoms reflect specific factors for PTSD or general predispositions to other stress-induced disorders. Furthermore, the combined effect of several factors should be studied. Theoretical orientation may lead to the focus on one facet, but this may prove immature hypotheses. Finally, given that some individuals do not recover from their initial symptoms, it is important to identify individuals at risk for PTSD and in need of clinical intervention. There are indications that early cognitive behavioral interventions of individuals with acute stress disorder reduce chronic PTSD (Bryant, Sackville, Dang, Moulds, \& Guthrie, 1999). Future research is needed to test whether the efticacy increases when individuals-at-risk are treated. Ironically, the longer PTSD persists, the less relevant the original trauma comes to be in terms of explaining symptoms. That is, the more justifiable the diagnosis is (persisting symptoms long after the stressor is gone), the less justifiably it can be called posttraumatic stress disorder. In summary, the empirical studies show that PTSD is not an inevitable outcome of preeclampsia, pregnancy loss, and exposure to a train crash. Even if the DSM-IV subjective stressor criteria are met, only a minority develops clinical levels of the 
disorder, which is typically in the acute post-trauma phase. The course varies by the type of traumatic event and is determined by the intensity of acute symptoms. Alter pregnancy loss, clinical PTSD levels subside within months, and after exposure to a train cnash, they tend to be chronic PTSD symptoms are also significantly related to depressive symptoms. Moreover, independently of objective indicators of stressormagnitude, pretraumatic factors and peritrammatic reactions have predictive power in determining the onset of PTSD symptoms, which suggests that the stressor may trigger rather than cause PTSD, given sufficient vulnerability is present. The findings also suggest that neuroticism may exacerbate PTSD, and that symptom-based measures tap arousal symptoms that were present before trauma. Furthermore, persistent PTSD appears characterized by a reasoning bias, in which inferences about external situations are made on the basis of subjective emotional experiences. This tendency is also characteristic of other anxiety patients, and is not situation specific. A similar tendency, based on PTSD intrusions, shows a robust relationship with the severity of both acute and chronic PTSD symptoms. These tendencies might be risk or maintaining factors for the disorder. The precise psychological process involved in the transformation of a traumatic experience into PTSD remains to be identified. Clearly, a theory or model should incorporate the rapidly cumulating empirical studies and it is the scientific process that must provide the establishment of PTSD in psychiatric nosology.

\section{REFERENCES}

American Psychiatric Association (1994). Diagnostic and statistical mantual of mental disorders (4 ed.). Washington, DC: Author.

Arntz, A. (2001). Emorional reasoning and anxien disorders. Paper presented at the World Congress of Behavioral and Cognitive Therapies, July 17-21, 2001, Vancouver.

Arntz, A., Rauner, M., van den Hout, M. (1995). "If I feel anxious, there must be danger": Ex-consequentia reasoning in inferring danger in anxiety disorders. Behaviow Research and Therapy, 33,917-925.

Bemat, J.A., Ronfeldt, H.M., Calhoun, K.S., \& Arias, I. (1998). Prevalence of traumatic events and peritramatic predictors of postraumatic stress symptoms in a nonclinical sample of college students. Joumal of Trawnatic Stress" $1 /, 645-664$.

Binks, T.M., Radnitz, C.L., Moran, A.l., \& Vinciguerra, V. (1997). Relationship between level of spinal cord injury and posttraumatic stress disorder symptoms. Annals of New York Academy of Sciences, $821,430-432$.

Blank, A.S. (1993). The longitudinal course of posttraumatic stress disorder. In; J.R.T. Davidson \& E.B. Foa (Eds.), Postrammatic stress disorder: DSM-IV and beyond (pp. 3-22). Washington, DC: American Psychiatric Press.

Brewin, C.R., Andrews, B., \& Rose, S. (2000a). Fear, helplessness, and horror in postraumatic stress disorder: investigating DSM-IV criterion $A 2$ in victims of violent crime. Journal of Traumatic Stress, 13,499-509. 
Brewin, C.R., Andrews, B., Rose, S., \& Kirk, M. (1999). Acute stress disorder and posttraumatic stress disorder in victims of violent crime. American Joumal of Psychiatry, 156, 360-366.

Brewin, C.R., Andrews, $\mathbb{B} .$, \& Valentine, J.D. (2000b). Meta-analysis of risk factors for posttraumatic stress disorder in trauma-exposed adults. Joumal of Consulting and Clinical Psychology, 68, 748-766.

Bryant, R.A., Sackville, T., Dang, S.T., Moulds, M., \& Guthrie, R. (1999). Treating acute stress disorder: An evaluation of cognitive behavior therapy and supportive counseling techniques. American Journal of Psychiatry, 156, 1780-1786.

Clark, D.M. (1999). Anxiety disorders: why they persist and how to treat them. Behaviour Research and Therapy, 37, S5-S27.

Clark, D.M., Salkovskis, P.M., Hackmann, A., et al. (1994). A comparison of cognitive therapy, applied rellaxation and imipramine in the treatment of panic disorder. British Journal of Psychiatry, 164, 759-769.

de Silva, P., \& Marks, M. (1999). Intrusive thinking in posttraumatic stress disorder. In W. Yule (Ed.), Post ramatic stress disorders (pp. 161-175). New York: Wiley \& Sons.

Dunmore, E., Clark, D.M., \& Ehlers, A. (1999). Cognitive factors involved in the onset and maintenance of posttraumatic stress disorder (PTSD) after physical or sexual assault. Behaviour Research and Therapy, 37, 809-829.

Ehlers, A., \& Clark, D.M. (2000). A cognitive model of posttraumatic stress disorder. Behavioum Research and Therapy, 38, 319-345.

Ehlers, A., Margraf, J., Roth, W.T., et al. (1988). Anxiety induced by false heart rate feedback in patients with panic disorder. Behaviour Research and Therapy, 26, 1-11.

Ehlers, A., Mayou, R.A., \& Bryant, B. (1998). Psychological predictors of chronic postraumatic stress disorder after motor vehicle accidents. Joumal of Abnormal Psychology, 107, 508-519.

Elhai, J.D., Frueh, C., Davis, J.L., \& Hamner, M.B. (2001). Subtypes of MMPl-2 symptom patrems in combat veterans with PTSD. Paper presented at the annual meeting of the International Society for Traumatic Stress Studies, New Orleans.

Foa, E.B., \& Riggs, D.S. (1993). Posttramatic stress disorder and rape. In J. Oldham, M.B. Riba, \& A. Tasman (Eds.). Ammual review of psychiary, Vol. 12 (pp. 273303). Washington DC: American Psychiatric Association.

Foa, E.B., Riggs, D.S., Dancu, C.V., \& Rothbaum, B.O. (1993). Reliability and validity of a brief instrument for assessing post-traumatic stress disorder. Joumal of Tranmaric Srress, 6, 459-473.

Gray, M.J., \& Lombardo, T.W. (2001). Complexity of trauma narratives as an index of fragnented memory in PTSD: A critical analysis. Applied Cognitive Psychology, 15, $\mathrm{S} 171-\mathrm{S} 186$.

Horowitz, M.J., Wilner, N.R., Kaltreider, N.B., \& Alvarez, W. (1980). Signs and symptoms of posttraumatic stress disorder. Archives of General Psychiatry, 37, 85-92.

Jones, J.C., \& Barlow, D.H. (1990). The etiology of posttraumatic stress disorder. Clinical Psychology Review, 10, 299-328. 
Joseph, S. (1999). Social support and mental health following trauma. In W. Yule (Ed.), Post-tramatic stress disorders (pp. 71-91). New York: Wiley \& Sons.

Kelly, B., Raphael, B., Judd, F, et al. (1998). Posttraumatic stress disorder in response to HIV infection. General Hospital Psychiatry, 20, 345-352.

Kindt, M., \& van den Hout, M.A. (2002). Dissociation and memory fragmentation: Experimental effects on meta-memory but not on actual memory performance. Behaiour Research and Therapy, in press.

Kleber, R., \& van der Hart, O. (1998). Peritraumatische dissociatie: Acute reacties op schokkende gebeurtenissen en hun gevolgen. Directieve Therapie, 18, 340-355.

March, J.S. (1990). The nosology of posttraumatic stress disorder. Joumal of Anxiety: Disorders, 4, 61-82.

McNally, R.J. (2001). On the scientific status of cognitive appraisal models of anxiety disorder. Behaviour Research and Therapy, 39, 513-521.

McNally, R.J. (1992). Psychopathology of posttraumatic stress disorder (PTSD): Boundaries of the syndrome. In M. Başoğlu (Ed.), Torture and its consequences: Current treatment approaches (pp. 229-252). Cambridge: CUP.

Merckelbach, H., Muris, P., van den Hout, M., \& de Jong, P. (1991). Rebound effects of thought suppression: Instruction-dependent? Behowioumal Psychotherapy, 19, 225238.

O'Donohue, W., \& Eliott, A. (1990). The current status of post-traumatic stress disorder as a diagnostic category: Problems and proposals. Jounal of Traumatic Stress, 5, 421-439.

Rothbaum, B.O., Meadows, E.A., Resick, P.A., \& Foy, D.W. (2000). Cognitive behavioral therapy. In E.B. Foa, T.M. Keane, \& M.J. Friedman (Eds.), Effective treatments for PTSD (p. 60-83). New York: Guilford Press.

Pitman, R.K., Lanes, D.M., Williston, S.K., et al. (2001). Psychophysiologic assessment of posttraumatic stress disorder in breast cancer patients. Psychosomatics, 42, 133-140.

Porter, S., \& Birt, A.R. (2001). Is traumatic memory is special? A comparison of traumatic memory characteristics with memory for other emotional life experiences. Applied Cognitive Psychology, 15, S101-S117.

Rose, S., \& Bisson, J. (1998). Brief early psychological interventions following trauma: A systematic review of the literature. Journal of Traumatic Stress, 11, 697-710.

Shalev, A.Y., Peri, T., Canetti, L., \& Schreiber, S. (1996). Predictors of PTSD in injured trauma survivors: A prospective study. American Journal of Psychiatry, 153, 21. 225 .

Shallev, A.Y., Schreiber, S., Galai, T., \& Melmed, R.N. (1993). Post-traumatic stress disorder following medical events. British Journal of Clinical Psychology, 32, 247 . 253.

Shemesh, E, Rudnick, A., Kaluski, E., et al (2001). A prospective study of posttraumatic stress symptoms and nonadherence in survivors of a myocardial infarction (MI). General Hospital Psychiatry, 23, 215-222. 
Shipherd, J.C., \& Beck, J.G. (1999). The effects of suppressing trauma-related thoughts on women with rape-related posttraumatic stress disorder. Behaviour Research and Therapy, 37, 99-112.

Shobe, K.K., \& Kihlstrom, J.F. (1997). Is traumatic memory special? Current directions in psychological science, 6, 70-74.

Solomon, S.D., \& Canino, G.J. (1990). Appropriateness of DSM-III-R criteria for postraumatic stress disorder. Comprehensive Psychiatry, 31, 227-237.

Southwick, S.M., Krystal, J.H., Morgan, A., Johnson, D., Nagy, L.M., Nicolaou, A., Heninger, G.R., \& Charney, D.S. (1993). Abnormal noradrenergic function in posttraumatic stress disorder. Archives of General Psychiatry, 50, 266-274.

Steil, R. \& Ehlers, A. (2000). Dysfunctional meaning of posttraumatic intrusions in chronic PTSD. Behaviour Research and Therapy, 38, 537-558.

Yehuda, R., \& McFarlane, A.C. (1995). Conflict between current knowledge about posttraumatic stress disorder and its original conceptual basis. American Joumal of Psychiatry, 152, 1705-1713. 


\title{
Samenvatting / Dutch summary
}

\author{
Beschermende en KWEtsbaarheidsfactoren voor het RISico op Post- \\ TRAUMATISCHE STRESS STOORNIS
}

$\mathrm{I}$

1980 werd posttraumatische stress stoornis (PTSS) formeel opgenomen als angststoornis in de psychiatrische diagnostiek (APA, 1980) en gedefinieerd als karakteristieke symptomen die volgen op een traumatische gebeurtenis. Dit was mede een gevolg van sociale en politieke ontwikkelingen van de jaren $70.0 \mathrm{~m}$ aan de huidige PTSS-criteria (APA, 1994) te voldoen, moet sprake zijn van blootstelling aan of getuige zijn van feitelijke of dreigende dood, ernstig letsel of bedreiging van de fysieke integriteit. Bovendien dient de persoon hierop te reageren met intense angst, hulpeloosheid of afgrijzen. De karakteristieke symptomen zijn (1) voortdurende herbelevingen van de gebeurtenis (bv. intrusieve onaangename herinneringen, nachtmerries), (2) aanhoudende vermijding van de betreffende herinneringen/ emotionele afstomping (bw. vermijding van gedachten en gevoelens, verminderde belangstelling) en (3) verhoogde prikkelbaarheid (bv. slaapproblemen, irritaties, overdreven schrikreacties). De diagnose wordt gesteld indien van elk cluster een bepaald minimum van symptomen ten minste één maand aanhoudt en aanzienlijk lijden veroorzaakt. Van acute PTSS spreekt men wanneer de duur korter is dan drie naanden; van chronische PTSS indien deze langer is.

PTSS is eén van de weinige psychiatrische stoornissen met een etiologische factor in de criteria, hetgeen suggereert dat de etiologie van de stoornis bekend is. Sinds 1980 hebben echter vele studies aangetoond dat slechts een minderheid van getraumatiseerde individuen PTSS ontwikkeit. Bovendien blijkt dat acute PTSS niet voor iedereen een chronisch verloop heef. Welke mechanismen verklaren het ontstaan en de instandhouding van PTSS-symptomen?

Een invloedrijke wetenschappelijke verklaring hiervoor wordt geboden door de cognitieve theorie van PTSS, zoals beschreven door met name Foa en Riggs (1993) en Ehlers en Clark (2000). Volgens deze opvattingen is de traumatische gebeurtenis onverenigbaar met bestaande "veiligheidsschema's" (vanzelfsprekendheden), die iemand gedurende het leven verworven heeft (bv. de wereld is betekenisvol, anderen zj.jn te vertrouwen, nare gebeurtenissen overkomen alleen anderen), hetgeen een gevoel van dreiging teweeg brengt. Pogingen de gebeurtenis te integreren in de bestaande 
netwerken zouden zich manifesteren als herbelevingssymptomen, die kort na de gebeurtenis deel uitmaken van een normaal verwerkingsproces. Vermijdingsstrategieën zouden dit process belemmeren. De traumatische gebeurtenis zou ook bestaande "gevaarsschema"s" kunnen activeren (bv. de wereld is gevaarlijk, de persoon is zelf kwetsbaar), hetgeen eveneens een gevoel van dreiging veroorzaakt. Individuen met extreem rigide schema's zouden meer moeite hebben om een traumatische gebeurtenis te verwerken. Ook wordt veronderstell dat traumatische herinneringen kwalitatief anders zijn dan andere herinneringen. Het geheugennetwerk van de traumatische gebeurtenis zou gekenmerkt worden door een ruimere omvang, meer desorganisatie, fragmentatie en intensere reacties. Naarmate deze kenmerken sterker zijn, zou de integratie van de herinneringen in de context van andere ervaringen moeilijker zijn. Tenslotte is de rol van gedachten en interpretaties in de acute posttrauma periode benadrukt. PTSS-symptomen zouden in stand worden gehouden doordat deze geïnterpreteerd worden als voorbode van een op handen zijnde catastrofe (bijvoorbeeld "deze symptomen betekenen dat ik gek ben aan het worden"), waardoor de angst en vermijdingsstrategieën worden versterkt. Kortom, volgens Ehlers en Clark (2000) vereist het herstel van een traumatische ervaring: (1) elaboratie en integratie van de traumatische herinneringen in de context van andere ervaringen, (2) modificatie van negatieve interpretaties van (de gevolgen van) het trauma en (3) vermindering van vermijdingsstrategieën. Hoe passen beschermende en kwetsbaarheidsfactoren voor PTSS-symptomen in dit model?

Cognitieve theorie voorspelt welke condities leiden tot acute PTSS-, chronische PTSSsymptomen en tot herstel. Dit proefschrift omvat een aantal empirische studies naar beschermende en kwetsbaarheidsfactoren voor PTSS-symptomen, die overeenkomstig zijn met deze theorie. Na een inleidend eerste deel, worden in het tweede deel de studies gepresenteerd. Deze studies omvatten verschillende onderzoeksgroepen en vraagstukken, betreffende de traumatische gebeurtenis, pretraumatische factoren, peritraumatische factoren en posttraumatische factoren.

Karakteristieke traumatische gebeurtenissen impliceren een dreiging die extern van het individu is, zoals geweld, rampen en ongevallen. Volgens de cognitieve theorie kan PTSS ook ontstaan na andere ernstige incidenten. Hoofdstuk 1 omvat een retrospectieve, exploratieve studie die verricht werd naar PTSS na preeclampsie. Preeclampsie is een ziekte die 6 tot $8 \%$ van zwangerschappen compliceert (van Beek \& Peeters, 1998). De klinische symptomen treden vaak onverwacht op en ontwikkelen zich meestal in de tweede helft van de zwangerschap. De symptomen kunnen zeer ernstig zijn voor de moeder (bv. aanzienlijk verhoogde bloeddruk), maar ook voor de ongeboren baby, die vaak in gevaar is door bijbehorende ontoereikendheid van de placenta. Via vragenlijsten werd onderzocht of preeclampsie kan leiden tot PTSS. De deelnemers waren vrouwen die in de voorafgaande twee jaren een ziekenhuisopname hadden voor preeclampsie, vroeggeboorte of een normale bevalling. De meeste van hun partners deden ook mee. Hoofdstuk 2 betreft een prospectieve studie naar PTSSsymptomen na zwangerschapsverlies. Uitzonderlijk aan dit onderzoek was dat het de 
mogelijkheid gaf pretraumatische factoren te meten vóndat de traumatische gebeurtenis plaatswond. Bovendien konden de longitudinale gevolgen van een discrete, relatief homogene, gebeurtenis worden gemeten. In advertenties werden zwangere vrouwen met een zwangerschapsduur korter dan 12 weken opgeroepen mee te doen aan een onderzoek naar de beleving van de zwangerschap. Onmiddelijk na de aanmelding ontvingen de deelnemers de eerste vragenlijsten. Twintig en 30 weken in de zwangerschap en één maand na de verwachte geboortedatum ontvingen zij korte, algemene vragenlijsten waarin ook werd gevraagd naar een eventuele miskraam of doodgeboorte. Deelnemers die dit hadden meegemaakt, werden vervolgens gebeld en gevraagd om mee te doen aan vervolgonderzoek. De meesten van hen vulden ongeveer één maand en vier maanden na het verlies een vragenlijst in over PTSS-klachten en andere factoren. Hoofdstuk 2 presenteert de prevalentie van PTSS na zwangerschapsverlies. Andere vraagstukken van deze studie zijn beschreven in latere hoofdstukken (hoofstuk 3, 4 en 5). Opvallend was dat de schatting van acute PTSS na vroege preeclampsie en zwangerschapsverlies ongeveer $25 \%$ was. De ernst van de symptomen van PTSS na zwangerschapsverlies vertoonde gelijkenis met een klinische PTSS-populatie. De symptomen namen binnen vier maanden na het verlies sterk af. De bevindingen suggereren dat. PTSS kan volgen op deze medische complicaties. Ook werd de voorspellende waarde onderzocht van objectieve en subjectieve indicatoren van de ernst van het trauma. Objectieve indicatoren (bv. zwangerschapsduur) voorspelden een klein deel van de variantie van symptomen. De subjectieve indicatoren (peritraumatische reacties) waren belangrijker.

Volgens de cognitieve theorie zijn negatieve attributies over de effecten van de traumatische gebeurtenis cruciaal bij het ontwikkelen van PTSS-symptomen, zoals vroege PTSS-Symptomen negatief interpreteren en andere gebeurtenissen als gevaarlijker beschouwen. Neuroticisme is een stabiele persoonlijkheidstrek, die bestaat uit de gegeneraliseerde neiging om zichzelf en de wereld negatief te interpreteren (Watson \& Pennebaker, 1989). Volgens de theorie vergroot neuroticisme het risico op PTSS-symptomen. Een verband tussen deze factoren is inderdaad gevonden in dwarsdoorsnede onderzoeken (Bowman, 1999). De aard van dit verband is echter onduidelijk: neuroticisme zou een voorspeller kumnen zijn van PTSS-klachten, hoewel neuroticisme ook verhoogd kan zijn na een trauma (Reich, Noyes, Coryell, \& O'Gorman, 1986). Bovendien is er een andere mogelijke verklaring. Symptomen van verhoogde prikkelbaarheid zijn niet alleen kenmerkend voor PTSS maar ook voor neuroticisme. Wellicht hebben mensen met een hogere mate van neuroticisme voorafgaand aan het trauma meer symptomen van verhoogde prikkelbaarheid en is de toename van deze klachten onafhankelijk van neuroticisme. Ofwel, het verband tussen neuroticisme en PTSS-symptomen zou verklaard kunnen worden door overlappende symptomen. In hoofdstuk 3 worden beide verklaringen onderzocht in de prospectieve zwangerschapsstudie. In de vroege zwangerschap werden neuroticisme en pretraumatische prikkelbaarheid gemeten als voorspellers van PTSS-symptomen na een zwangerschapsverlies. Neuroticisme voorspelde inderdaad PTSS-symptomen, met 
name de symptomen van verhoogde prikkelbaarheid. Neuroticisme hing echter ook sterk samen met deze symptomen vóor het zwangerschapsverlies. $\mathrm{Na}$ statistische controle op pretraumatische symptomen was het verband tussen neuroticisme en PTSSklachten niet meer significant. Met andere woorden, neuroticisme was geen voorspeller van een toename van deze symptomen ten gevolge van het zwangerschapswerlies. Dit suggereert dat overlap in symptomen de relatie tussen neuroticisme en PTSSsymptomen verklaart.

Cognitieve theorie woorspelt dat de integratie van traumatische gebeurtenissen deels afhangt wan de kwaliteit van de herinneringen, die mede bepaald wordt door de kwaliteit van peritraumatische codering in het geheugen. Peritraumatische dissociatie omvat veranderingen in de functies van geheugen, identiteit en bewustzijn die gewoonlijk geïntegreerd zijn (Marmar, Weiss, \& Metzler, 1997). Volgens de theorie resulteert het in gefragmenteerde herinneringen. Peritraumatische dissociatie is inderdaad én van de sterkste predictoren van PTSS-symptomen (Marmar et al., 1997). Er is echter geen empirisch bewijs dat peritraumatische dissociatie verband houdt met geheugenfragmentatie. Peritraumatische dissociatie zou eveneens een vroege voorloper kunnen zijn van vermijding van de gebeurtenis. Hoofdstuk 4 betreft de prospectieve zwangerschapsstudie, waarin onderzocht werd of de relatie tussen peritraumatische dissociatie en PTSS-symptomen na zwangerschapsverlies werd gemedieerd door geheugenkenmerken (zoals fragmentatie) of vermijding van traumatische herinneringen. Tevens werden pretraumatische predictoren van peritraumatische dissociatie en PTSS-symptomen bestudeerd. Hieruit bleek dat peritraumatische dissociatie werd voorspeld door minder controle over emoties, meer algemene dissociatie en cen lagere opleiding. Acute PTSS-symptomen werden voorspeld door eerdere negatieve gebeurtenissen, minder emotionele controle en meer algemene dissociatie. Door toevoeging van peritraumatische dissociatie aan deze predictoren werd meer variantie van acute PTSS-symptomen verklaard, hetgeen een onafhankelijke rol suggereert. Volgens dwarsdoorsnede analyses werd het verband tussen peritraumatische dissociatie en acute PTSS-symptomen gemedieerd door zelfgerapporteerde geheugenfragmentatie en vermijding van herinneringen.

De factoren die volgens Ehlers en Clark (2000) leiden tot herstel van de traumatische gebeurtenis tonen een gelijkenis met het "sense of coherence" concept (SOC). Antonovsky (1987) definieerde de SOC als het vermogen om een ingrijpende gebeurtenis als begrijpelijk, controleerbaar en betekenisvol te beschouwen. Mensen met een hoge SOC zouden beter in staat zijn om geschikte hulpmiddelen zoals sociale steun te selecteren en mobiliseren om dergelijke ervaringen te verwerken. Een hoge SOC zou derhalve beschermen tegen PTSS-klachten. Retrospectieve studies bieden steun voor deze hypothese (bv. Frommberger et al., 1998). De interpretatie van dit verband is echter lastig doordat de SOC beïnloed kan worden door een traumatische gebeurtenis (Geyer, 1997). In de prospectieve zwangerschapsstudie werd de SOC gemeten vóór het zwangerschapswerlies en onderzocht werd of de SOC de mobilisatie van crisissteun na het verlies voorspelt. Hoofdstuk 5 rapporteert de bevindingen. Een 
hoge SOC had een bescheiden voorspellende waarde in de mate van crisissteun. Beide factoren hingen samen met minder PTSS-symptomen. De SOC hing echter ook sterk samen met neuroticisme en was geen onafhankelijke predictor van PTSS-klachten.

Tenslotte voorspelt cognitieve theorie dat de instandhouding van PTSS-klachten wordt bepaald door de wijze waarop individuen gevolgen van het trauma interpreteren. Negatieve interpretaties (bijvoorbeeld 'deze symptomen betekenen dat ik nooit meer dezelfde zal zijn") versterken angst en vermijdingsstrategieën. Dit model komt overeen met cognitieve modellen van andere angststoornissen, in die zin dat de stoornis blijft bestaan doordat individuen de betekenis van bepaalde symptomen catastroferen (Clark, 1999). Er zijn aanwijzingen dat andere angsipatiënten tevens onjuiste conclusies trekken over situaties op grond van informatie over angstreacties. Dat wil zeggen: zij gebruiken angstgerelateerde informatie om verkeerde gevolgtrekkingen te maken over ophanden zijnd gevaar (Amtz, Rauner, \& van den Hout, 1995). Deze "emotion-based reasoning" (ER) neiging was niet situatiespecifiek en zou symptomen in stand kunnen houden door angst te vergroten, vermijding te versterken en te motiveren om selectief op zoek te gaan naar gevaarsbevestigende informatie. Het is onduidelijk of PTSSpatiënten deze neiging ook vertonen. Analoog aan ER kan gevaar ook worden afgeleid uit de aanwezigheid van PTSS-gerelateerde intrusies: "intrusion-based reasoning" (IR), Als deze neiging inderdaad gerelateerd is aan PTSS, is het de vraag of het de instandhouding van symptomen voorspelt. Hoofdstuk 6 beschrifft een dwarsdoorsnede onderzoek, waarin onderzocht werd of Vietnamveteranen met chronische PTSS de ERneiging (die bij andere angstpatiënten is gevonden) en tevens de IR-neiging vertonen. Om de effecten van traumablootstelling te controleren, werden zij vergelekem met Vietnamveteranen zonder PTSS. De resultaten tonen aan dat Vietnamveteranen met PTSS onjuiste conclusies trokken over situaties op grond van informatie over angstreacties. Dit laat een parallel zien tussen PTSS en andere angststoornissen, in die zin dat ER een risicofactor zou kunnen zijn voor het ontwikkelen van de stoomis. PTSS wordt echter ook gekenmerkt door intrusieve herinneringen; veteranen met PTSS vertoonden ook IR. Intrusieve herimneringen komen veel voor kort na het trauma. Als deze worden geïnterpreteerd als aanstaand gevaar zou dit angst vergroten en PTSSsymptomen instand houden. Hoofdstuk 7 presenteert een longitudinale studie die verricht werd onder acuut-getraumatiseerde getuigen van de treinramp die op 27 maart 2001 plaatsvond in Pécrot, België. Hierbij werd getracht om de cruciale causaliteitskwestie met betrekking tot IR te verduidelijken. Bestudeerd werd of $I R$ een rol speelt bij de transitie van acute naar chronische PTSS-symptomen. Bij getuigen van de ramp werden ongeveer drie weken na de ramp IR en PTSS-klachten gemeten. $\mathrm{Na}$ drie en een halve maand werden PTSS-klachten opnieuw gemeten (de prevalentie van PTSS was overigens 24\%). De resultaten van de Vietnamveteranen werden gerepliceerd bij acuut-getraumatiseerden. IR voorspelde tevens chronische PTSSklachten, zelfs na controle op acute PTSS-klachten maar dit was niet statistisch significant. De bevindingen suggereren dat IR betrokken is bij het ontstaan en de 
instandhouding van PTSS-symptomen. Meer duidelijkheid over causaliteit kan echter pas verkregen worden na vervolgonderzoek.

Kortom, de empirische studies tonen aan dat PTSS geen onontkoombaar gevolg is van preeclampsie, zwangerschapswerlies en getuige zijn van de treinramp. Zelfs wanneer aan het DSM-IV traumacriterum is voldaan, ontwikkelt slechts een minderheid de stoomis. Het verloop verschilde per gebeurtenis en werd mede bepaald door de ernst van acute PTSS-klachten. De symptomen namen na zwangerschapsverlies binnen een paar maanden af en waren meer chronisch na de treinramp. Onafhankelijk van objectieve indicatoren van de ernst van het trauma verklaarden pretraumatische en peritraumatische factoren het ontstaan van PTSS-klachten, hetgeen de rol van andere factoren dan de gebeurtenis benadrukt. De bevindingen suggereren dat neuroticisme en PTSS overlappende symptomen hebben. Meetinstrumenten voor PTSS die klachten van prikkelbaarheid niet koppelen aan de traumatische gebeurtenis, kunnen klachten meten die reeds voor het trauma aanwezig waren. Bovendien bleek dat chronische PTSS in verband stond met een redeneerneiging waarbij gevolgtrekkingen over externe situaties worden gemaakt op grond van subjectieve emotionele ervaringen. Deze neiging is ook kenmerkend voor andere angstpatiënten en is niet situatiespecifiek. Een soortgelijke neiging, op grond van PTSS-intrusies, toonde een sterke relatie met acute en chronische PTSS-symptomen. Deze neigingen kunnen risicofactoren zijn voor het ontstaan of de instandhouding van PTSS. Het exacte psychologische proces dat verantwoordelijk is voor de transformatie van een traumatische gebeurtenis naar PTSS moet nog geïdentificeerd worden. PTSS werd mede erkend ten gevolge van sociale en politieke ontwikkelingen; het wetenschappelijke proces dient zorg te dragen voor plaatsing in de psychiatrische classificatie en theorievorming. 


\section{Dankwoord / Acknowledgments}

$\mathrm{D}^{\mathrm{i}}$ it proefschrift kwam mede dankzij de hulp van anderen tot stand. Sommigen wil ik met name noemen. I especially thank professors Marcel A. var den Hout and Richard J. McNally for their intellectual and emotional advise and support. It has been enriching, both professionally and personally, to be mentored by two experts, who are helpful, quick with comments, enthusiastic, and lots of fin to be around. I look forward to our continued collaboration. Marianne Cuisinier, Annette Heffels en Renate Kuiper bedank ik voor hulp bij de zwangerschapstudie. Mike Macklin, Scott Orr, and Roger Pitman, I thank for their support and help with the subject recruitment of the Vietnam combat study. I am grateful to the Netherlands America Commission for Educational Exchange (NACEE) for backing my stay at Harvard University with a Fulbright scholarship. L'étude sur la catastrophe de Pécrot n'aurait pas été possible sans l'aide de deux personnes: dr. Jean-Paul Hoton, qui je remercie pour sa confrance, Marian Ramakers-van Kuijk bedank ik voor haar inzet en geduld bij het tolken. Inge Boullart, Timo Ekhart, Louis Peeters, Maartje van Rij en Marc Spaanderman zeg ik dank voor hun waardevolle bijdrage aan de preeclampsiestudie. Special thanks are due to the Harvard/MGH group, especially Antje Bohne, Rike Buhlmann, Sue Clancy, Andrea Haehnel, Nancy Keuthen, Cary Savage, and Sabine Wilhellm, for their support and encouragement. Amoud Amtz en Merel Kindt bedank ik voor de constructieve discussies. Erik Schouten en Bert Hoekzena bedank ik voor ondersteunende hulp. Angela Verweij betuig ik dank voor haar zorgvuldige, praktische hulp. Jeffrey Roelofs bedank ik voor hulp met de eerste poster. Peter Muris bedank ik voor zjin stimulerende rol. Carlo Mittendorff, Vera Schalken en Joep Huisintveld bedank ik voor de verbreding van mijn trauma-blik. Peter Giesen, Josephine Giesen-Bloo an Simkje Sieswerda bedank ik voor hun steun bij en rondom de promotie. De (ex)collega's bij DMKEP bedank ik voor de prettige werksfeer. De Twentsche Courant Tubanlia en Uitgeverij van Oorschot gaven toestemming on de folo van de ramp in Enschede en het gedicht van Adriaan Morriën af te drukken; mijn dank daavvoor. Het schrijven van een proefschrift vraagt niet alleen volharding van de promovenda, maar ook van anderen. Mijn dank gat in het bijzonder uit naar mijn partner Oria Pilet, mijn zus Esther, andere familieleden en vrienden voor hun steun. Tenslotte ben ik mijn ouders Maria Nelissen en Fred Engelhard dankbaar; aan hen draag ik dit boek op. 



\section{Curriculum Vitae}

Tris Engelhard was born on December 6, 1969 in Maastricht. From 1982 until $\| 989$, Ishe went to High School (Atheneum) at the Stedelijk Lyceum in Maastricht. During this period, from 1987 to 1988, she was an exchange student at Oak Grove High School, in Missouri, USA. After a year of work and traveling, she studied Economics from 1990 until 1992 at the University of Amsterdam and Maastricht University. From 1992 until January 1997, she studied Health Sciences at Maastricht University. During this period, she conducted research at Harvard University for 6 months, in collaboration with Professor R.J. McNally. From September 1997, until March 2002, she was a Ph.D. student at the Department of Medical, Clinical and Experimental Psychology at Maastricht University, and carried out the studies included in this dissertation. During this period, she was a Fulbright scholar at Harvard University, conducting research for 6 months with Professor McNally. Since April 2002, she is Assistant Professor at the Department of Medical, Clinical and Experimental Psychology at Maastricht University.

\section{LIST OF PUBLICATIONS (ENGELHARD, FORMERLY NELISSEN)}

Bögels, S.M., Engelhard, 1.M., Rosmuller, S. \& van den Hout, M.A. (submitted). Reasoning and the development of embarrassment in children.

Buhlmann, U., Savage, C.R., Deckersbach, T., Wilhelm, S., Engelhard, I.M., Baer, L., Jenike, M.A. (submitted). Cognitive retraining for nonverbal menory impairment in obsessive-compulsive disorder.

Engelhard, L.M., van den Hout, M.A., \& Arntz, A (2001). Postraumatic stress disorder after pregnancy loss. General Hospital Psychiatry, 23, 62-66.

Engelhard, I.M., van den Hout, M.A., Arntz, A., \& McNally, R.J. (in press). A longitudinal study of "Intrusion-based reasoning" and PTSD after a train disaster. Behaviour Research and Therapy.

Engelhard, I.M., van den Hout, M.A., \& Hoton, J.P. (2001). Stress post-traumatique après une catastrophe ferroviaire. L'après-Pécrot [Posttraumatic stress in community residents exposed to the Pecrot train collision]. Joumal du Médecin, 1378,1-4.

Engelhard, I.M., van den Hout, M.A., \& Kindt, M. (accepted pending revision). The relationship between neuroticism, pretraumatic stress, and posttraumatic stress: A prospective study. Personality and Individual Differences. 
Engelhard, I.M., van den Hout, M.A., Kindt, M. Arntz, A., \& Schouten, E. (in press). Peritraumatic dissociation and posttraumatic stress after pregnancy loss: A prospective study. Behaviour Research and Therapy.

Engelhard, I.M., van den Hout, M.A., \& Vlaeyen, J.W.S. (submitted). The sense of coherence, crisis support, and postraumatic stress after pregnancy loss: A prospective study.

Engelhard, I.M., Macklin, M.L., McNally, R.J., van den Hout, M.A., \& Arntz, A. (2001). Emotion- and intrusion-based reasoning in Vietnam veterans with and without chronic posttraumatic stress disorder. Behaviour Research and Therapy. 39, $1339-1348$.

Engelhard, I.M., Merckelbach, H., \& van den Hout, M.A. (accepted pending revision). The Guilty Knowledge Test and the Stroop Test in the detection of deception: An exploratory study. Psychological Reports.

Engellhard, I.M., van Rij, M., Boullart, I., Ekhart, T.H.A., Spaanderman, M.E.A., van den Hout, M.A., \& Peeters, L.L.H. (in press). Posttraumatic stress disorder after preeclampsia: An exploratory study. General Hospital Psychiatry.

Keuthen, N.J., Deckersbach, T., Wilhelm, S., Engelhard I.M., Forker, A., O'Sullivan, R.L., Jenike, M.A., \& Baer, L, (2001). The Skin Picking Scale (SPS): Scale development and psychometric analyses. Psychosomatics, 42, 397-403.

Keuthen, N.J., Wilhelm, S., Deckersbach, "T., Engelhard I.M., Forker, A.E., Baer, L., \& Jenike, M.A. (2001). The Skin Picking Scale (SPS): Scale construction and psychometric analyses. Joumal of Psychosomatic Research, 50, 337-341.

Nelissen, 1.M., Muris, P., \& Merckelbach, H. (1995). Computerized exposure and in vivo exposure treatments of spider fear in children: two case reports. Joumal of Behavior Therapy and Experimental Psychiatry, 26, 153-156.

van den Hout, J.H.C., Vlaeyen, J.W.S., Peters, M.L., Engelhard, I.M., \& van den Hout, M.A. (2000). Does failure hurt? The effects of failure feedback on pain report, pain tolerance, and pain avoidance. European Jounal of Pain, 4, 335-346.

van den Hout, M.A., Engelhard, I.M., Jansen, A., Merckelbach, H., \& Schouten, E. (submitted). Neuroticism, "negative disambiguation", and self reported sexual abuse.

van den Hout, M.A., Engelhard, I.M., \& Kindt, M (2001). Zwangerschapsverlies, zenuwachtig-achtigheid en posttraumatische stress-problemen [Pregnancy loss, neuroticism, and posttraumatic stress symptoms]. Directieve Gedragstheraptie, 21, 314.

Wilhelm, S., Keuthen, N.J., Deckerbach, T., Engelhard, I.M., Forker, A.E., Baer, L., O'Sullivan, R.L., \& Jenike, M.A. (1999). Self-injurious skin picking: Clinical characteristics and comorbidity. Journal of Clinical Psychiatry, 60, 454-459. 


\section{LIST OF PRESENTATIONS (ENGELHARD, FORMERLY NELISSEN)}

Bögels, S.M. \& Nelissen, I.M. (1998, November). Redeneren en de ontwikkeling van sociale emoties bij kinderen [Reasoning and the development of social emotions in children]. Paper presented at the annual meeting of the Vereniging voor Gedragstherapie [Society for Behavior Therapy], Veldhoven.

Boullart, I., van Rij, M., Engelhard, I.M., Ekhart, T.H.A., Peeters, L.H.L. (2001, May).

Postraumatic stress disorder after preeclampsia. Poster presented at the annual conference of Maastricht Medical Students Research, Maastricht.

Ekhart, T.H.A., Engelhard, I.M., van Rij, M., Boullart, I., van den Hout, M.A., Schouten, E., Spaanderman, M.E.A., \& Peeters, L.L.H. (2001, March). Prevalence and risk factors of PTSD after preeclampsia. Poster presented at the annual meeting of the Society for Gynecologic Investigation, Toronto, Canada.

Ekhart, T.H.A., Engelhard, I.M., van Rij, M., Boullart, I., van den Hout, M.A., Schouten, E., Spaanderman, M.E.A., \& Peeters, L.L.H. (2001, November). Prevalence and risk factors of PTSD after preeclampsia. Poster presented at the annual meeting of the Dutch Society for Gynecologic Investigation, Nijmegen.

Engelhard, I.M. (2001, October). Vulnerability and the course of posttraumatic stress. Paper presented at the meeting of Experimental Psychopathology on Trauma and psychopathology, Leiden.

Engelhard, I.M. (2002, September). Peritraumatic dissociation and Positraumatic Stress. In C.R. Brewin (Chair), Dissociative processes in psychopathology. Symposium accepted to the meeting of the European Association for Behavioural and Cognitive Therapies (EABCT), Maastricht.

Engellard, I.M. (2002, November). The sense of coherence in early pregnancy predicts crisis support and PTSD symptoms after pregnancy loss. Poster session submitted to the meeting of the International Society for Traumatic Stress Studies (ISTSS), Baltimore, USA.

Engelhard, I.M. (2002, November). Pretraumatic predictors of posttraumatic stress after pregnancy loss. In O. van der Hart (Chair), Prospective research of predictors of PTSD symptoms. Symposium submitted to the meeting of the ISTSS, Baltimore, USA.

Engelhard, I.M., van den Hout, M.A., Arntz, A., \& McNally, R.J. (2001, December). "Intrusion-based reasoning" and PTSD after a train disaster: A longitudinal study. Poster presented at the annual meeting of the ISTSS, New Orleans, USA.

Engelhard, I.M., van den Hout, M.A.n, Arntz, A., \& McNally, R.J. (2002, September). Trauma-reminders as cues for contextual threat perceptions. In M. Kindt, \& I.M. Engelhard (Chair), Mechanisms involved in the onset and maintenance of PTSD. Symposium accepted to the meeting of the EABCT, Maastricht.

Engelhard, L.M., van den Hout, M.A., \& Kindt, M. (2000, March). Risk factors for PTSD after pregnancy loss. In P. Brewster (Chair), Tratmatic experience associated with pregnancy and childbirth. Symposium conducted at the World Conference of the ISTSS, Melbourne, Australia. 
Engelhard, I.M., van den Hout, M.A., \& Kindt, M. (2000, November). Is neuronicism a risk factor for the development of posttraumatic stress disorder? Poster presented at the annual meeting of the ISTSS, San Antonio, USA.

Engelhard, I.M., van den Hout, M.A., \& Kindt, M. (2001, July). Peritraumatic dissociation and the development of PTSD. In C.R. Brewin (Chair), Dissociative processes in psychopathology: Clinical applications. Symposium conducted at the World Congress of Behavioral and Cognitive Therapies, Vancouver, Canada.

Engelhard, I.M., Macklin, M.L., McNally, R.J., van den Hout, M.A., \& Arntz, A. (2000, September). Perceptions of threat in persistent posttraumatic stress disorder. In M.A. van den Hout (Chair), Personality, memory, and reasoning in posttraumatic stress disorder. Symposium conducted at the annual meeting of the EABCT, Granada, Spain.

Engelhard, I.M., Macklin, M.L., McNally, R.J., van den Hout, M.A., \& Amtz, A. (2000, November). Emotional reasoning in chronic posttraumatic stress disorder. Poster presented at the annual meeting of the ISTSS, San Antonio.

Nelissen, I.M. (1997, March). Lie-detection. Paper presented at the annual meeting of the Vereniging Belangenbehartiging Geestelijke Gezondheidkunde (VBGGK) on Perpetrators or Victims, Maastricht.

van den Hout, J.H.C., Vlaeyen, J.W.S., Nelissen, IIM., \& Peters, M.L. (1997). Does failure hurt? The effects of failure on pain reports, pain tolerance, and avoidance. Poster presented at the annual meeting of the European Federation of the International Association for the Study of Pain, Barcelona, Spain.

Wilhelm, S., Keuthen, N.J., Nelissen, I.M., Deckersbach, T., Forker, A., Baer, L., McNally, R.J., O'Sullivan, R.L., \& Jenike, M. (1997, November). Recurrent selfinjurious skin-picking: Phenomenology and comorbidity. Poster presented at the annual meeting of the Association Advancement of Behavior Therapy (AABT), Miami, USA.

Wilhelm. S., Keuthen, N.J., Nelissen, I.M., Deckersbach, T., Forker, A., Baer, L., McNally, R.J., O'Sullivan, R.L., \& Jenike, M. (1997, November). Recurrent selfinjurious skin-picking: A functional analysis. Poster presented at the annual meeting of the AABT, Miami, USA. 